\title{
LA RIVER(S)
}

\author{
by \\ Michel Pilon-Briggs
}

\begin{abstract}
A thesis submitted to the Faculty of Graduate and Postdoctoral Affairs in partial fulfillment of the requirements for the degree of
\end{abstract}

\author{
Master of Architecture \\ M.Arch
}

Azrieli School of Architecture and Urbanism

\author{
Carleton University \\ Ottawa, Canada
}

(C) 2019

Michel Pilon-Briggs 


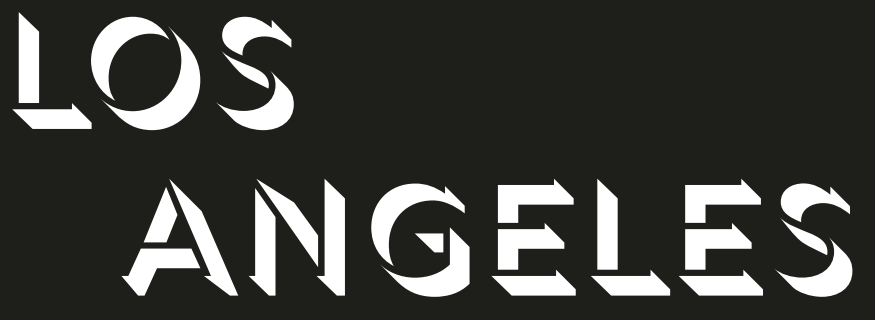

$\frac{20}{2}$ 


\section{ABSTRACT}

The Los Angeles River is unlike any other. From its headwaters in the San Fernando Valley to its mouth at the Pacific Ocean, it runs beneath 110 bridges and is almost entirely constrained by concrete. Since its channelization in 1938, the river has stood still in time, in course, and in its intermittent flows. This thesis investigates the fundamental natures of the LA river and its relation to the city then-and-now; to question its condition of loss and its relationship to water and the city. The research presents a deconstructed atlas of the mythologized river, its development and its absence - and presence - within the city. Building on a conceptual study of three lenses - the invisible, the infrastructural, and the cinematic - this thesis imagines through storytelling multiple reconstructions of the LA River through image and text to re-conceptualize, re-engage, and re-activate it before its eventual renovation. 


\section{CONTENTS}

ABSTRACT

I

ACKNOWLEDGEMENTS

LIST OF FIGURES

PROLOGUE

INTRODUCTION

PART I

1 HISTORICAL CONTEXT

4

$\begin{array}{ll}1.1 & \text { Origins } \\ 1.2 & \text { Settlement } \\ 1.3 & \text { Flood Controls } \\ 1.4 & \text { Channelization } \\ 1.5 & \text { Hardscape }\end{array}$

2 THE RIVER TODAY

2.1 Watershed

2.2 Anatomy

3 SCOUTING

4 ATLAS OF THREE RIVERS

PART II

5 STAGING THE RIVER

6 CONCLUSION

REFLECTION 


\section{ACKNOWLEDGEMENTS}

Thank you -

To Ozayr Saloojee for your thoughtful insight, patience, positivity, and encouragement. This research and thesis would not have been possible without your guidance.

To my family for your endless support, love, and for always believing in me. To my parents for inspiring me to pursue architecture. I never imagined myself here and it wouldn't have been possible without you. To my brother for putting up with me over the past three years in the most selfless way.

To all my friends who have made the past three years memorable. To Olivia for your everyday support, advice, and enthusiasm. To Alisha and Annie for always being positive and encouraging spirits, since day one. I could not imagine going through this without you. 


\section{LIST OF FIGURES}

Figure 1

Layered historical maps from 1968, 1902, and 1912. (Source: Zanja Madre Map, 1968, prepared by William Moore, Water and Power Associates. Los Angeles, West, 1902, University of Texas Libraries. Los Angeles Freeway Map, 1917, Automobile Blue Book, University of Texas Libraries.) 5

Figure 2

Pueblo de los Ángeles Map. (Source: Los Angeles Public Library Photo Archive)

Figure 3

Zanja Madre Map. (Source: Blake Gumprecht)

8

Figure 4

Central Plaza of Pueblo de los Ángeles, c.1850. (Source: Los Angeles

Public Library Photo Archive)

Figure 5

Pueblo de los Ángeles, 1850. (Source: Los Angeles Public Library Photo Archive)

Figure 6

The first reservoir of Los Angeles, 1860. (Source: Los Angeles Public Library

Photo Archive)

Figure 7

Waterwheel, 1863. (Source: Los Angeles Public Library Photo Archive)

Figure 8

Aqueducts in California Map

Figure 9

Historical map details of the Los Angeles River (Source: David Rumsey, Los Angeles \& San Bernardino topography. Wm. H. Hall, State Engineer,

Sacramento. Circa 1880)

Figure 10

1938 Flood. (Source: USC Digital Libraries)

Figure 11

Historical photographs showing the evolution of the Los Angeles River.

(Source: Los Angeles Public Libraries)

Figure 12

Los Angeles County Watersheds Map

Figure 13

Los Angeles precipitation data. (Source: Hydrologic Report 2016-2017

County of Los Angeles Department of Public Works)

Figure 14

December 6th, 2018 rainstorm. (Source: Twitter)

Figure 15

October 27th, 2018 site visit images

Figure 16

Los Angeles River Map

Figure 17

Los Angeles River reaches

Figure 18

Sixteen sections of the Los Angeles River.

Figure 19

Reaches 1-4 of the Los Angeles River in the San Fernando Valley. 
Figure 20

Figure 21

Figure 22

Figure 23

Figure 24

Figure 25

Figure 26

Figure 27

Figure 28

Figure 29

Figure 30

Figure 31

Figure 32

Figure 33

Figure 34

Figure 35

Figure 36

Figure 37

Figure 38

Figure 39

Figure 40

Figure 41

Figure 42

Figure 43

Figure 44
Reach 5 of the Los Angeles River.

Reach 6 and 7 of the Los Angeles River near downtown, from Elysian

Valley to the Rio Hondo.

Reach 8 of the Los Angeles River from Rio Hondo to Long Beach Port.

Bridges of the Los Angeles River

Scouting Map

40

Video stills taken while driving over the bridges that cross the Los

Angeles River, series 1 of 2 .

41

Video stills taken while driving over the bridges that cross the Los

Angeles River, series 2 of 2 .

Los Angeles River Bridge Atlas

Los Angeles River Confluences

Los Angeles River Confluence Atlas

Still tracing

Moving tracing

Concrete tracing

Industrial land uses in Los Angeles County Map

Freeways in Los Angeles County Map

Railroads in Los Angeles County Map

Controlled movement in downtown Los Angeles Map

The Freeway River collage

The Invisible River collage

The three greenest areas near Los Angeles River Map

60

Atlas of movies shot in the Los Angeles River $\quad 62$

The Cinematic River collage $\quad 64$

Layered photographs $\quad 66$

$\begin{array}{ll}\text { Serial slide model } & 67\end{array}$

$\begin{array}{ll}\text { Layered slides study } & 68\end{array}$ 


\section{PROLOGUE}

I grew up beside the Los Angeles River and lived with its myth, but never had an intimate connection with it. I never walked along its edges, trespassed into its bed, or witnessed the spectacle of the turbulent river. Now, the many revitalization studies awakened my curiosity.

This is a story through the Los Angeles River. 


\section{INTRODUCTION}

Los Angeles tells a story of extremes and contradictions and it "makes nonsense of history and breaks all the rules." It is a desert city that experiences seismic volatility, unstable mountain ranges, seasonal wildfires and infrequent, heavy rains. Whether natural or artificial, Los Angeles expands to its limits.

The Los Angeles River tells a story of discovery and abundance, violence and danger. The once free-flowing, meandering river has long been channelized to neutralize the fear of flash floods. The river has no resemblance to its natural course, materiality, and water supply and has become a polluted landscape full of industrial and residential discharges. The hard, concrete edge of the river bank and chainlink fences challenge the concept of river and natural landscape, perpetuating the perception of it as a hostile territory and contributing to its physical and conceptual disconnection from society and the urban landscape. It is a concrete landscape in search of a new narrative.

In order to understand this city and its river, its intricacies, exuberances, dynamism and diversity - you have to take time to take it all in, to immerse yourself within and throughout as Hector Tobar and Tomas Benitez concluded in the Los Angeles Times article after their journey in search of LA's true nature: "On that drive, we saw the world change 10 or 15 different times. That's because LA is really numerous cities in time and space, some of them layered on top of each other...Los Angeles is a city built of many messy collisions. The confusion, delight, loathing and bliss you feel when you take the time to truly see it - that, to me, is the essence of Los Angeles." ${ }^{2}$

1 Banham, Reyner. Reyner Banham Loves Los Angeles, BBC, 1972.

2 Tobar, Hector. "Finding the Real L.A." Los Angeles Times, May 2010. 
Los Angeles has always been a place to be seen in, and to be dreamt of. Whether in reality or in film, it is a dreamscape of untold sunshine, blue skies, and endless expanse. Everything in LA sets itself up to be framed and re-framed; it is constantly imaged and imagined. The city and its river does not resist representation, but is a stage for performance.

From these perspectives, the Los Angeles River is a unique and strange urban phenomena - a place of otherness that has potential to interact with its edges and the surrounding urban fabric. How might we better come to know this myth that runs beneath 110 bridges, almost entirely constructed of concrete?

This thesis sets out to explore this fifty-one mile urban Los Angeles River. This project takes the time to scout and find the river, examine its utility, its dualities, its place in time, and offer it a voice. It turns the Los Angeles River into an Atlas to document and study the river in all its complexities. Divided into two parts, it first de-constructs the nature of the river and then re-constructs it through a series of narratives. It becomes a provocation in image and in narrative that is spatial, physical, and material.

This project acknowledges the revitalization efforts thus far and suggests, instead other, multiple readings of the river. Through the interpretation of three themes - the invisible, the infrastructural, and the cinematic - an exploration of five sites, framed by the concept of water, brings the river to the forefront of the urban imagination in image and text. As a space awaiting its future renovation and revitalization, this mythologized river that cuts through the city will be engaged and reactivated through narrative. As the landscape architect, David Fletcher writes about the river: "we need to develop new narratives to understand and appreciate urban watersheds and how they function."3 The intention is that through these fifteen narratives the LA River(s) can be re-discovered.

3 David Fletcher, "Flood Control Freakology." The Infrastructural City: Networked Ecologies in Los Angeles. Ed. Kazys Varnelis. Actar: New York, 2009, pp. 258-274. 


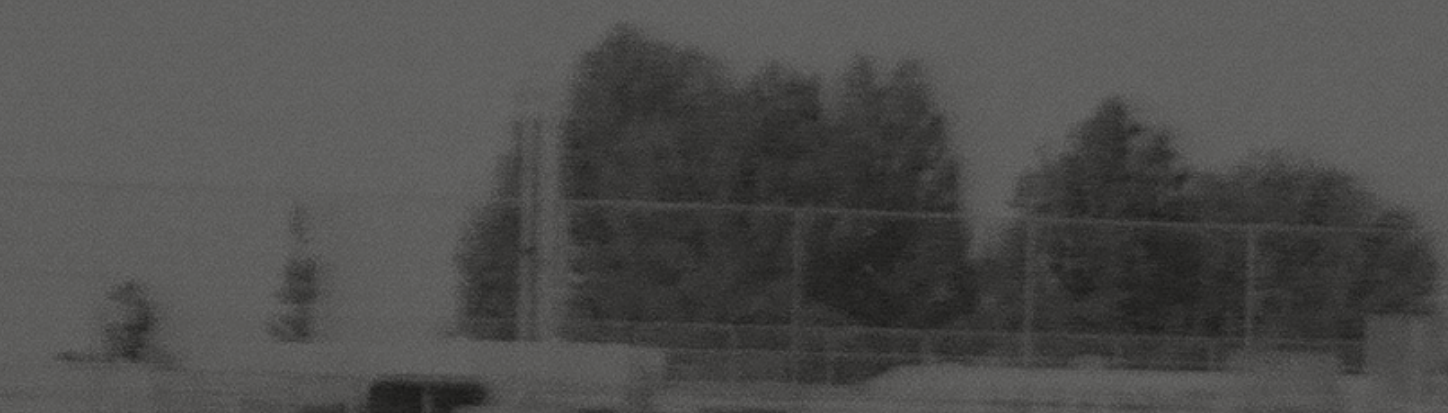




\section{HISTORICAL CONTEXT}

\subsection{Origins}

"To understand Los Angeles is to know its precise geography; the natural environment provides the significant window onto the urban landscape."

To know Los Angeles, we must first know of the river and understand its past and present landscapes. The story of Los Angeles is a story of water in Southern California. Water was essential to the growth of Los Angeles.

The native river is called an upside-down river because its water does not come directly from mountain runoff, but from a subterranean reservoir. ${ }^{2}$ This underground spring originates at the base of the Santa Monica Mountains and eventually gave rise to a shallow river that meandered atop a deep basin. ${ }^{3}$

The soil that covers the San Fernando basin is a result of years of sedimentary deposition from a number of intermittent mountain streams. As a result, the soil is made up of soft, sedimentary rocks which produce an impervious soil. Seasonal runofffrom the mountains would result in a shallow flow above ground. In fact, the boundary between land and water was never entirely defined. Despite its natural low-flow capacity, the tendency for the river to change course during high volume episodes was common. Because of this low and inconsistent flow, the river was never able to scour and create its own permanent channel. This meandering river produced an unpredictable landscape that would naturally make and unmake space in the basin, redefining the terrain and local ecologies. This fertile landscape consisted of the river, streams, arroyos, washes, mudflats, wetlands, and lakes 1 Paulette Singley, "Los Angeles - Between Cognitive Mapping and Dirty Realism." Shaping the City: Studies in History, Theory and Urban Design, edited by Rodolphe El-Khoury and Edward Robbins, Taylor \& Francis, 2004, 154.

2 Gumprecht, Blake. The Los Angeles River: Its Life, Death, and Possible Rebirth. The John Hopkins University Press, 2001, 13.

3 Gumprecht, 13. 


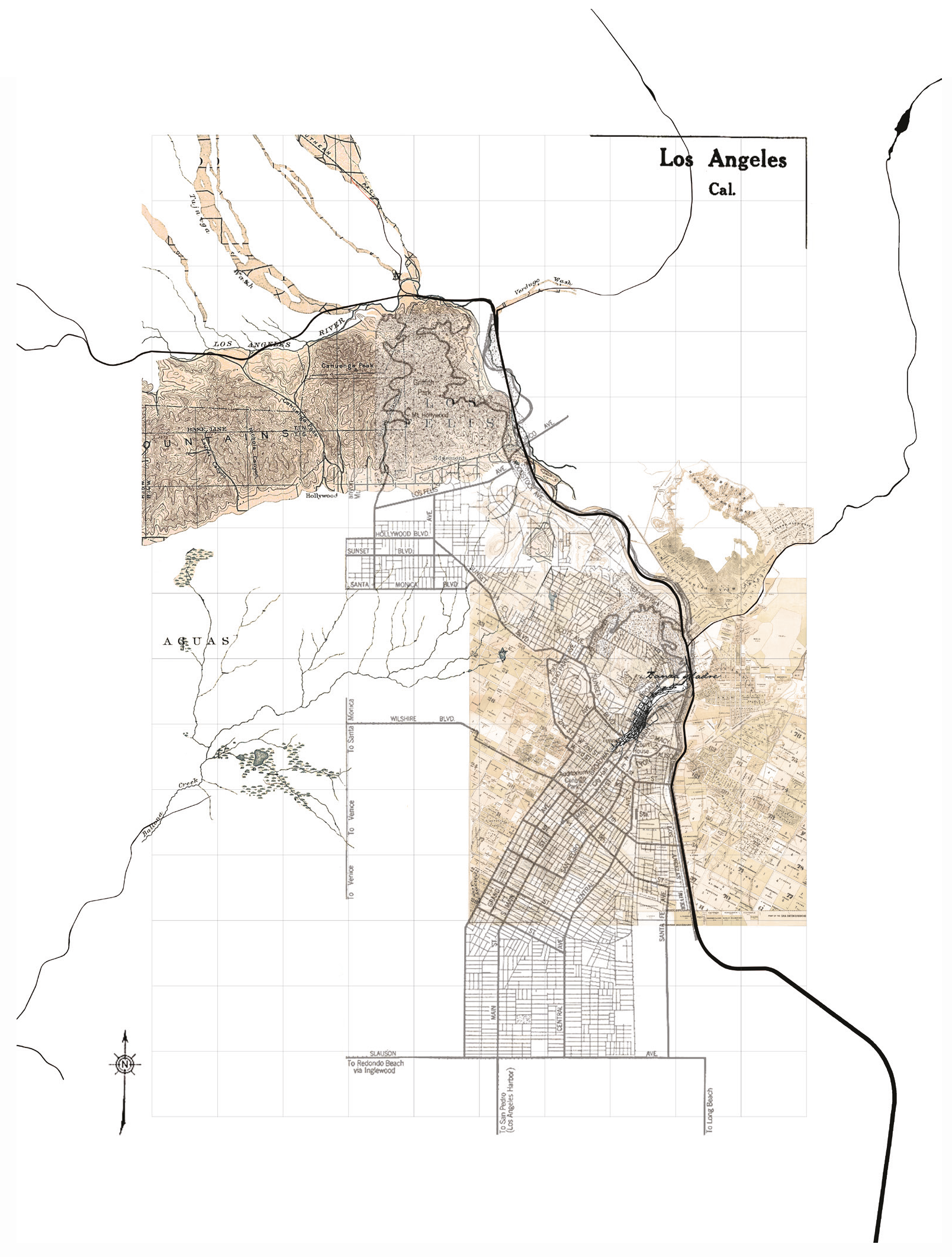

Figure 1: A layered historical map illustrating the meandering nature of the river and its wetlands. 
that created a rich riparian ecosystem full of vegetation and wild life. Historical maps (Figure 1 on page 5) collaged together illustrate the braided nature of the river and its shifting courses. In 1825, the meandering river changed course from flowing west along Ballona Creek to the Santa Monica Bay and flowing south towards San Pedro Bay where it remains today. ${ }^{4}$ During this time, Hollywood was a marshland with Ballona Creek and many streams running through it. Even the names of streets, such as La Cienega Boulevard, which is Spanish for "swamps," reference this previously wet and fertile terrain.

\subsection{Settlement}

The Gabrielino Indians settled along the banks of the river with its largest settlement, Yangna, located in what is now downtown Los Angeles. The river provided a source of water and food for the Tongva people, a home, and a livelihood. ${ }^{5}$ The first Spanish expedition encountered over 200 Indian villages along the river's edges. Father Juan Crespi describes the landscape as ideal for Spanish settlement:

We entered a spacious valley, well grown with cottonwoods and alders, among which ran a beautiful river. This plain where the river runs is very extensive. It has good land for planting all kinds of grain and seeds, and is the most suitable site of all that we have seen for a mission, for it has all the requisites for a large settlement. ${ }^{6}$

The Spanish crown recognized the potential of this land near the river and in 1781 founded El Pueblo de Nuestra Señora la Reina de los Ángeles (the Town of Our Lady the Queen of the Angels) on high land, half a mile west of the river, El Río de Porciúncula. This settlement was a part of the Spanish presence in California and consisted of three types of

4 William Deverell and Tom Sitton, Water and Los Angeles: A Tale of Three Rivers, 19001941. University of California Press, 2017, 149.

5 Gumprecht, 7.

6 Herbert Eugene Bolton, 1870-1953. "Fray Juan Crespi : Missionary Explorer on the Pacific Coast. 1769-1774." B. Berkeley : University of California Press, 1927. Original Format: University of British Columbia. Library. Rare Books and Special Collections. F5813.1.C92 B7. Web. 24 Jan. 2019. BC Historical Books. 
settlement patterns: the presidio (military), the mission (religious), and the pueblo (civil).? The pueblo was a farming community responsible for providing food to the other two settlements. Thus, the location of the settlement was crucial to its founding and survival. Water was drawn from the river through the construction of a Zanja Madre or "Mother Ditch." ${ }^{\text {T }}$ This first aqueduct channeled water from the river to the pueblo and its fields, providing water for both domestic use and irrigation. The pueblo successfully grew into one of the region's richest agricultural areas, producing surpluses of wheat, corn, barley, beans, and most notably wine and oranges. This image of paradise contributed to its population increase and ultimate decline as a bountiful, edenic landscape. ${ }^{9}$

In 1850, the city's rapid growth challenged its water system and resources. The city started charging for water use and employed Zanjeros who had the most important and lucrative role of maintaining the Zanjas, ditches and reservoirs as well as policing and rationing water to those with water permits. ${ }^{10}$ Private water carriers delivered clean water directly from the river to some residents at cost because the new water pipe distribution system was not yet reliable. In the 1860s, the water supply system consisted of nine Zanjas, a water wheel, a reservoir, and wooden pipes. The water wheel raised water from the river to a certain height that would allow water to flow by gravity to homes, fields, and storage. ${ }^{11}$ The central plaza held the city's first reservoir showing the importance of water to the community. The completion of the railroad and a subsequent eleven year drought only compounded the reliance, strain, and instability on the river. It became

7 Gumprecht, 439.

8 Abraham Hoffman and Teena Stern, "The Zanjas and the Pioneer Water Systems for Los Angeles." Southern California Quarterly, vol. 89, no. 1, 2007, pp. 1-22. JSTOR, www.jstor. org/stable/41172351.

9 Gumprecht, 440.

10 Hoffman and Stern, 4.

11 "Water and Power Associates: Informing the Public about Critical Water and Energy Issues Facing Los Angeles and California." Water and Power Associates: Water in Early Los Angeles, waterandpower.org/museum/Water_in_Early_Los_Angeles.html. 
Figure 2: The map shows the origins of the pueblo as a farming community. The central square is highlighted in red.
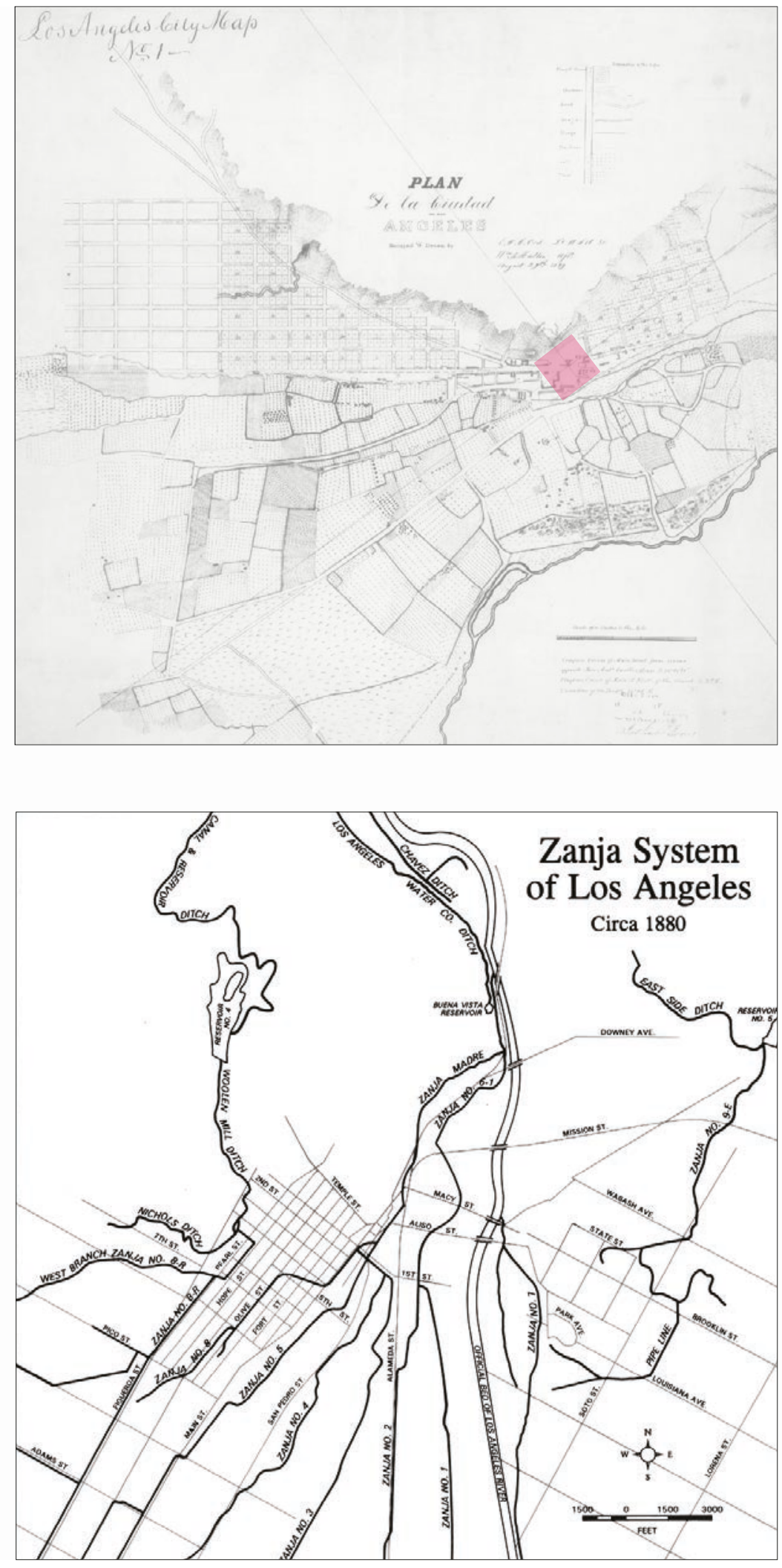

Figure 3: Zania Madre or 'Mother Ditch' was the first aqueduct that channeled water from the Los Angeles River to the pueblo, which provided water for domestic use and irrigation. 


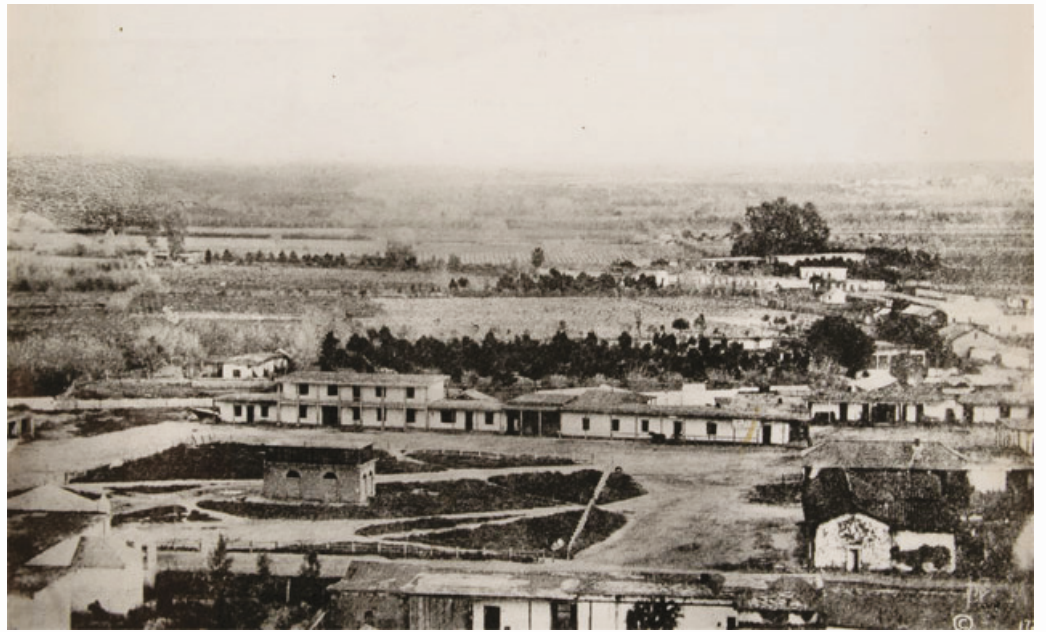

Fiqure 4: Central Plaza of Pueblo de los Ángeles, c.1850.

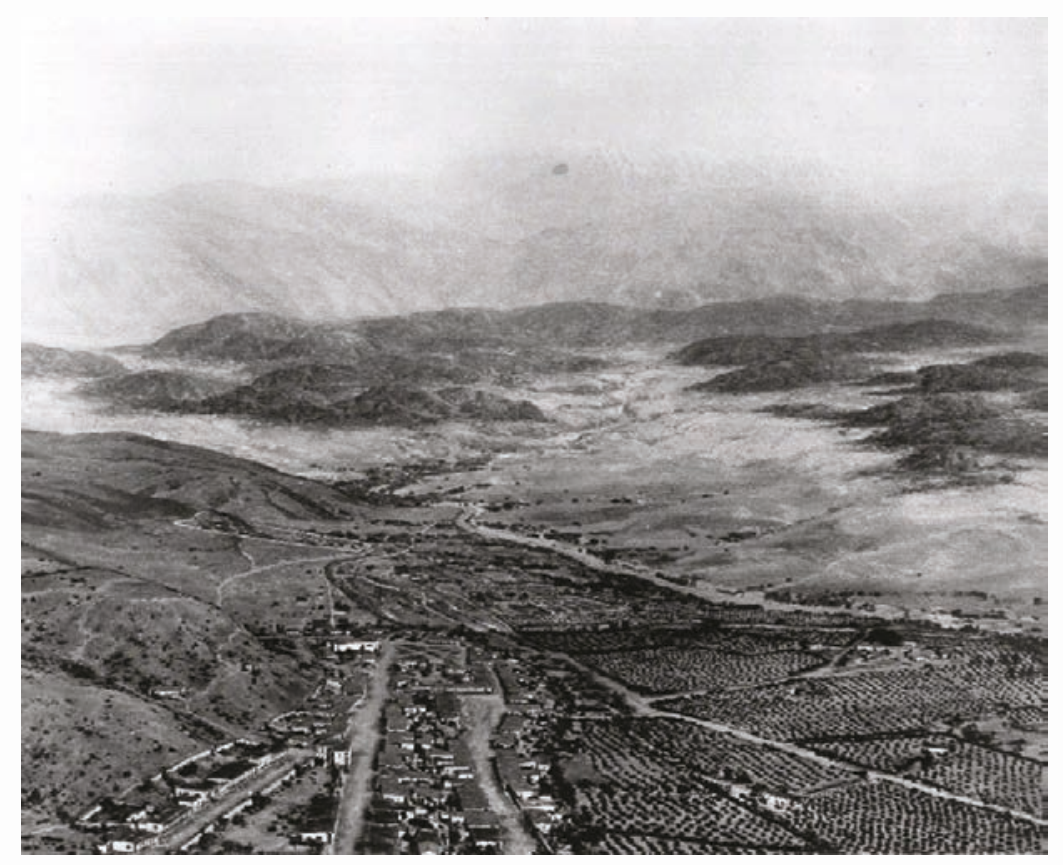

Figure 5: Pueblo de los Ángeles, 1850.

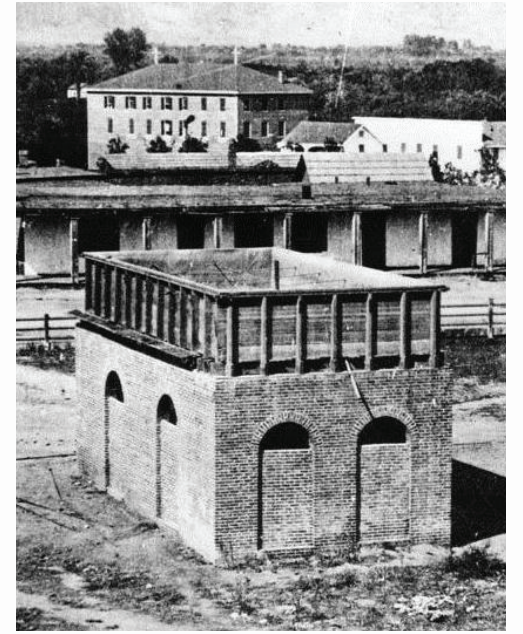

Figure 6: The first reservoir of Los Angeles, 1860.

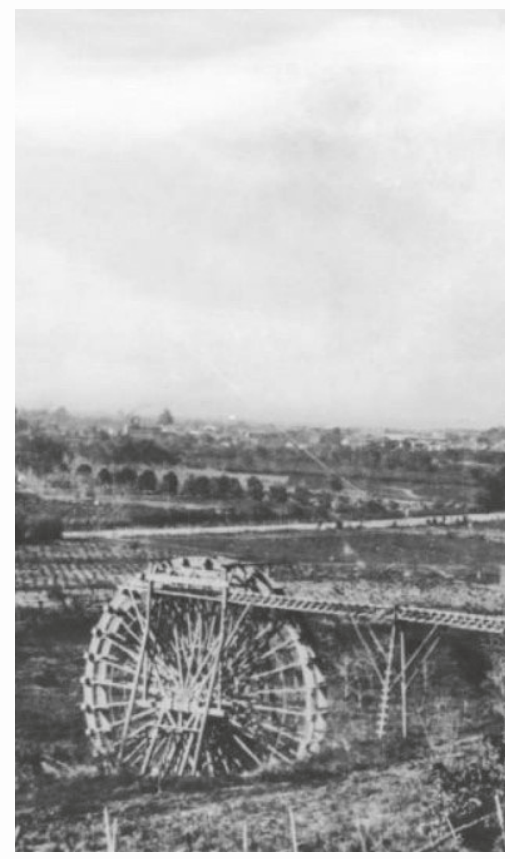

Figure 7: Waterwheel, 1863. 
clear in 1905 that LA's expansion could no longer be supported by the now drained river. William Mulholland, chief engineer of the city's water department sought to annex Owen's Valley, 250 miles northeast, as the solution. Los Angeles purchased the land and water rights in a controversial manner that allowed the city to siphon water from Owen's Valley. ${ }^{12}$ Through campaigning, voters approved a \$24 million bond to fund the aqueduct in 1907, allowing the construction of the 225 mile aqueduct. Diverting water from Mono County to Los Angeles proved that city growth was valued over agriculture. Roosevelt states water "is more valuable to the people as a whole if used by the city than if used by the people of the Owens Valley."13

\section{Or, as William Mulholland of Los Angeles putiteven more succinctly in response to the completion of the Owens River Aqueduct in late 1913: "There it is. Take it." And that is precisely what happened. ${ }^{14}$}

Mulholland and his supporters radically transformed Los Angeles through water imperialism. A large-scale hydraulic infrastructure was forced upon the landscape and deterritorialized water in order to supply a distant metropolis. The goal of the Los Angeles aqueduct was successful as it provided four times more water than its river. ${ }^{15}$ However, Los Angeles' growth came at the expense of Owen's Valley. While San Fernando Valley turned into lush and profitable farmland, the land at the source responsible for Los Angeles' growth into what Donald Worster calls a "modern hydraulic society" was drying out and

12 The California Water Wars was a series of disputes between Los Angeles and Owen's Valley farmers that occurred between 1902-1907. The conflict began when Frederick Eaton, a city engineer and later the mayor of Los Angeles, purchased land and subsequently the water rights from local farmers. By purchasing the land as a private citizen, Eaton prevented Bureau of Reclamation's plan to improve irrigation for the local farmers. It was through deception, collusion and insider information that Eaton along with his partner William Mulholland were able to achieve their pursuit to bring more water to Los Angeles. This conflict also inspired the 1974 film, Chinatown and the relationship between Los Angeles and Owen's Valley remains controversial into the twenty first century. Reisner, Marc. Cadillac Desert: The American West and Its Disappearing Water, Revised Edition. Penguin, 1993.

13 William L Kahrl, The Politics of California Water: Owens Valley and the Los Angeles Aqueduct, 1900-1927. California Historical Quarterly. Vol. 55, No. 1, 1976, 14.

14 Deverell and Sitton, 12.

15 Robert M. Fogelson, The Fragmented Metropolis: Los Angeles, 1850-1930. University of California Press, 1993. 


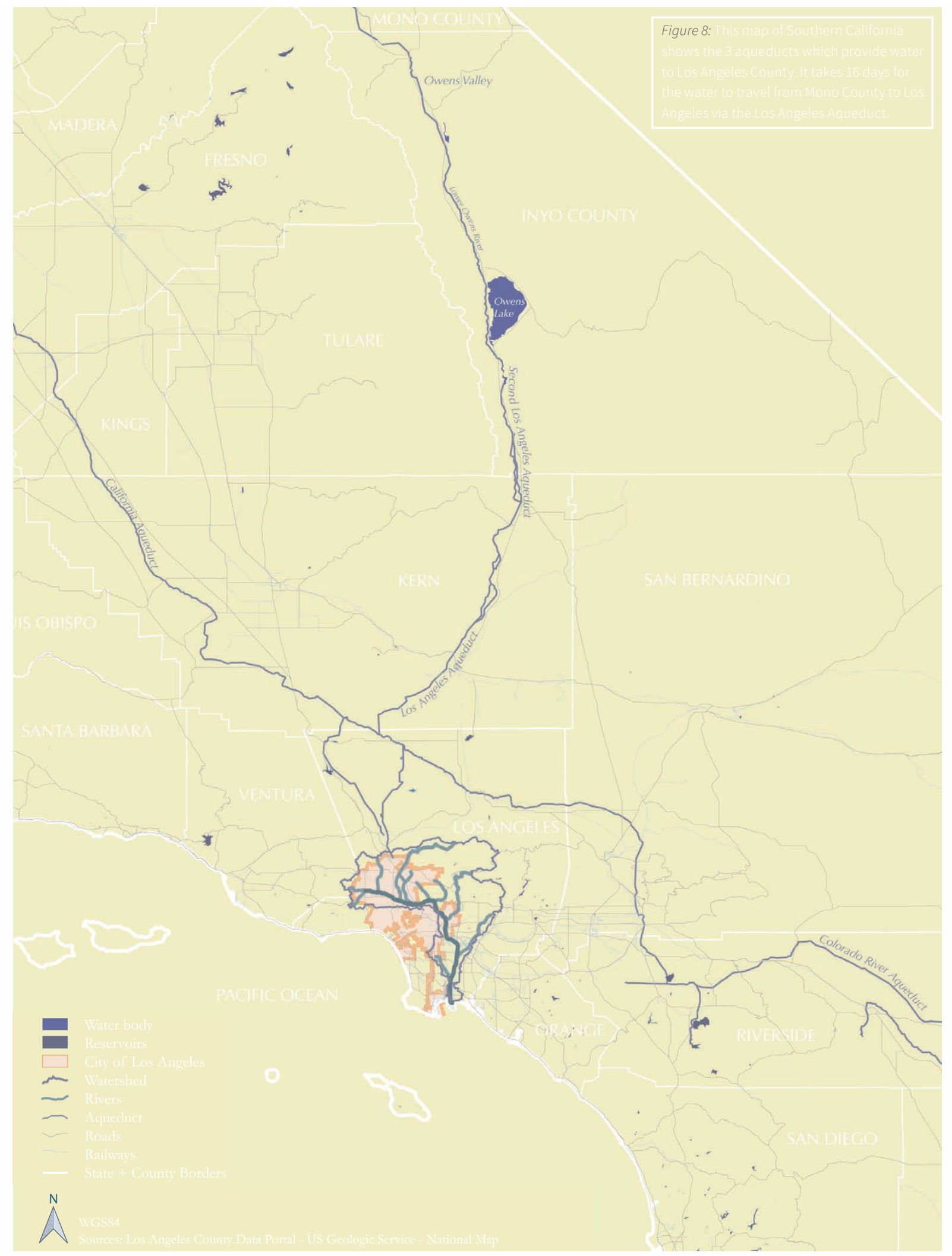



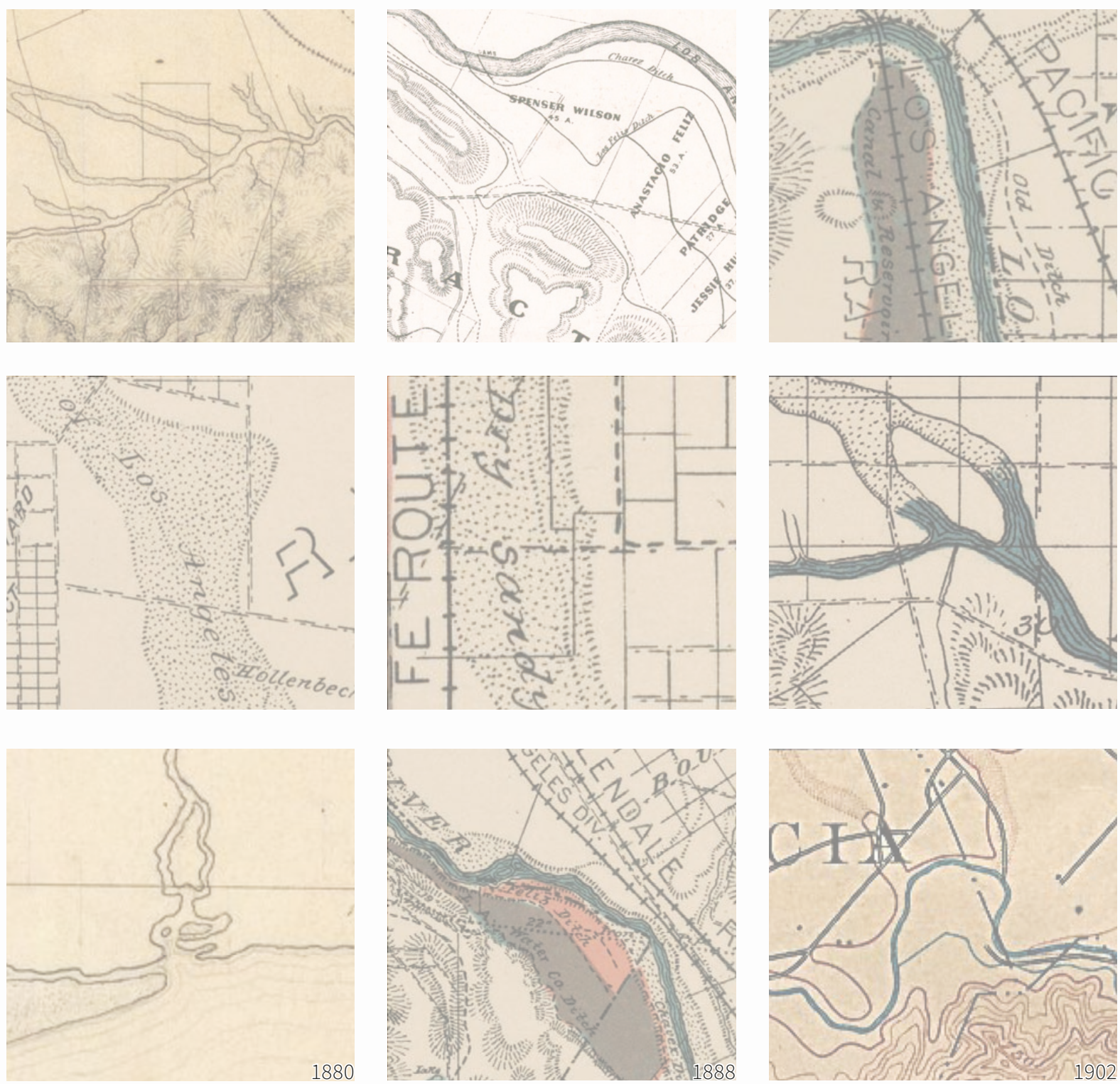

Figure 9: Details of maps highlighting the historical nature of the Los Angeles River: an alluvial wash that occasionally meandered. (Source: David Rumsey, Los Angeles \& San Bernardino topography. Wm. H. Hall, State Engineer, Sacramento. Circa 1880) 
suffering from intense dust storms. ${ }^{16}$ Los Angeles grew to 1.2 million and tripled in area by annexation and suburbanization resulting in what Fogelson called a "fragmented metropolis."17

28 years later, the Colorado River Aqueduct reached Southern California. By the 1940s, three rivers were consecutively tapped for water and wells were drilled for groundwater. The aqueducts as "artificial rivers" fed the "growth machine" of Los Angeles. ${ }^{18}$ Present day water sources include Los Angeles and California Aqueduct as a part of the State Water Project, the Colorado Aqueduct, and local groundwater. ${ }^{19}$ The river, however, is no longer used as a water source.

\subsection{Flood Controls}

Although no longer a valuable and prominent water source, the river was still prone to flooding during significant rain events due to the climate and topography. The river becomes filled with racing waters during the winter rain events. The high mountains, often receiving significantly more rain than the lowlands resulted in water and debris tumbling down the mountain at greatspeed. The eastern San Fernando Valley, the San Gabriel Valley, and the plain from Los Angeles to Long Beach were all vulnerable to floods. At times, flash floods would spread across the landscape transforming "the coastal plain from the city to the sea into a great lake."20

\footnotetext{
16 Donald Worster, Rivers of Empire: Water, Aridity, and the Growth of the American West. New York Pantheon Books, 1985.

17 Fogelson, 2.

18 Irene J. Klaver and J. Aaron Frith, "A History of Los Angeles's Water Supply: Towards Reimagining the Los Angeles River," in: A History of Water, Series 3, Vol. 1. From Jericho to Cities in the Seas: A History of Urbanization and Water Systems. Editors Terje Tvedt and Terje Oestigaard. I.B. Tauris. London, New York, New York, 2014, 520.

19 "Water Sources." Department of Public Works, dpw.lacounty.gov/wwd/web/YourWater/ WaterSources.aspx.

20 Gumprecht, 455
} 

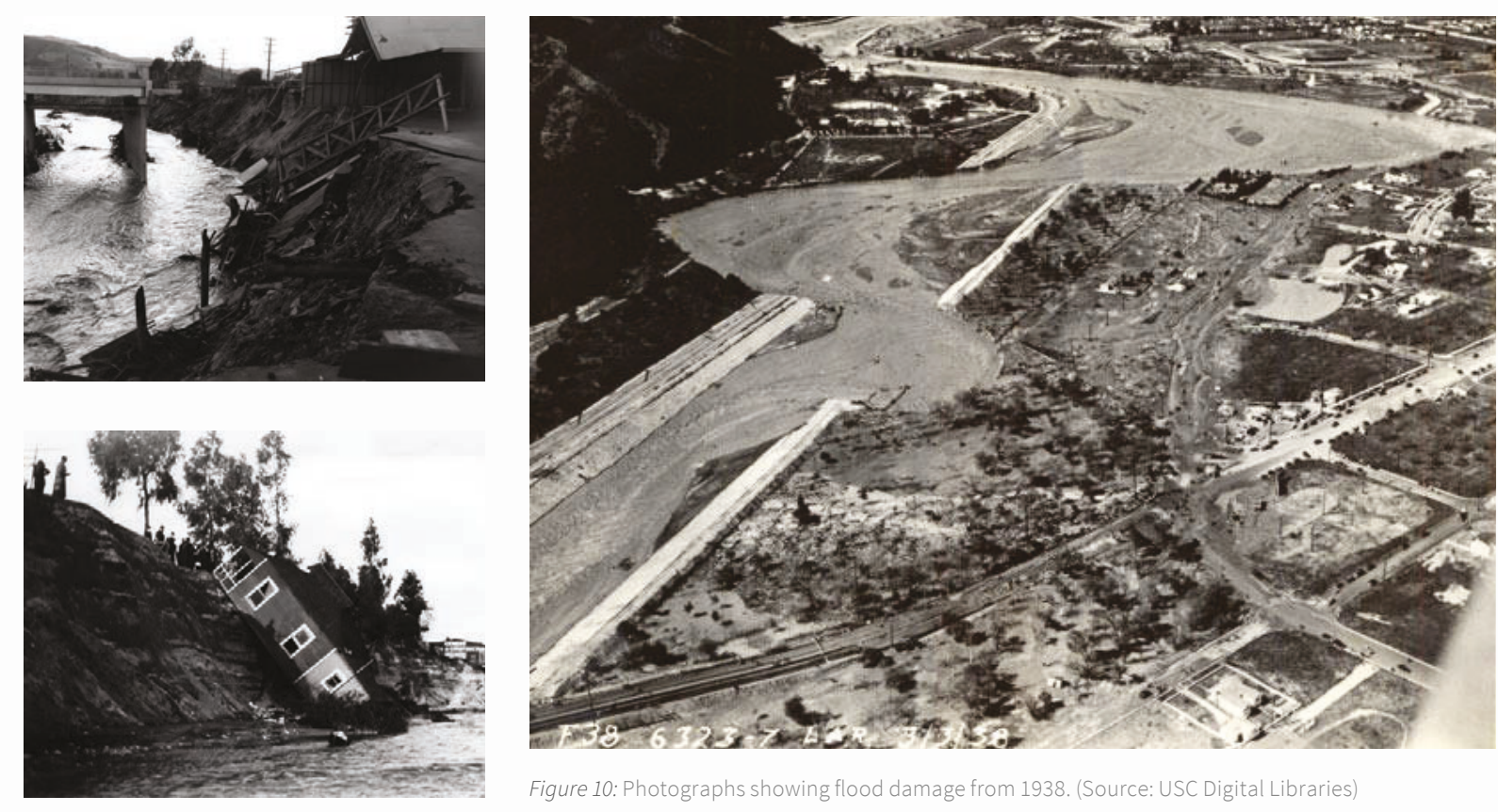

Figure 10: Photographs showing flood damage from 1938. (Source: USC Digital Libraries)

There were over 60 floods documented since the Spanish presence in Los Angeles. ${ }^{21}$ Damage was extensive and costly; bridges collapsed, houses washed away, and casualties occurred. The idea of managing flood risk began in the late nineteenth century, however it was clearly never at the scale that would eventually be realized. There were at least seven major floods before the 193850 -year flood which cemented the need for an extensive flood management program necessary for the further growth of Los Angeles. In 1938, the Army Corps of Engineer's stepped in to channelize the river and its tributaries. Funding came from the federal government through the Works Progress Administration and later with the passing of the Flood Control Act gave full responsibility to the Army Corps of Engineers. ${ }^{22}$ 
Pre-channelization
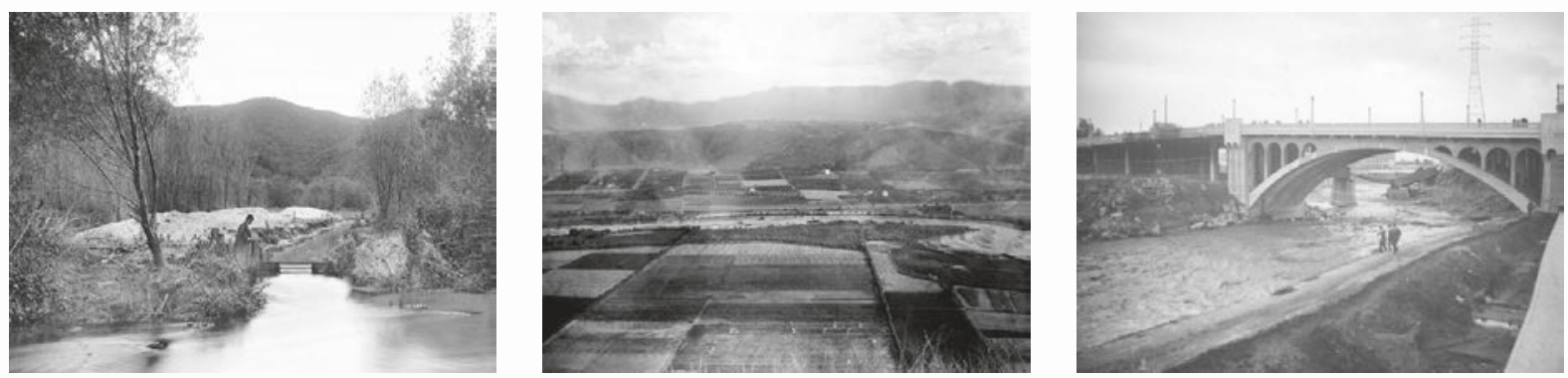

Channel construction
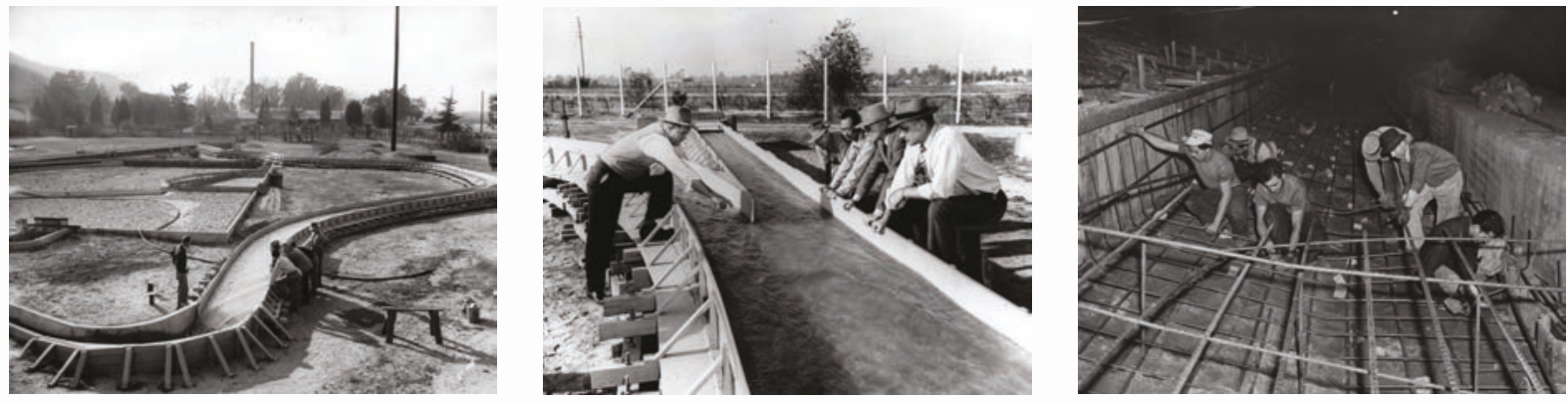

$\vec{v}$
$\omega$
$\infty$
1

Post-channelization
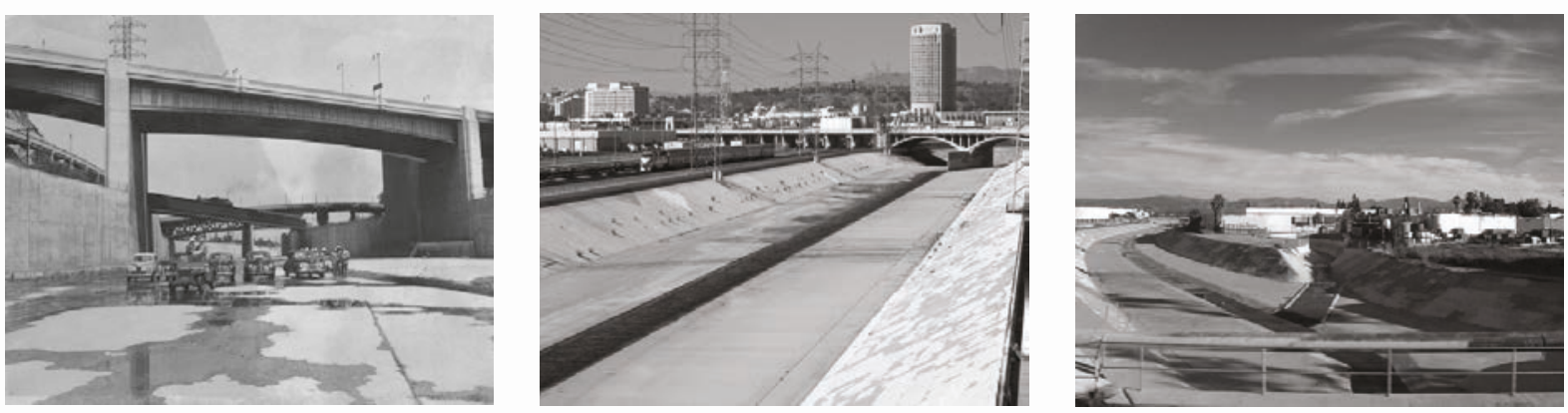

흉

Figure 11: Historic photographs showing the evolution of the Los Angeles River. (Source: Los Angeles Public Libraries) 


\subsection{Channelization}

As a result, nature's unpredictability was tamed. Using cement to control its route and flow, "fortress-like walls rose where willows once stood." ${ }^{23}$ Natural meanders were straightened and any evidence of vegetation was removed. It took 3.5 million barrels of cement, 147 million pounds of reinforced steel, and 460,000 tons of stones to complete the new design of the river in 1968. ${ }^{24}$ With an average slope of 29 percent, the deep and wide channel expedites runoff, like a chute from the San Gabriel Mountains, the San Fernando Valley, and Los Angeles directly to the Pacific Ocean. Streets and sewers are connected to drains along the river, acting as artificial tributaries to this new system.

Channelization was a functional flood-control project and in this form was not designed as a civic amenity. In addition to the concretized river, it consisted of tributaries that function as debris basins, dams, and reservoirs. Of the river and its tributaries total length of 837 miles, 205 miles are engineered. ${ }^{25}$ Three major dams were constructed to reduce downstream flow rates and to retain water for recharging groundwater. It was apart of a larger system that was purely infrastructural.

\subsection{Hardscape}

Channelization created a ripple effect that permeated through the entirety of the built environment, resulting in not only a material transformation, but creating a hardscape, new edge conditions, and alternate narratives - and ultimately ushering in a new era of growth in Los Angeles.

\footnotetext{
Gumprecht, 467.

Ibid., 226 .

Los Angeles Regional Water Quality Control Board. Recreational Use Reassessment Of
} The Engineered Channels Of The Los Angeles River Watershed, 2013. 
As we have seen, the river is an ecological de-construction of nature and natural processes; the natural ground was extracted and transformed into a hardscape using concrete to tame and control the flow of water. It has become a site of an industrial process and system that is fixed, irreversible, and isolated from the built environment. Although it was primarily a material alteration, it was also a metaphorical one. Deterritorialization of water from its ground lessened the distinction between natural and cultural, creating a hardscape.

With the surface blanketed in concrete, the once riparian edges have become industrial corridors. Fixing the river's course meant that the floodplain was now profitable and habitable. It created a new edge condition between the encroaching city, expressing and symbolizing the tension between the two opposites: natural and artificial. This new architectural tension, and duality will be explored. On the days that it rains, we witness that the river does have a function and nature is a powerful force. What this result does not consider is the secondary narratives that arise and these narratives will be addressed in the Atlas of Three Rivers. 
58

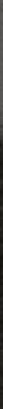

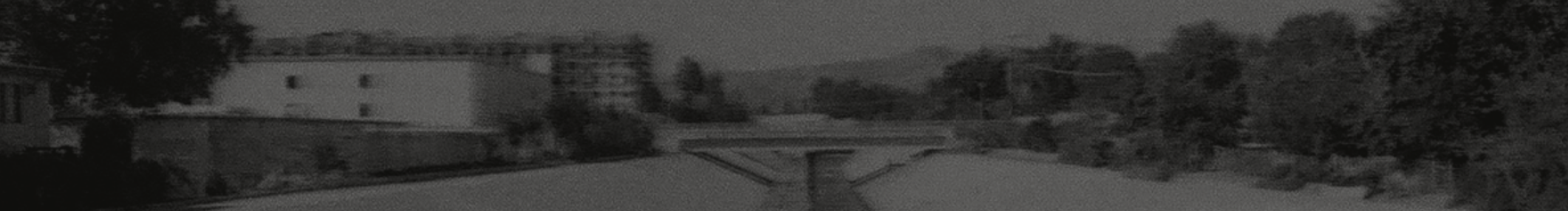




\section{THE RIVER TODAY}

\subsection{Watershed}

As we learned from the historical flood events, the river was seen first and foremost as a hydrological problem. This next chapter continues to study the river today as a hardscaped, urban system. The following section outlines the geographic, climatic, and spatial features to reveal its unique character as a river system.

Although there are six major watersheds located within Los Angeles County, the Los Angeles watershed is by far the most populated, with approximately nine million calling it home. This highly developed watershed covers an area of 834 square miles and is 37\% residential, 8\% commercial, $11 \%$ industrial, $44 \%$ open space. ${ }^{1}$ While the watershed is approximately one-third impervious, its terrain includes mountains, foothills, valleys, and the coastal plain. ${ }^{2}$

Figure 12: Map showing the Los Angeles County watersheds with the Los Angeles River Watershed highlighted in red.

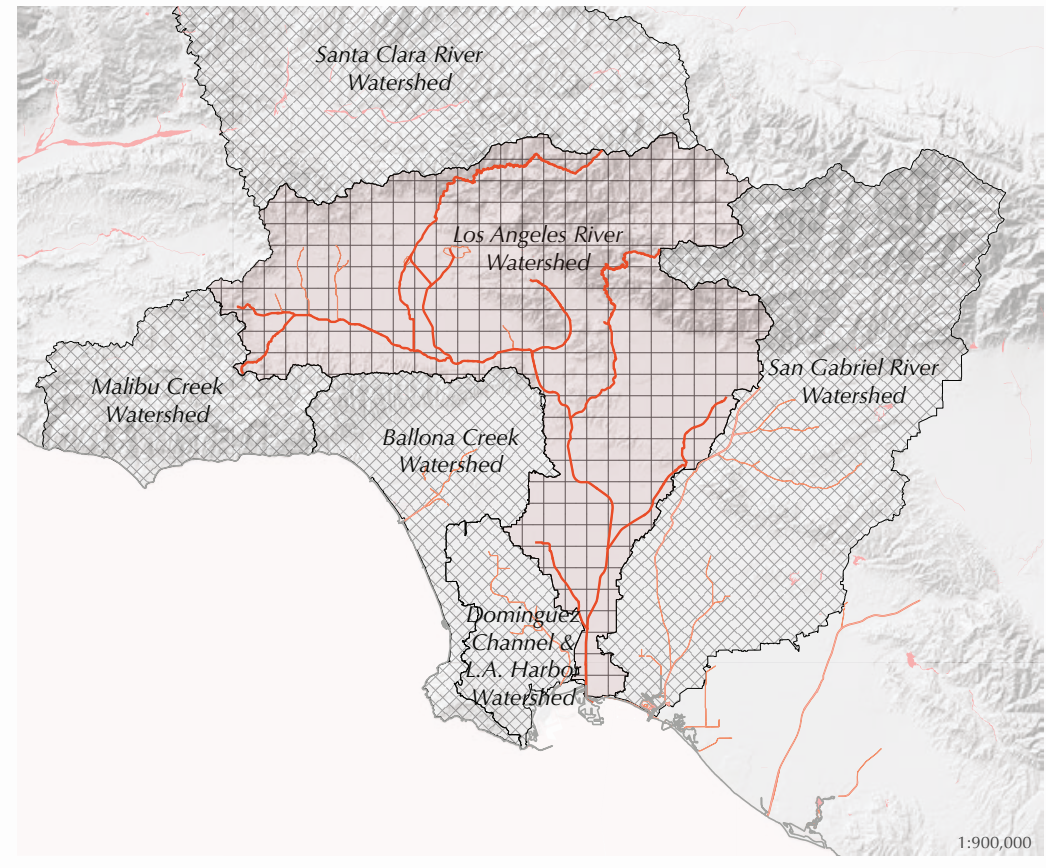

LACDPW: Los Angeles River Watershed. https://dpw.lacounty.gov/wmd/watershed/la/. 2 "Los Angeles River Watershed." City of Los Angeles Stormwater Program, https://www. lastormwater.org/about-us/about-watersheds/los-angeles-river/. 

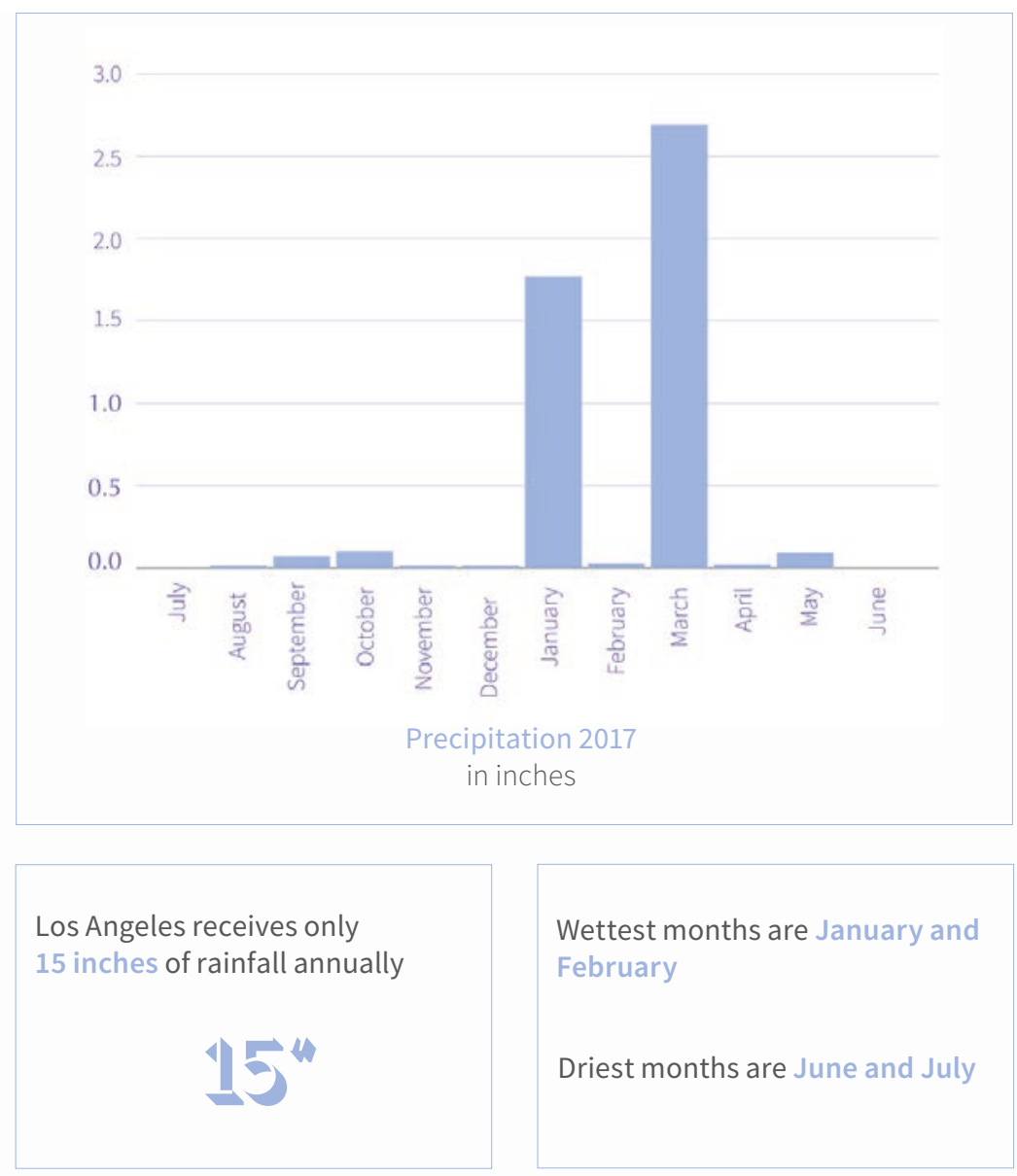

Wettest months are January and
February
Driest months are June and July

As discussed earlier, it is precisely these topographic features in relation to one other, along with the California climate, that is the elemental cause for the river's channelization.

Los Angeles is a semi arid region that receives less than 15 inches of rain per year. ${ }^{3}$ It is classified as a Mediterranean climate with hot and drysummers and coolerwetterwinters, though precipitation is lower annually than typical Mediterranean climates. It rains on average 36 days a year with the wet season occurring between November and March. ${ }^{4}$ Thus, water as one would imagine in a river, is a rare sighting here, as the river is empty more often than it is full.

3 Hydrologic Report 2016-2017 County of Los Angeles Department of Public Works. Water Resources Division available at http://ladpw.org/wrd/report/.

4 John Erdman, "8 Reasons Why Rain Is a Big Deal in Southern California." The Weather Channel, 21 Mar. 2018, weather.com/science/weather-explainers/news/ los-angeles-rain-why-its-a-big-deal. 
Precipitation data reveals the river's temporal nature. Occasionally, the river is a full force reminding us of its once volatile character, which is on average $1 \%$ or 3 days of the year. ${ }^{5}$ This can be classified as Wet Flow - where water is present in the channel and it is raining. ${ }^{6}$ Only in storm conditions is the breadth of the channel at capacity. Flood flows occur when there are high peak flows within a short amount of time. Dry Flow, on the other hand, is when water fills the small channel gully or exists as a thin sheet. This dry baseflow is relatively constant throughout the year amounting to a depth of 4 inches and comes from storm drain runoff, upwelling groundwater, and water reclamation discharges. ${ }^{7}$ With the river in this condition, it is common for algal production to occur, which David Fletcher calls a "sludge mat," along with garbage and foreign objects. ${ }^{8}$ With over 2,200 stormdrain outlets, the river and selected tributaries have become polluted water bodies with trash, metals, bacteria, and nutrients. ${ }^{9}$ A third of the current baseflow is from urban runoff and this amount has continually risen due to increased watershed urbanization as wastewater and precipitation is unable to permeate the hardscape.

\footnotetext{
5 "Functional Flow Rate (FFR)." LA River Index, http://riverlareports.riverla.org/tools-2/ functional-flow-rate-ffr/.

6 Ibid.

7 Ibid.

8 David Fletcher calls the river in this condition a 'freakology.' These freakologies are the inevitable outcome of the merging of infrastructural and natural systems. The nutrientrich, effluent waters, stormwater discharges, and inorganic debris feed and promote new kinds of growth, inhabitants and natures. For example, garbage acts as a substrate for new vegetation. He argues that a different kind of ecology exists for the Los Angeles River and its watershed and that its existence should be taken into consideration in the revitalization discourse. David Fletcher, "Flood Control Freakology." The Infrastructural City: Networked Ecologies in Los Angeles. Ed. Kazys Varnelis. Actar: New York, 2009, pp. 258-274.

9 "Los Angeles River Watershed." City of Los Angeles Stormwater Program, https://www. lastormwater.org/about-us/about-watersheds/los-angeles-river/.
} 

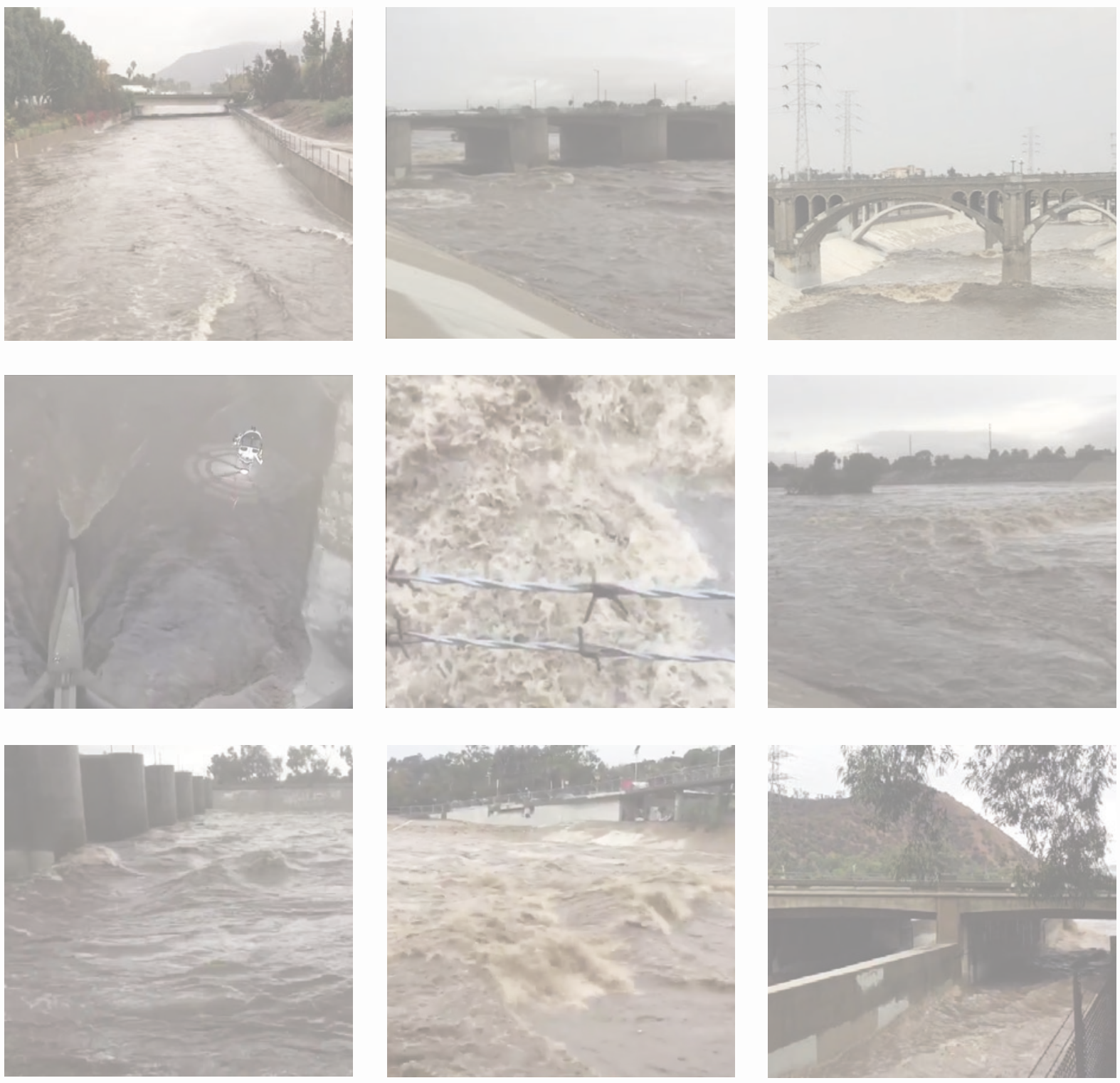

Figure 14: Images of the December 6th, 2018 rainstorm showing the turbulent waters that race out to the Pacific Ocean. (Source: Twitter) 
Dry Flow
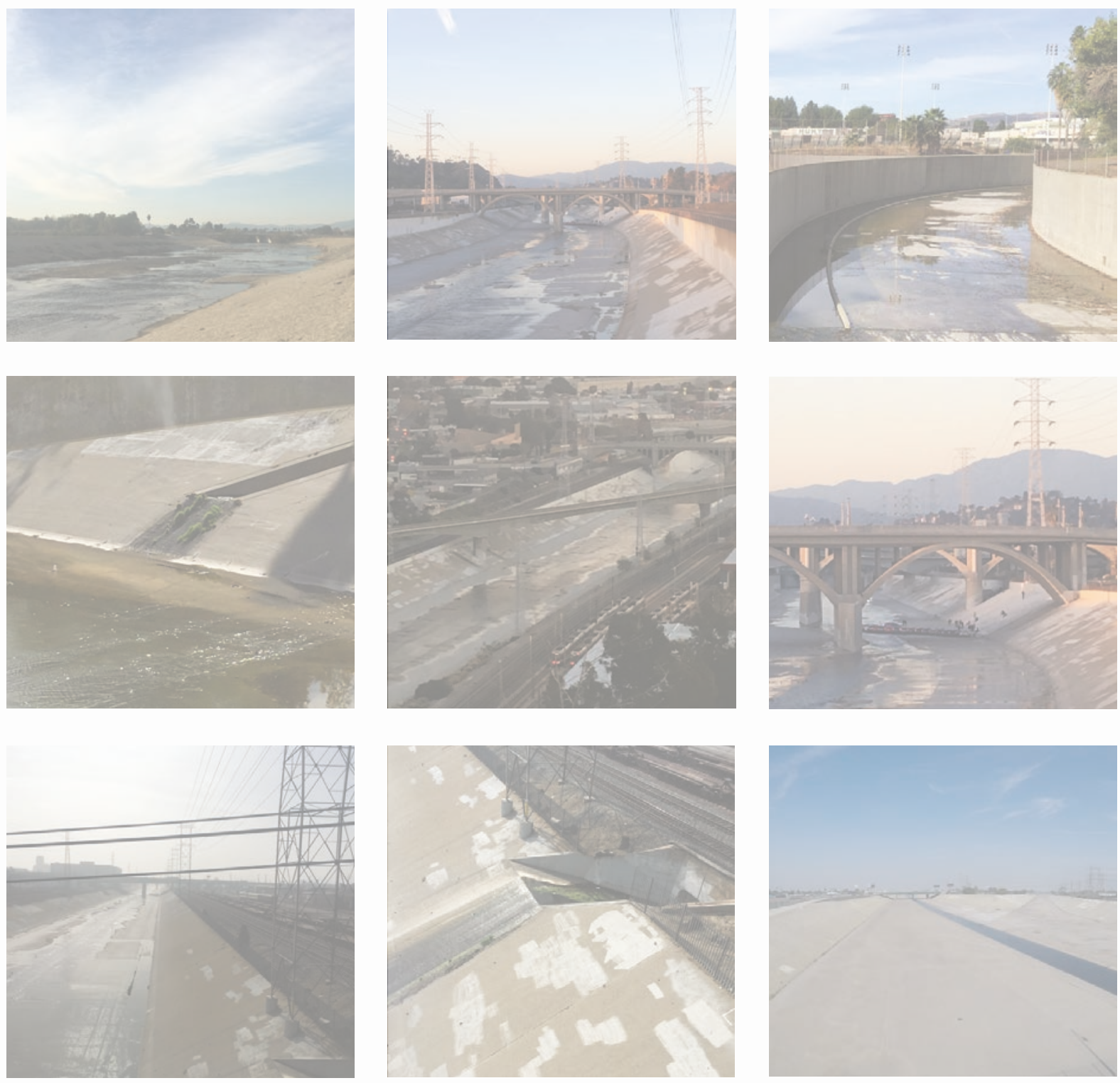

Figure 15: Photographs taken during the October 27th, 2018 site visit showing the condition of the river channel during the fall season. 
Channelization also altered the course of the river and even moved its starting point seven miles west to Canoga Park. ${ }^{10}$ Now, it begins at the confluence of the A rroyo C alabasas and B ell Creek with thes ource of water originating from the Santa Susana Mountains, the Simi Hills, and the northeastern edge of the Santa Monica Mountains. The channel continues east through the southern portion of the San Fernando Valley, paralleling the 101 freeway, where major tributaries, Pacoima Wash, Tujunga Wash, Verdugo Wash, and Burbank Western Channel connect. Bending southeast around the Hollywood Hills into the Los Angeles Basin, the river passes through an unlined, vegetated section known as the Glendale Narrows near Griffith Park and Elysian Park. The river becomes concrete-lined for the majority of its remaining course. After passing Dodger Stadium, the Arroyo Seco meets the river and follows the railway around the eastern edge of downtown Los Angeles. From this point, on the river maintains a relatively straight southern course, receiving water from Compton Creek and Rio Hondo, until it discharges into the Pacific Ocean at the Port of Long Beach.

The Los Angeles River winds itself through fourteen cities and is controlled by the Army Corps of Engineers and the Los Angeles Department of Public Works. ${ }^{11}$ The first 32 miles flow through the City of Los Angeles, while the last 19 miles run through several smaller cities and municipalities. At this division, it falls out of the Army Corps of Engineers jurisdiction and into the hands of the Los Angeles Department of Public Works.

10 Gumprecht, 470.

11 "Governance." Los Angeles River Revitalization, https://www.lariver.org/governance. Accessed 15 Jan. 2019. 


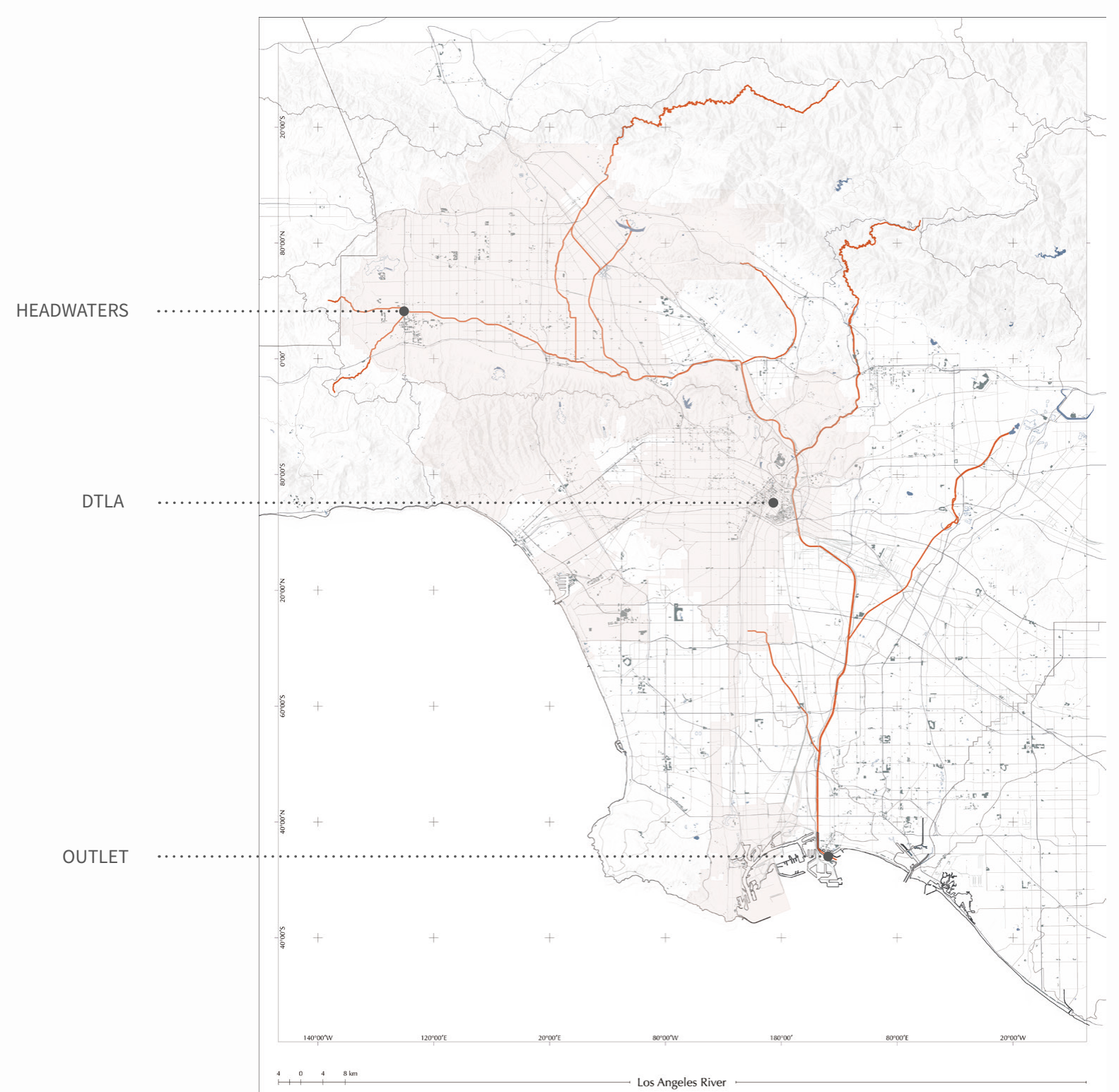

Figure 16: Map highlighting the course of the river as it winds through Los Angeles County. 


\subsection{Anatomy}

Although the river has been channelized into a concrete hardscape, the Los Angeles River represents many rivers as its character changes along its path. For this reason, it is divided into eight reaches (Figure 17 on page 27) due to differing channel geometries, materials, and flow velocities. ${ }^{12,13,14}$ Section diagrams were developed to understand the various conditions separating the waterway from the urban environment. This documentation of the hardscape explores the tension as expressed in its edges - looking to the industrial, commercial, and residential adjacencies. The sixteen sections, two per reach, (Figure 18 on page 28) illustrate the freeways that cut across the river, the railroads, the sparse vegetation, the confluences, and its undeveloped edges. It also highlights the progressive widening of the channel to accommodate more water as it approaches its outlet.

\footnotetext{
12 LA River Modeling Analysis for the Development of TMDLs for Metals in the Los Angeles River and Tributaries - Appendix A. https://www.waterboards.ca.gov/losangeles/board decisions/basin_plan_amendments/technical_documents/2005-006/04_0712/Dry\%20 Weather/LA\%20River\%20Metals-Appendix\%20A.pdf.

13 Lassche, T. "Modelling the LA River: Threats and Opportunities for the Los Angeles River, USA." University of Twente, 2016.

14 Los Angeles River Revitalization Master Plan. City of Los Angeles, 2007.
} 




Figure 17: The Los Angeles River is divided into eight distinct reaches due to differing channel geometries, materials, and flow velocities. 

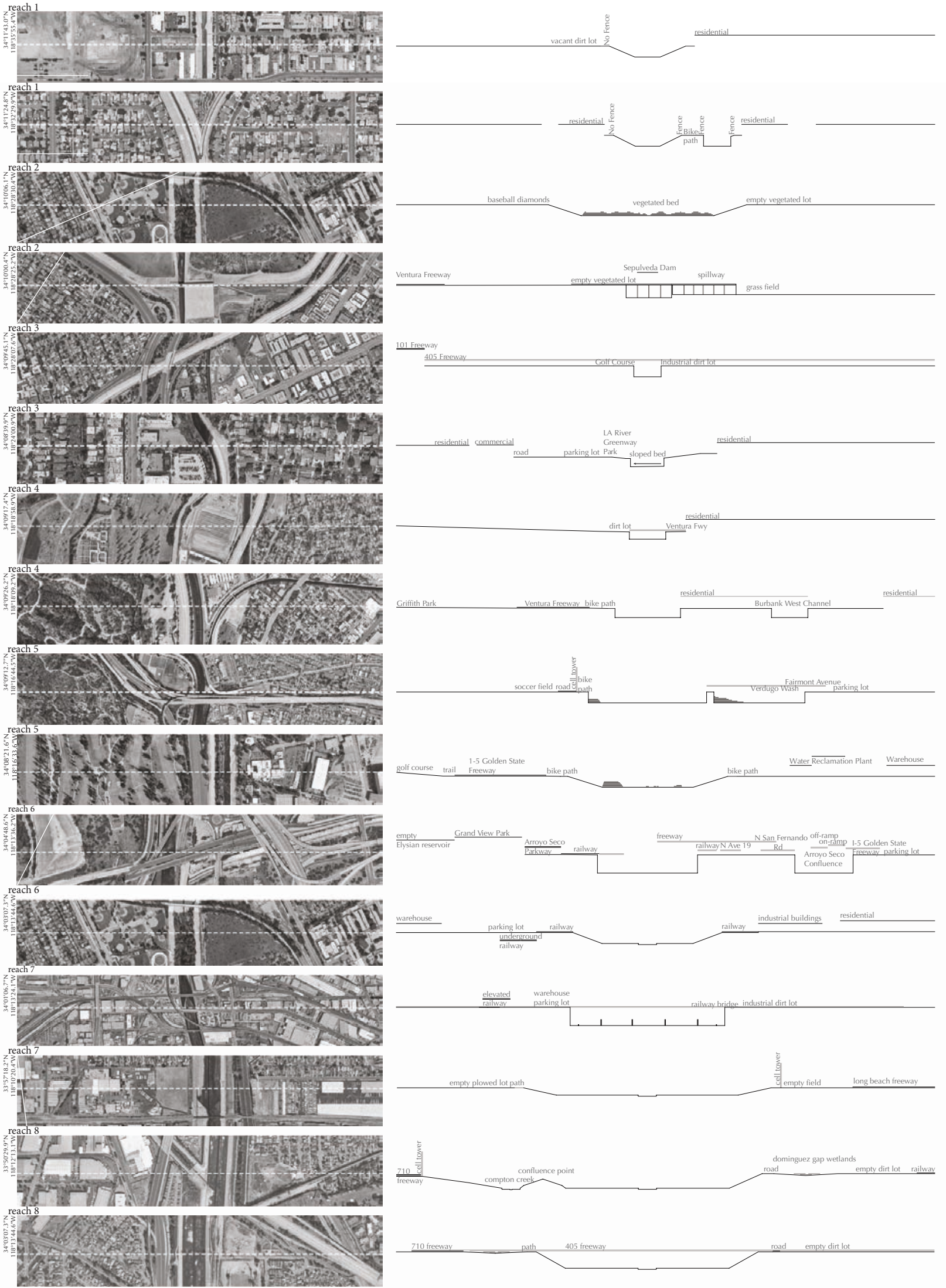

Figure 18: Sixteen sections of the river that illustrate the its edge conditions. 
Eight Reaches

\section{Reach 1 - Canoga Park}

On average, the concrete, trapezoidal channel is 20 feet deep with a bottom width ranging from 45 to 115 feet wide. There are three small tributaries that feed into river: Browns Canyon Wash, Aliso Creek, and Caballero Creek.

\section{Reach 2 - Sepulveda Basin}

The channel is approximately 60 feet wide with a soft bottom and experiences lower flow velocities than other parts of the river during storm events. This the only reach where the river runs through a large park and retention basin. The basin can be closed by the Dam which was constructed in response to the floods in the early 1900s. Just before the Sepulveda Dam, a stream joins the river filled with treated wastewater from the Tillman Water Reclamation Plant.

\section{Reach 3 - Sepulveda Dam to Tujunga Wash}

On average, the concrete-lined channel ranges from 45 to 60 feet wide and is the most narrow and curved reach. The channel runs through residential neighborhoods and the Tujunga Wash joins the river in this reach.

\section{Reach 4 - Tujunga Wash to Burbank West Channel}

The channel has a bottom width that ranges from 60 to 160 feet wide and is 15 feet deep. The peak velocities can be greater than 30 feet per second during storms.

\section{Reach 5 - Glendale Narrows}

The channel has a rocky riverbed with rough, trapezoidal banks and is approximately 130 feet wide. The flow velocity is slower, averaging 15-20 feet per second in storm conditions. In this reach, the groundwater pressure and water table are too high to allow for additional layers of concrete. Sediment deposits form sand bars where vegetation grows.

\section{Reach 6 - Elysian Park to First Street Bridge}

On average, the concrete-lined trapezoidal reach is 150 to 250 feet wide with a depth of 25 feet. Flow velocities are greater than 30 feet per second during storm events. Arroyo Seco joins the river in this reach.

\section{Reach 7 - First Street Bridge (DTLA) to Rio Hondo}

On average, the concrete-lined channel ranges from 200 to 400 feet wide. Flow velocities are greater than 30 meters per second during storm events. Rail tracks and freeways line the sides of the banks. At the very end of the reach, Rio Hondo joins the river.

\section{Reach 8 - Rio Hondo to Long Beach}

The concrete-lined channel is at its widest, reaching over 400 feet wide. Compton Creek joins the river before the estuary begins and flows for the remaining 3 miles into Long Beach Harbor. This tidal zone experiences the highest water content and greatest sediment load. 

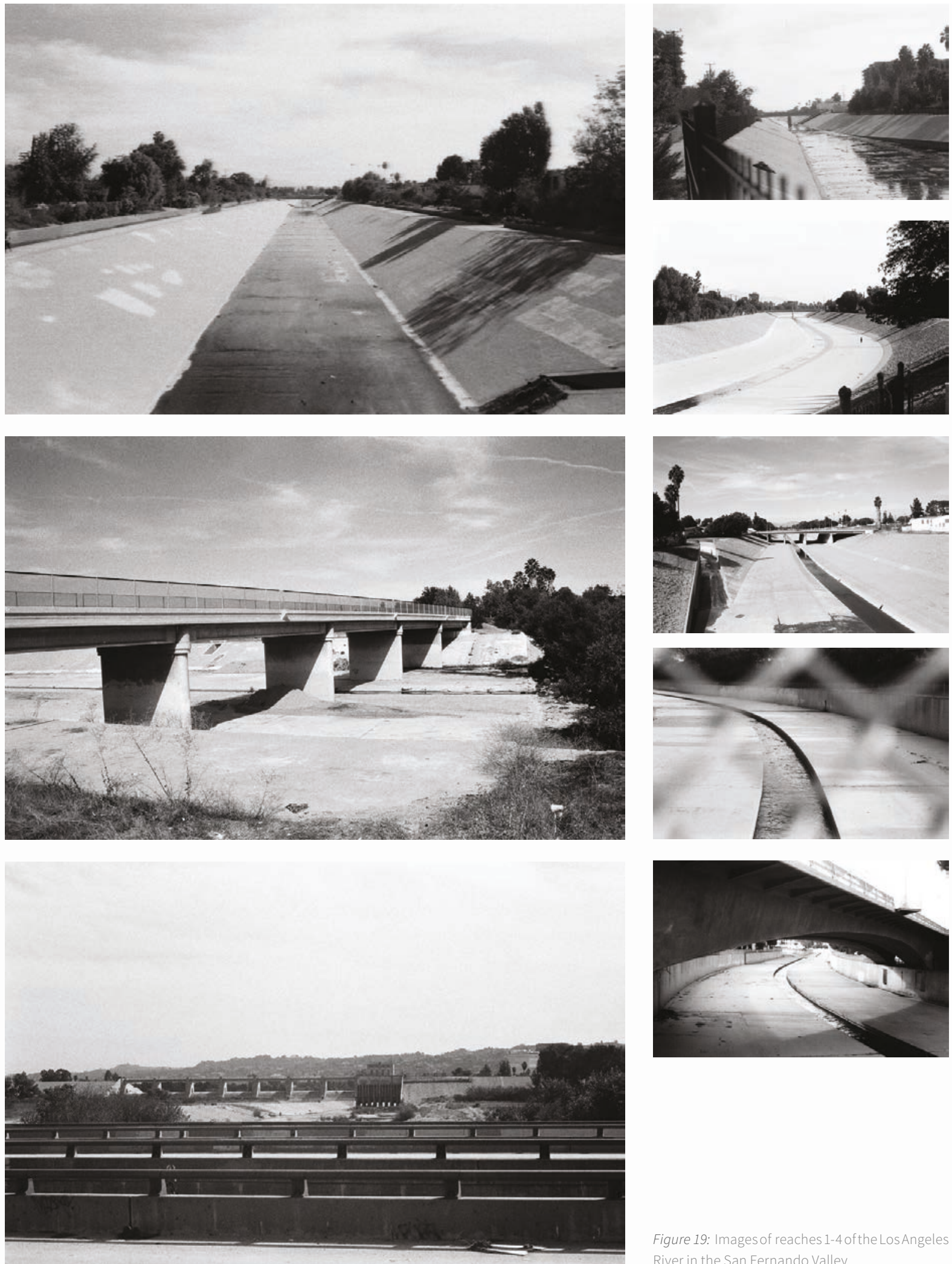

Figure 19: Images of reaches 1-4 of the Los Angeles River in the San Fernando Valley. 

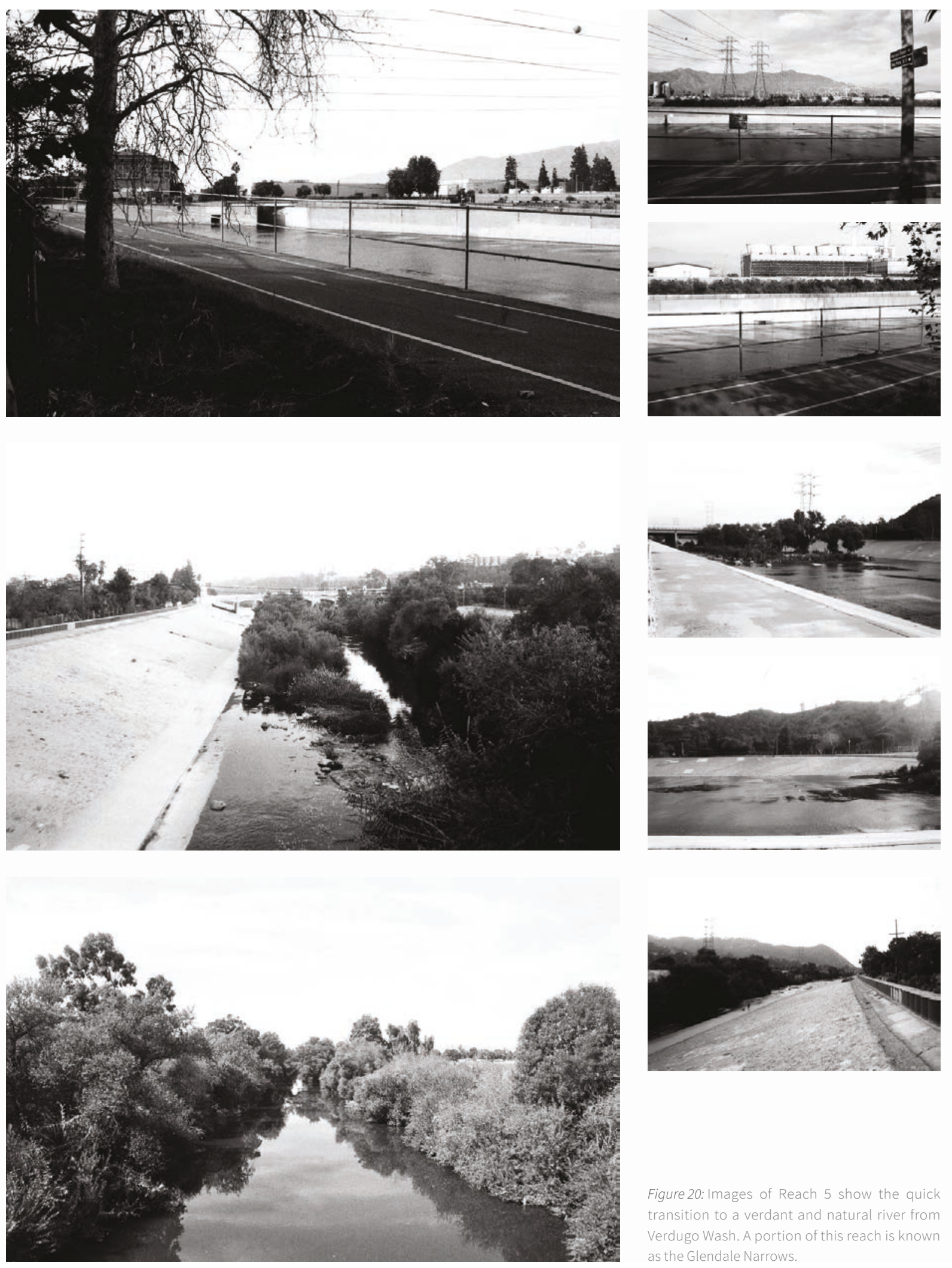

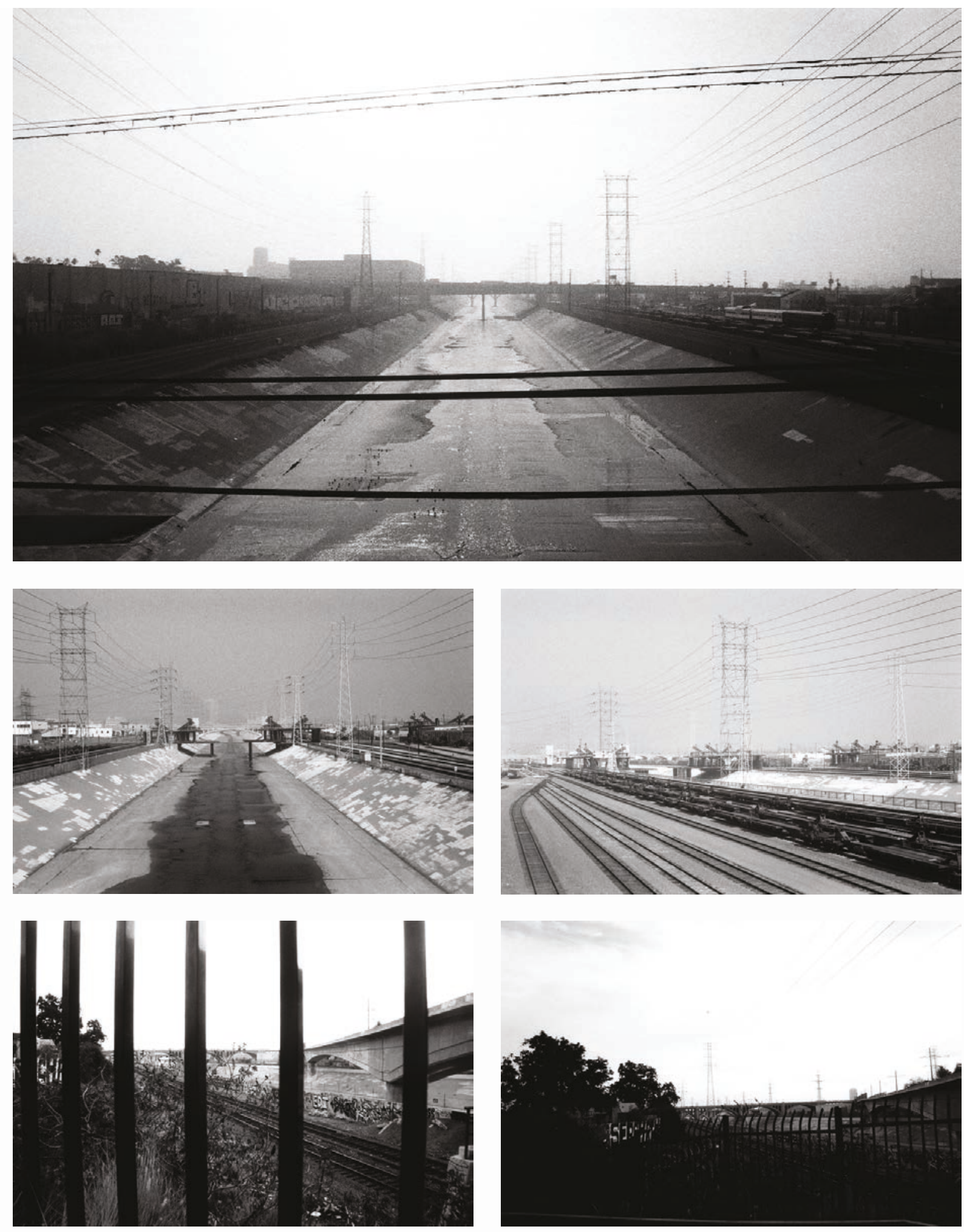

Figure 21: Images of Reach 6 and 7 of the Los Angeles River near downtown, from Elysian Valley to the Rio Hondo. 

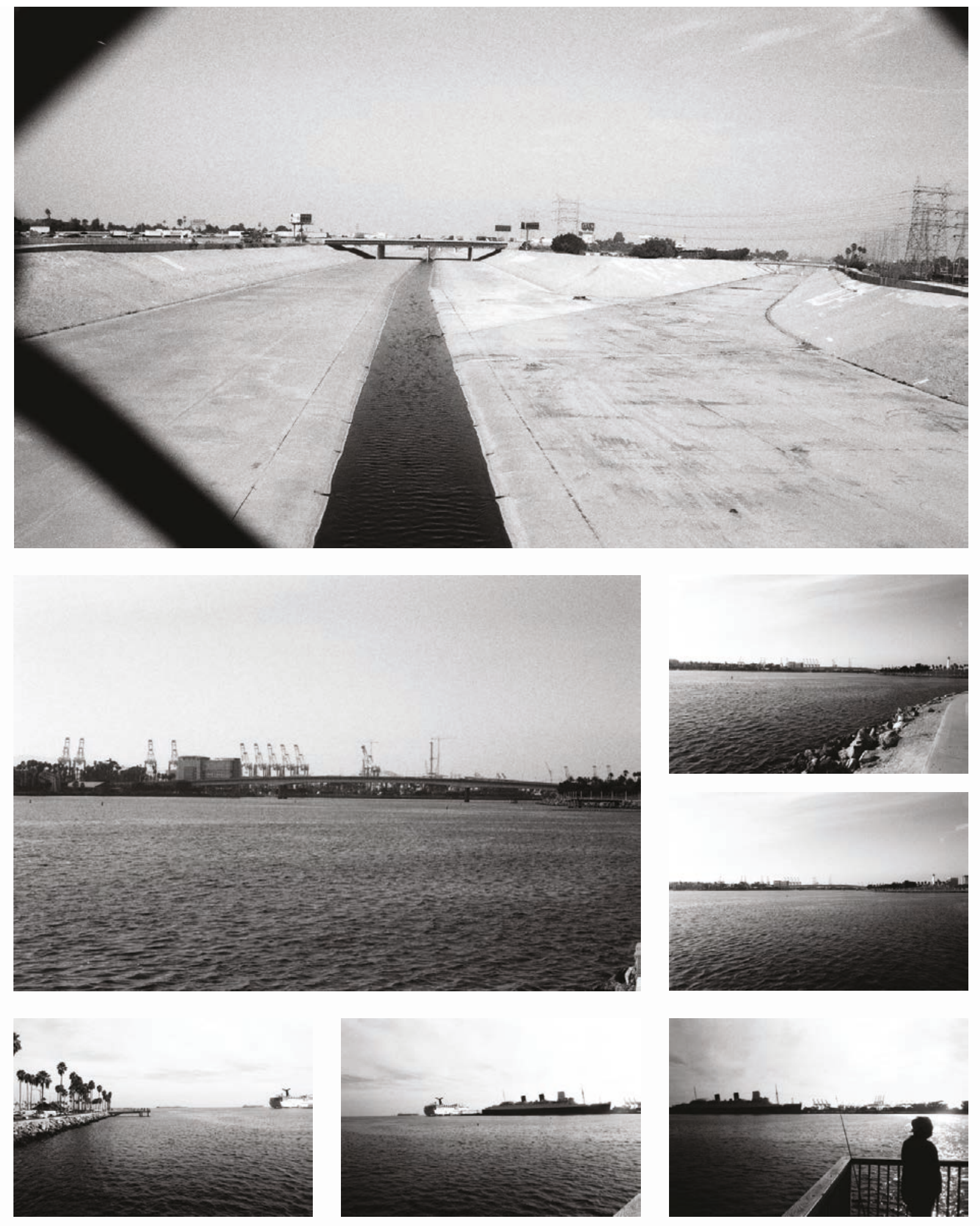

Figure 22: Images of Reach 8, the lower portion of the Los Angeles River from Rio Hondo to Long Beach Port. 
$\operatorname{lin}^{2}+\frac{1}{2}$

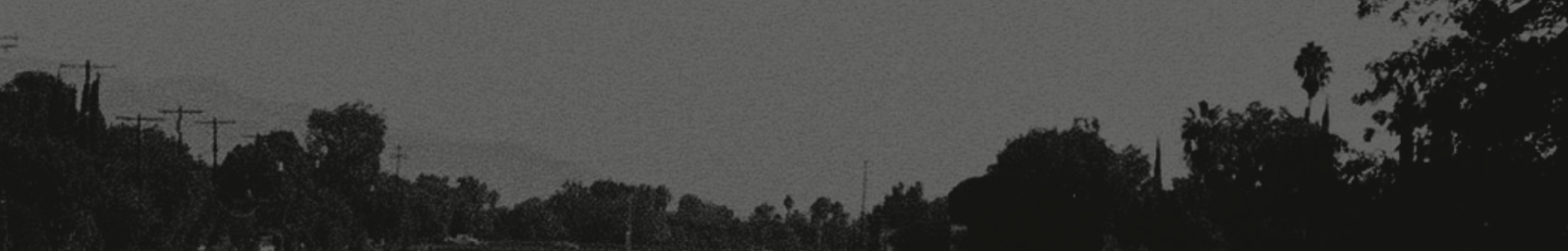

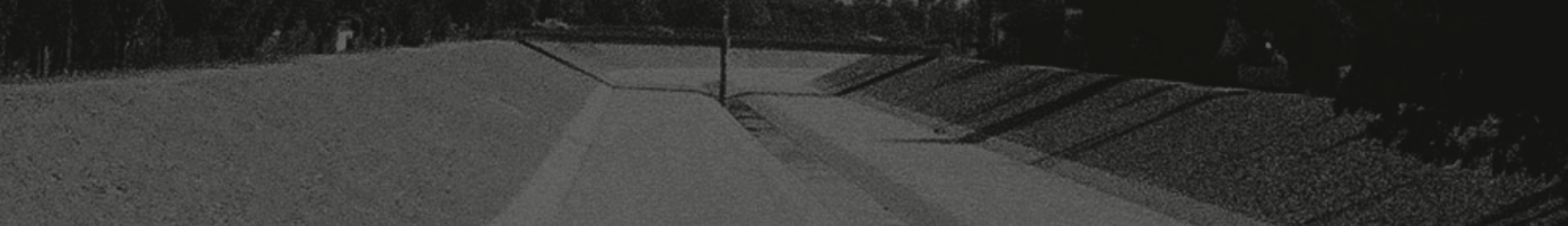

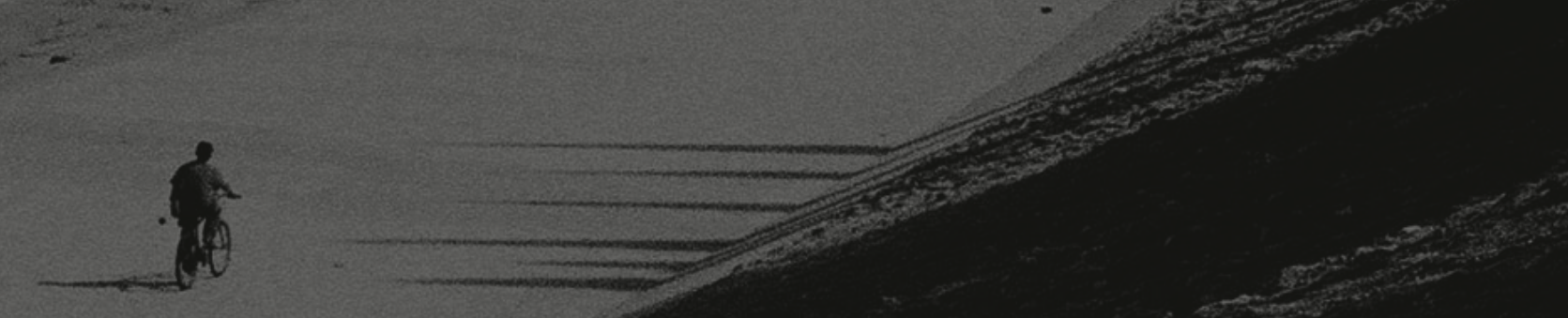

and 


\section{s SCOUTING}

It is important to see the river in all its complexities - and to experience it firsthand. A sitevisit was the first step in experiencing the fundamental nature of the river and its current relation to the city. To take a tour along the entire length of the Los Angeles River is to thoroughly comprehend its impact as a shaping force of Los Angeles. The intent was to witness the limitation of its construction - its presence and absence within the urban fabric - and to document it through sensorial understandings and processions.

How should this river (that is no longer a river in any recognisable form) be approached? Because of its 'difference' should we seek alternative methods to analyze an unusual river? Does the very nature of the 'unusual' demand unusual methods?

This thesis proposes a dialogue between probing, tracing, and scouting as a critical way to examine the hardscape. And to establish this dialogue, the research uses the following dualities: the fixed and the moving, distance and proximity, and isolation and accessibility.

In Curious Methods, Sean Burkholder and Karen Lutsky suggest that in order to gain insight into the muddy landscape, we must 'probe' it. In this case, to 'probe' means to engage with physically and conceptually. The goal is to understand how the site changes by how we - the user, the visitor - interact with it, challenging us to go beyond what we see on the surface. This can be done by gathering 'impressions' of the landscape, where "each one forging a new narrative, seeking to draw out the 'characters' of the landscape in an attempt to understand how they could be re-choreographed." This is a useful methodology to understand the Los Angeles River. Using scale as a method of investigation, tracings of the river were made in three ways: by car, following the length of the river; on foot, assessing and documenting

\footnotetext{
1 Karen Lutsky and Sean Burkholder, "Curious Methods," Places Journal, May 2017.
} 
the river; and by hand, taking imprints of the river's banks and bed. These tracings offer impressionistic versions of how the river is accessed and how we interact differently with the river; offering both physical and analytical insights.

Tracings were conducted by scouting, which correspond to the curious method of probing. The site tour of the river was the first act in addressing its unique urban condition and it played out as if I was location scouting for a film. To scout is to investigate and to analyze a space through the act of assembling information and gathering intelligence, which is most often visual. The act of scouting implies that the site is not well known, but is recognized for an aesthetic and possible value. A location scout seeks out sites that are suited to the particular atmosphere of the story or script. These locations set the tone and contribute to the overall visual and emotional portrayal of the film. Scouting also implies a future intervention or staging.

I look to Reyner Banham as a scout. As an outsider from London, Banham is captivated by Los Angeles and sets out to experience and document this landscape in a different way. In The Architecture of Four Ecologies and his movie 'Reyner Banham Loves Los Angeles', Banham discusses the importance of the automobile to Los Angeles. He analyzes the motorized metropolis in his novel, but experiences it first hand in the driver's seat in his film. His experience led to the concept of four ecologies, which examines the ways Angelenos use and relate to the beach, the foothills, the plains, and the freeways. They are unique topographic and infrastructural facets that contribute to an urban identity and frame Los Angeles in the popular imagination. 
The concept of "ecology" in Banham's perspective is a play on the traditional definition. Rather than biological, it is a cultural 'ecology' that speaks to how we relate to the built environment. By turning culture into an ecology, Banham highlights the way nature is connected to the urban environment. It is in an artificial sense that we see this relationship manifest as the hardscape supplants the natural landscape. While the relationship with the ground is different for each ecology (Surfurbia, Foothills, The Plains of Id and Autopia), Autopia relies upon the hardscape as infrastructure - a relationship to the ground that is based on mobile connections. This nature of mobility is central to Los Angeles;

Indeed the freeway system seem to have fixed Los Angeles in canonical and monumental form, much as the great streets of Sixtus V fixed Baroque Rome, or the Grand Travaux of Baron Haussmann fixed the Paris of la belle epoque. ${ }^{2}$

Autopia is the fourth ecology of the Angeleno as driving is "a coherent state of mind" where "freeways become a special way of being alive."3 The freeway was a unique identity because it allowed for freedom of movement and ease of connectivity at higher speeds. In this sense, the freeway system acts as a material logic to organize how one experiences and navigates the built environment, entertaining the urban landscape as a man-made material on which we navigate. The ground acts as a fabric that negotiates relationships that are spatial, infrastructural, and social.

By navigating the freeways and visiting landmarks such as the Eames House, Griffith Observatory, and the Watts Tower, driving makes visible the role mobility plays in Los Angeles. Banham puts his 'Autopia' idea to use in his 1972 film, performing a one-day tour of Los Angeles, 2 Reyner Banham, Los Angeles: The Architecture of Four Ecologies. University of California Press, 2009.

3 Banham, 213, 197. 
using a fictitious audio tour guide, Baeda-kar. ${ }^{4}$ For Banham to see Los Angeles through his rented car is to partake in the Angeleno way of life. With a camera directed out the front window, Banham recorded his journey.

I experienced Los Angeles in the same fashion as Banham - in my vehicle with a camera in hand. To experience the entire fifty one miles of the river, driving was necessary. Conducting a two-day tour in my car, I filmed the river as I crossed over the majority of its bridges. It was the most systematic and comprehensive way to experience the river and the most consistent point of view. The automobile is a detached way of seeing the river and driving over the bridges highlights this detachment, as it is at once in proximity and in distance. By filming while driving over its bridges, I not only partake in the Angeleno way of life, but I documented the life of the river as it is expressed in the built environment. In this way, Banham and my narrative experience merge two iconic LA personalities: driving and film. This site visit riffs off of Banham's method of storytelling and documentation because it relied upon a different way of seeing the built environment. Driving was the way of seeing, experiencing it as Angelenos experience it. The two architectures that defined the river were the bridges and the confluences. The following bridge and confluence atlases abstract the river through dissecting its components.

4 Reyner Banham, Reyner Banham Loves Los Angeles, BBC, 1972. 
The Bridge Atlas (Figure 24 on page 40) documents 110 bridges that cross the river. There are four different types of bridges: freeways, roads, private, and pedestrian. The movement over the river is experienced in time, at different speeds and perceptions. Its visibility is different depending on the type of bridge and the location of the bridge. At times, the railings of the bridges obstruct the view of the river and depending on the speed one crosses the bridge, the river can become more or less visible. As the channel width expands, closer to its outlet, the presence of the river becomes more apparent. It also results in a different bridge architecture that is less decorative and more utilitarian.

Driving over the many bridges is not the best way to see or experience the river. It was an exercise to see if one senses its presence in an everyday pursuit. How might we use representation to increase the river's visibility and engage this landscape?
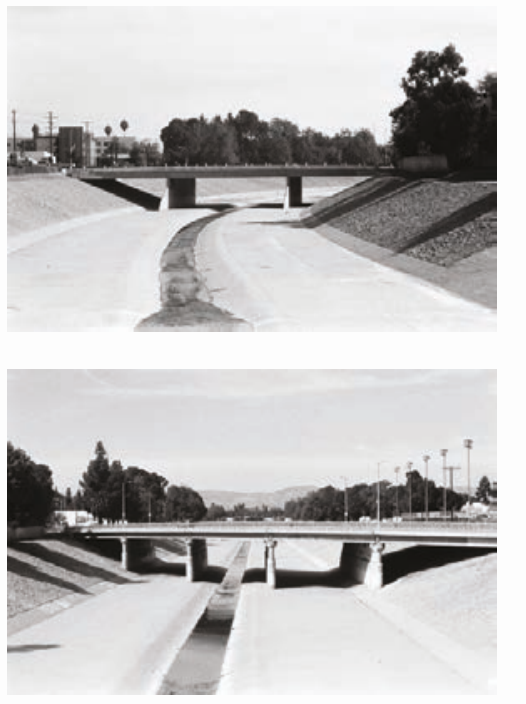

Figure 23: Photographs of the bridges that cross over the Los Angeles River in the San Fernando Valley and downtown Los Angeles. The bottom image shows the new 6th Street Viaduct under construction.

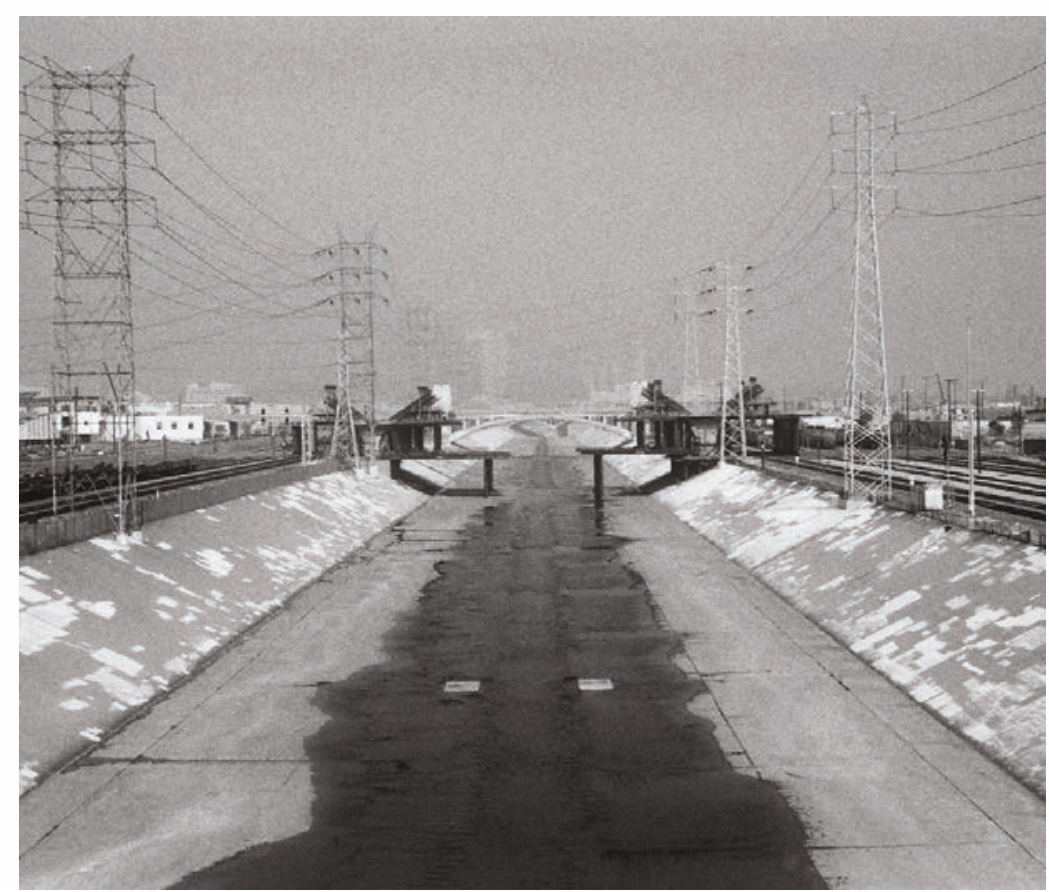




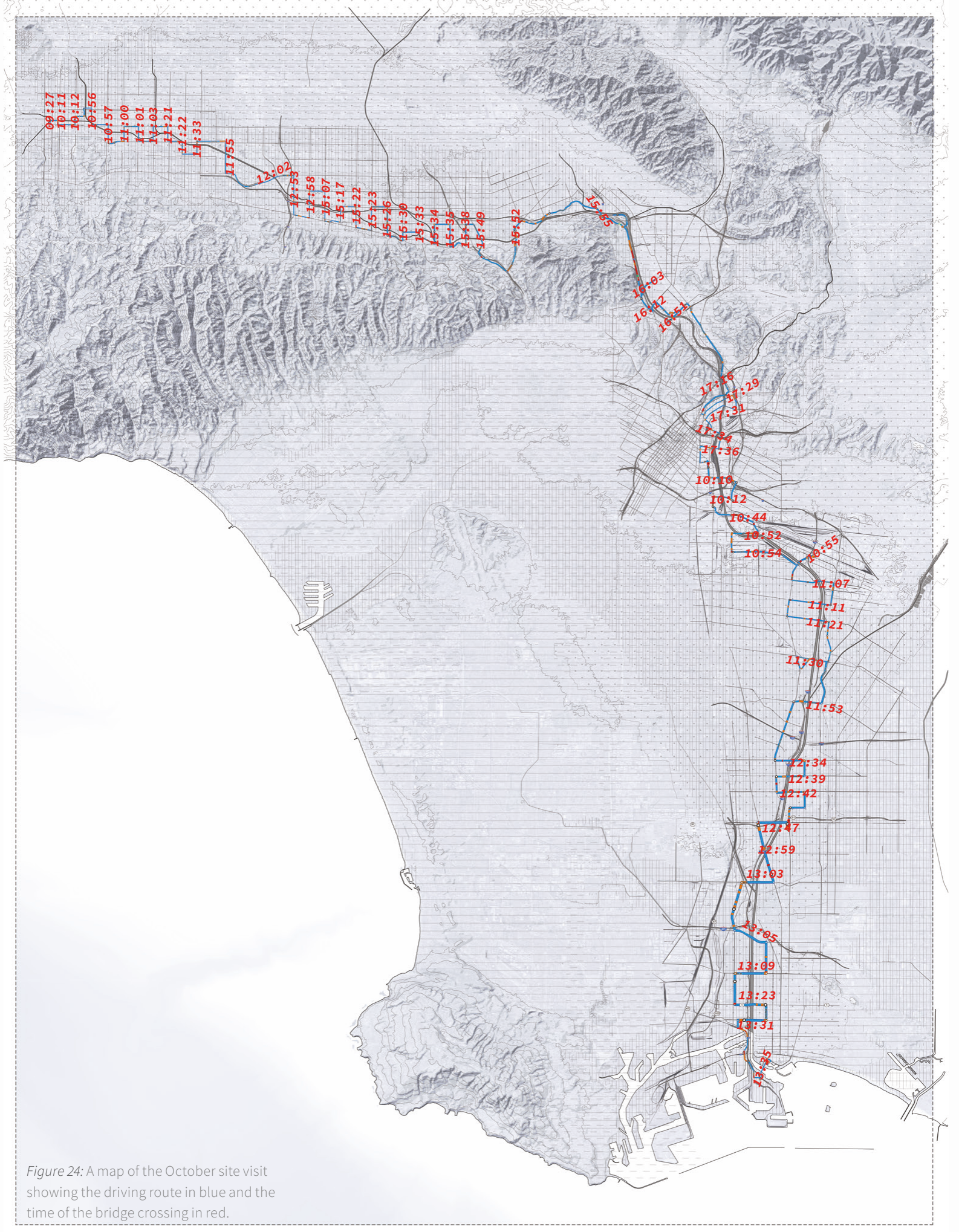




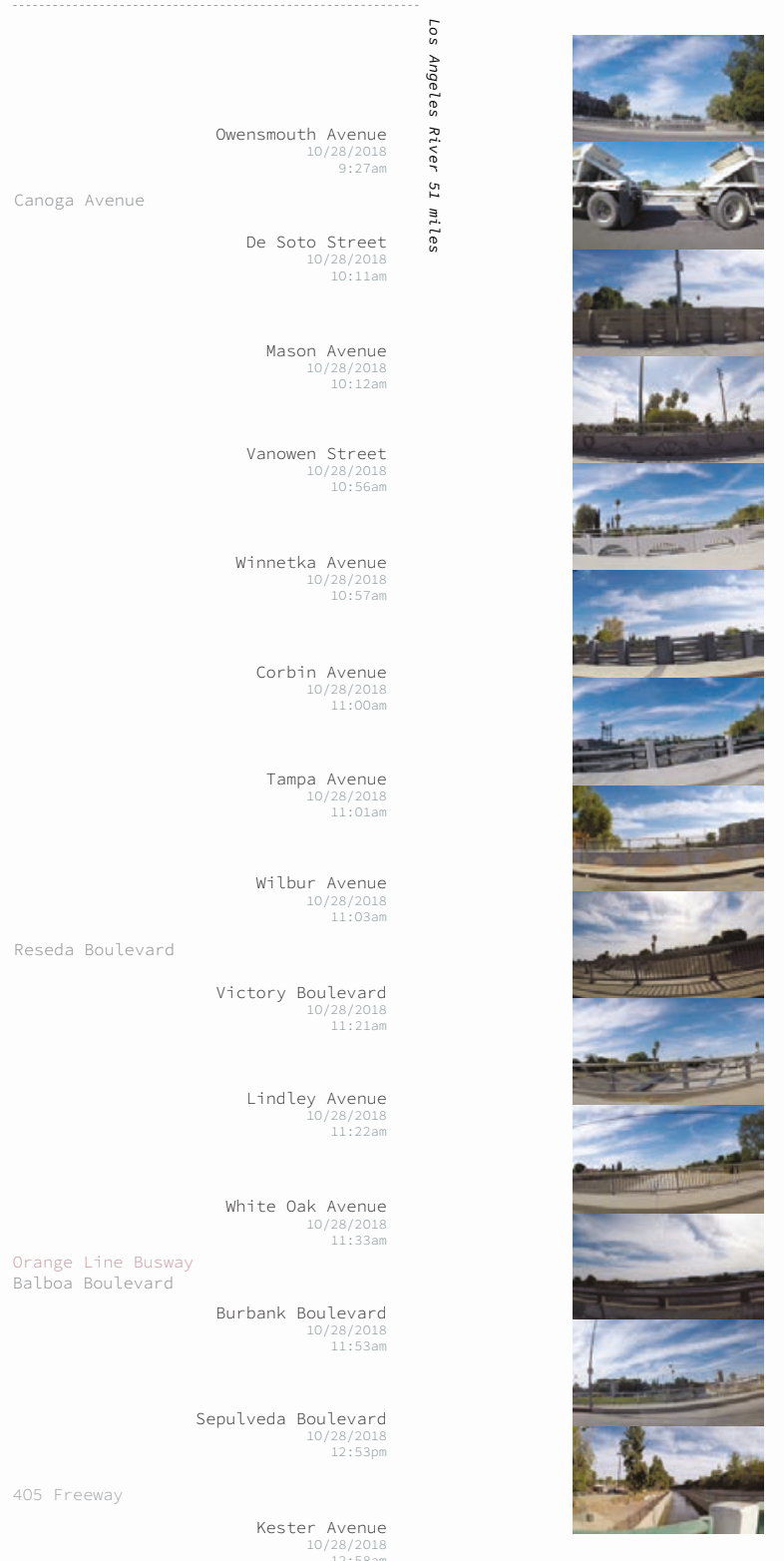

Van Nuys Boulevard

101 Freeway $\quad$ Hazeltine Aven

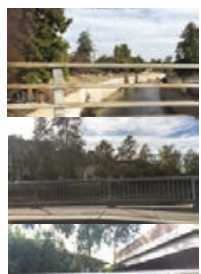

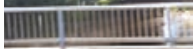

Woodman Avenue

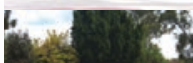

Fulton Avenue

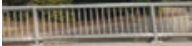

Coldwater Canyon Avenue
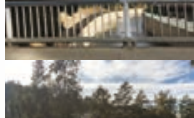

Whitsett Avenue

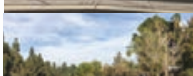

Laurel Canyon Boulevard

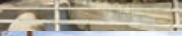

1

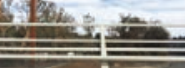

Colfax Avenue
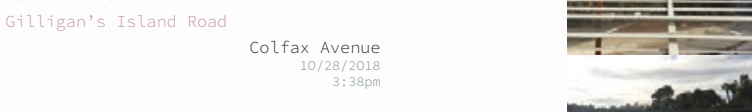

Tujunga Avenue
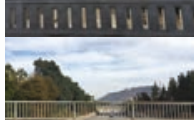

Vineland Avenue
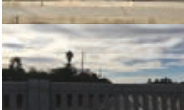

Lankershim Boulevard
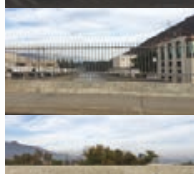

C. $1: 1: 1$

Riverside Drive

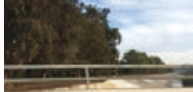

os Feliz Boulevard

Figure 25: Video stills taken while driving over the bridges that cross the Los Angeles River, series 1 of 2 

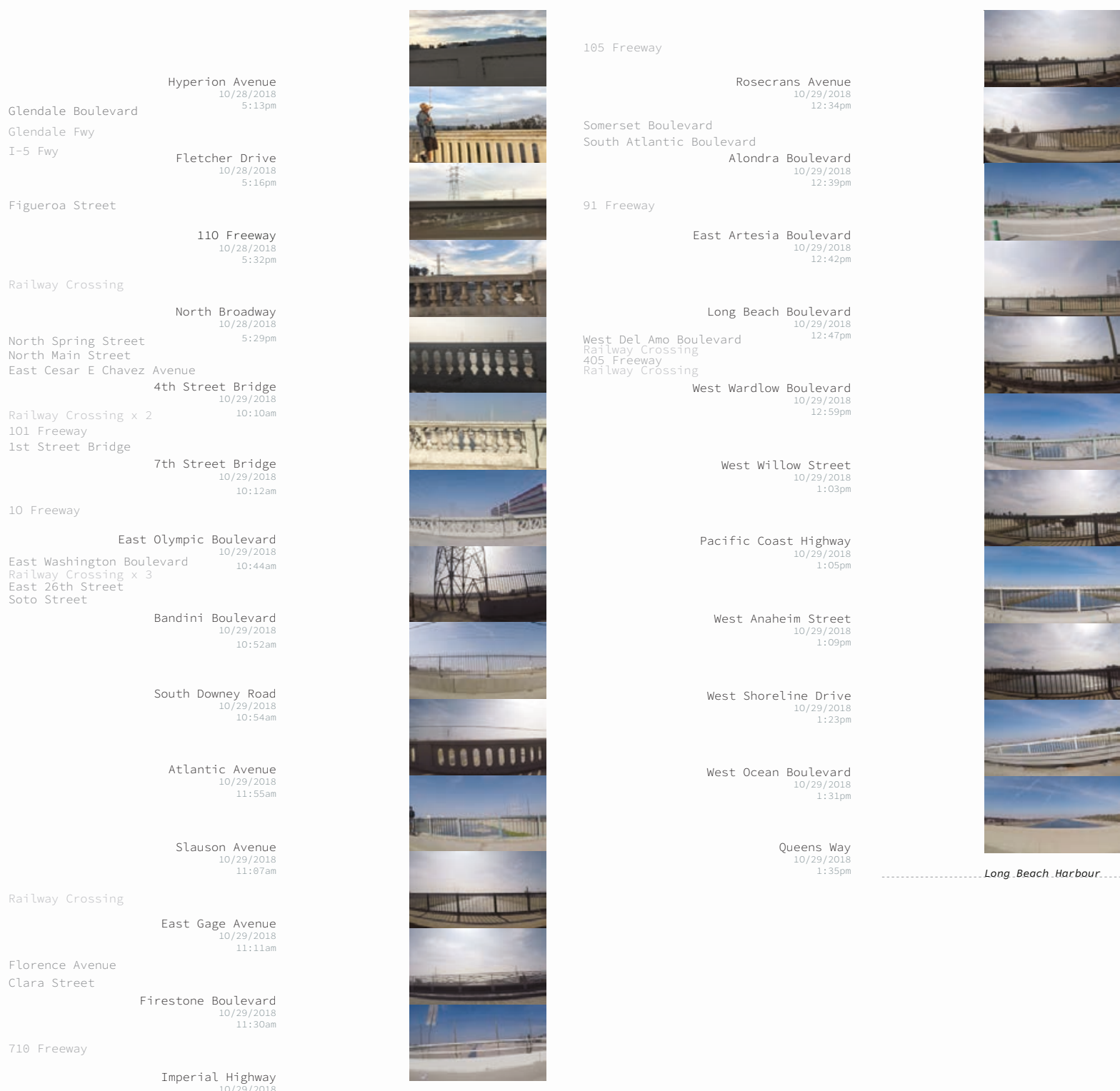

Long Beach Harbour

Figure 26: Video stills taken while driving over the bridges that cross the Los Angeles River, series 2 of 2 . 


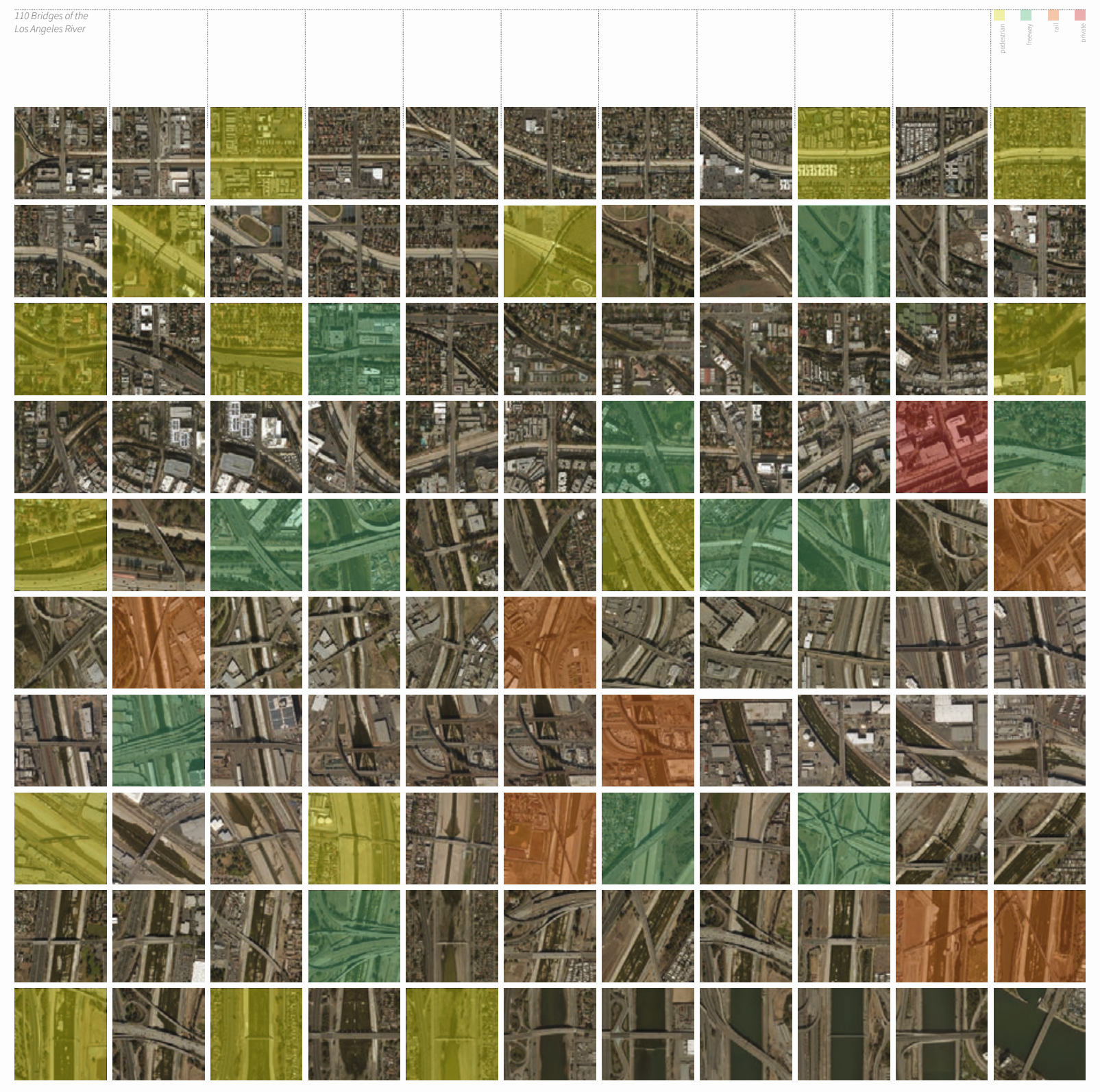

Figure 27: This Atlas catalogs all the pedestrian, roadway, freeway, railway and private bridges that cross the Los Angeles River. 
Confluence

Aflowing together of two or more streams or rivers.
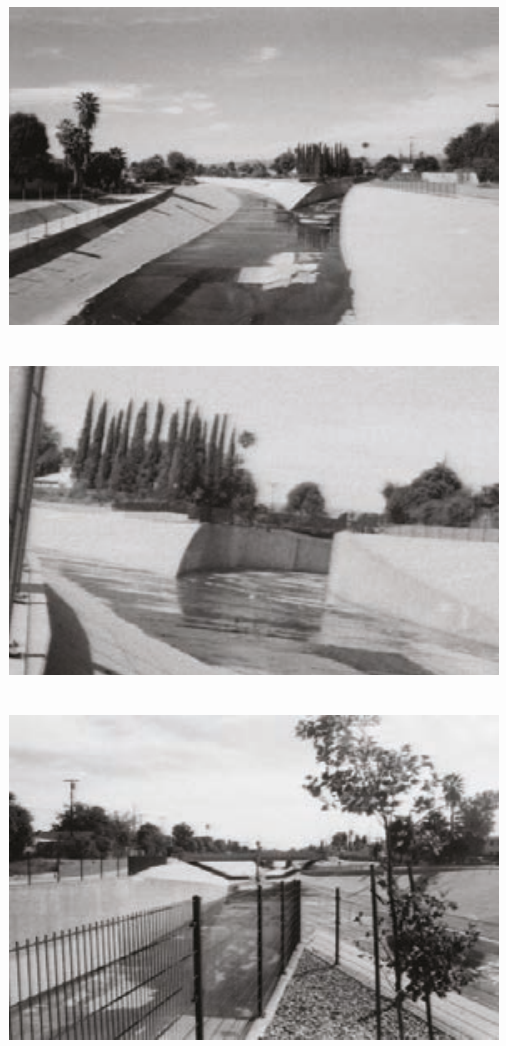

Figure 28: Los Angeles River confluences
The Confluence Atlas (Figure 29 on page 45) documents the nine tributaries that join the river in four different perspectives: plan, from the bridge, and two aerials looking downstream and upstream. The confluences are the most cinematic points in the river, where two waters collide - especially when it rains. These striking concrete confluences are a powerful expression of both engineering and infrastructure.
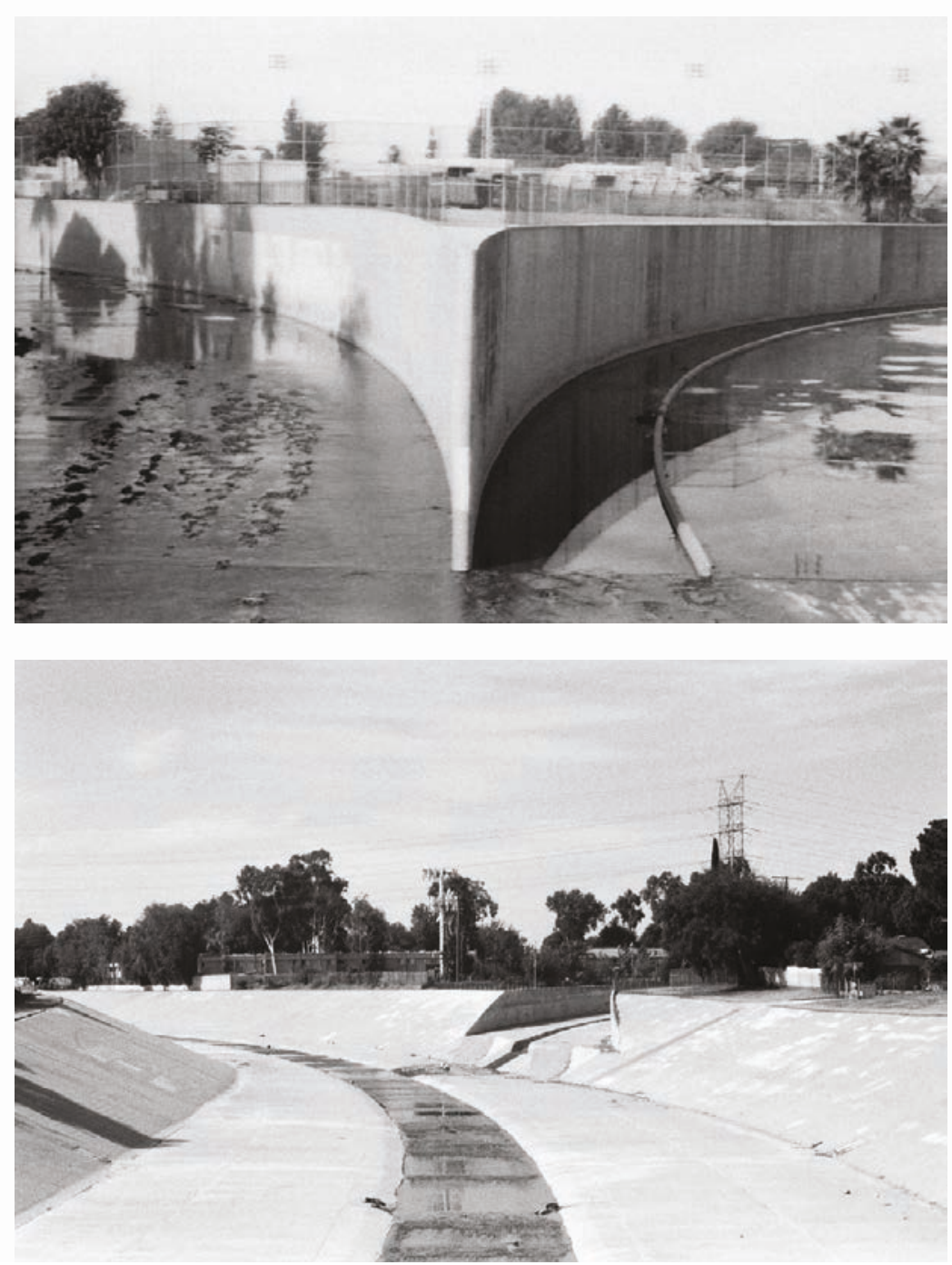

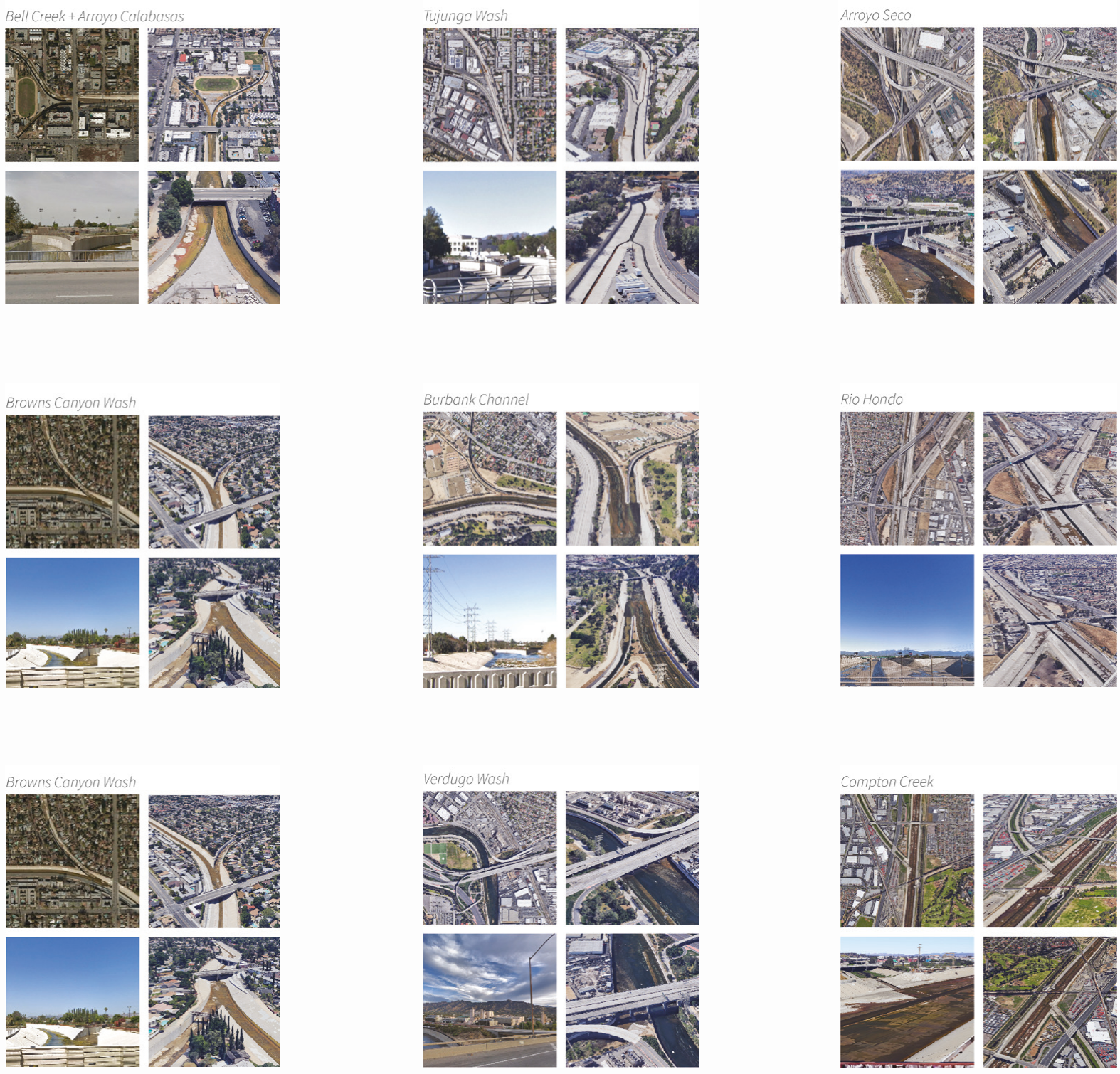

Figure 29: This Atlas catalogs the confluences of the Los Angeles River where the nine tributaries join the river. 
Material Tracings

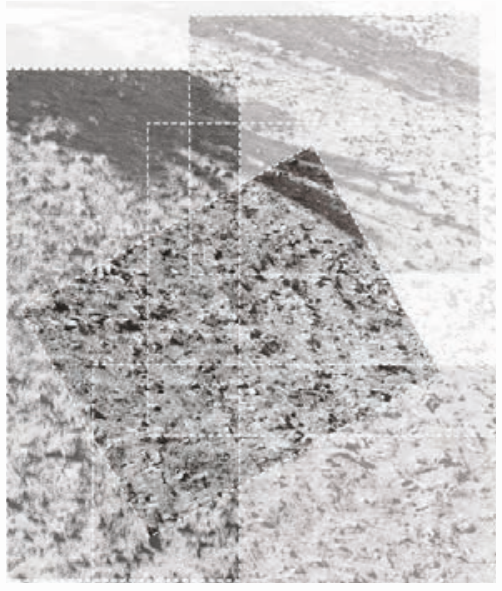

Figure 30: Concrete tracing

San Fernando Valley

October 28th, 2018.

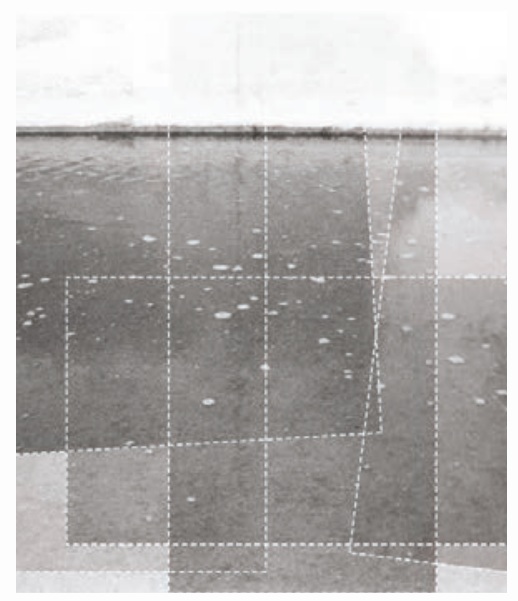

Figure 31: Still tracing

San Fernando Valley

October 28th, 2018

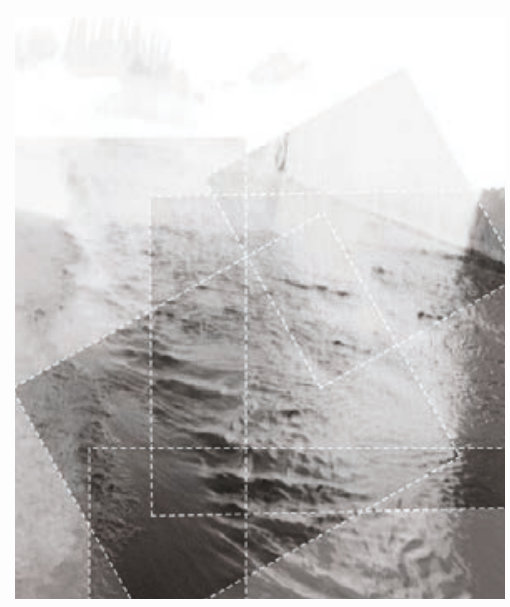

Figure 32: Moving tracing

San Fernando Valley October 28th, 2018 


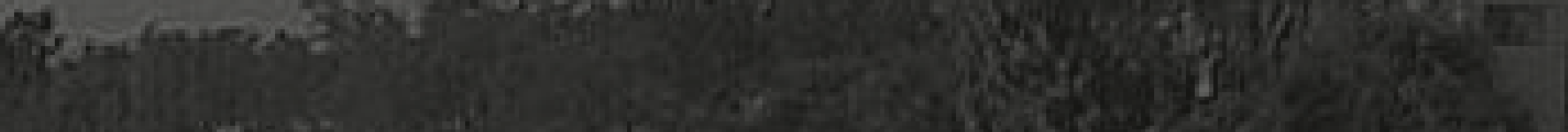

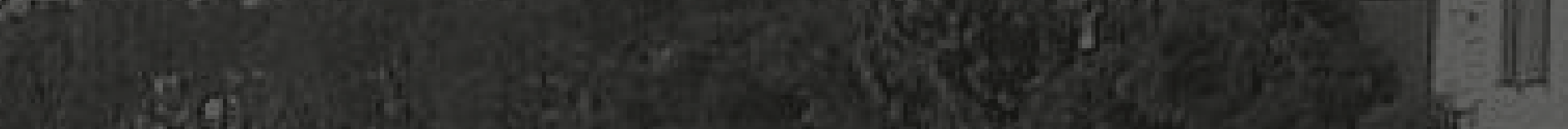

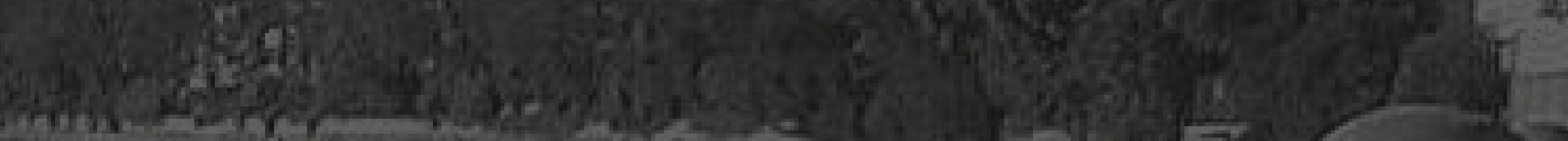

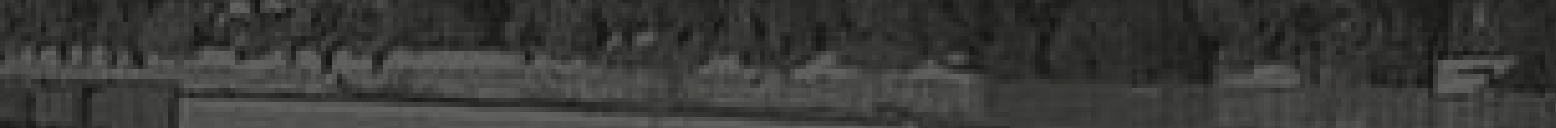
(iii
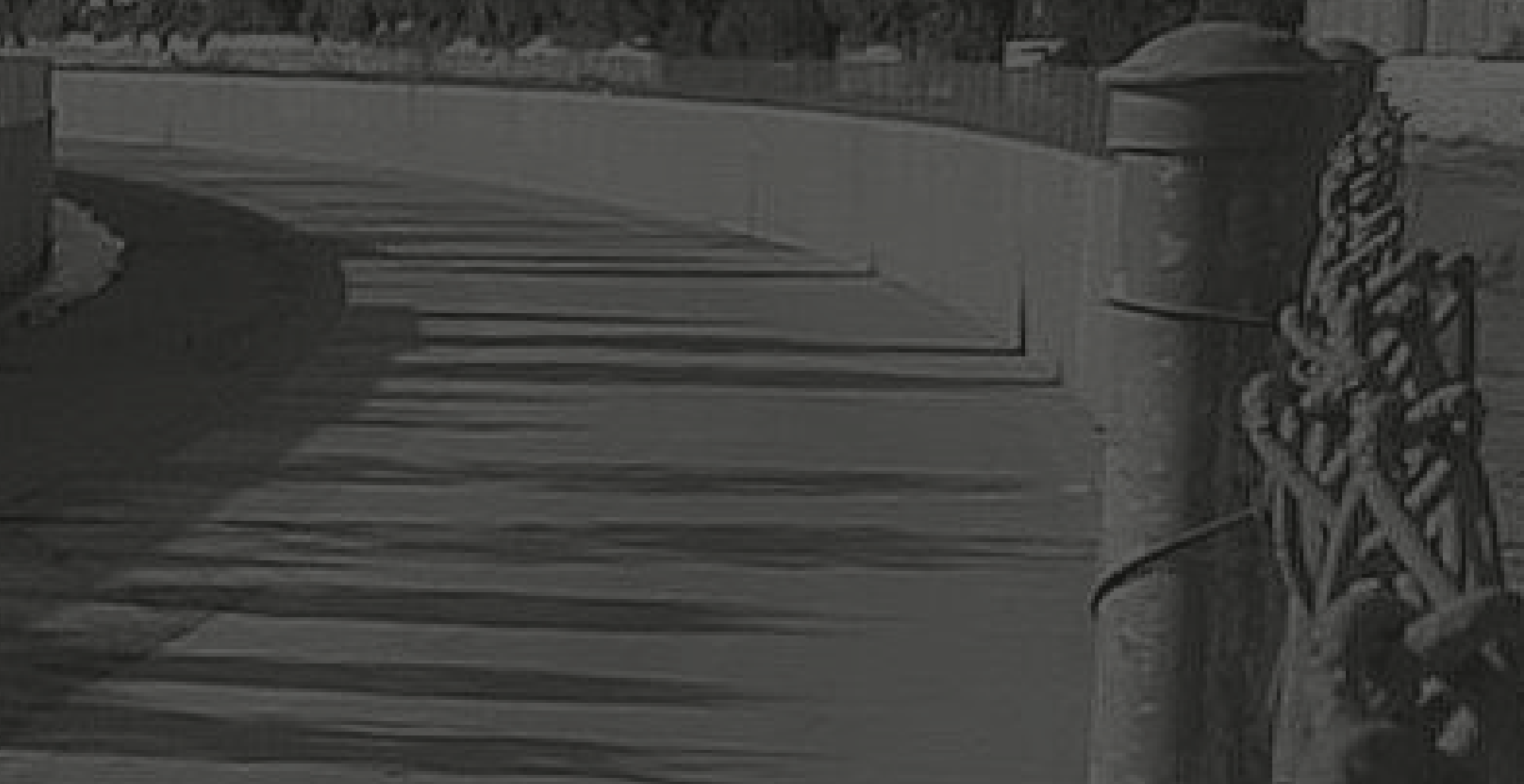


\section{ATLAS OF THIREE RIVERS}

To conceptualize and contextualize the Los Angeles River, this atlas traces three narratives: The Infrastructural River, The Invisible River, and The Cinematic River. The atlas is a translation of Banham's ecologies as it seeks to understand and analyze how space is perceived and used and how the river plays or fails to play a role in Los Angeles. It recognizes the interplay of the multiple, concurrent realities and uses thematic aspects that define Los Angeles to think about the river. Analytical abstractions trace the river to show how it is imagined and experienced. These three non-natural imaginaries of the river system reveal the multiple natures of the river. The infrastructural, invisible, and cinematic lenses define the character of the river beyond its physical nature. 


\section{The Infrastructural River}

The river is a typical Los Angeles construction - an infrastructural river. Los Angeles is a work of infrastructure where the urban fabric is laid out to promote a decongested metropolis. This infrastructural system provides productive movement whether it was once trolley cars, the railway, or now the automobile, the infrastructural river regulates through a calculated experience.

The river is an organizing logic for all other infrastructures. ${ }^{1}$ While the river disposes of unwanted water, it channels freeways, railways, cell towers, and power lines. A map (Figure 33 on page 50) shows the industrial zones along with the freeways and railways. Zooming in to downtown Los Angeles, a map (Figure 36 on page 53) illustrates how the adjacent land, just like the river, serves as a conduit and corridor of movement because as the river wraps around its eastern edge, it becomes lined by railways on both sides. ${ }^{2}$ After downtown, the river maintains this relationship to its edges, where the 701 parallels the river until its outlet. A map (Figure 34 on page 51), highlights all the freeways that cut across the river: 405, I-5, 10, the Glendale Freeway, and the Hollywood Freeway, while another map (Figure 35 on page 52) isolates the railroads in relation to the river. These edges have become a part of the river's identity because in most places, particularly in downtown LA, the river is uninhabitable and inaccessible, creating an industrial landscape that is larger than the channel's width.

The most comprehensive way to understand this relationship is from an aerial perspective. We can see that infrastructure dominates the ground plane and the skyline, in which the freeways emerge as the predominant feature. It is also in this perspective that we can read 1 Lane Barden, "The Los Angeles River Picturing Los Angeles: Conduits, Corridors, and the Linear City." The Infrastructural City: Networked Ecologies in Los Angeles. Ed. Kazys Varnelis. Actar: New York, 2009, pp. 80

2 Barden, 81. 


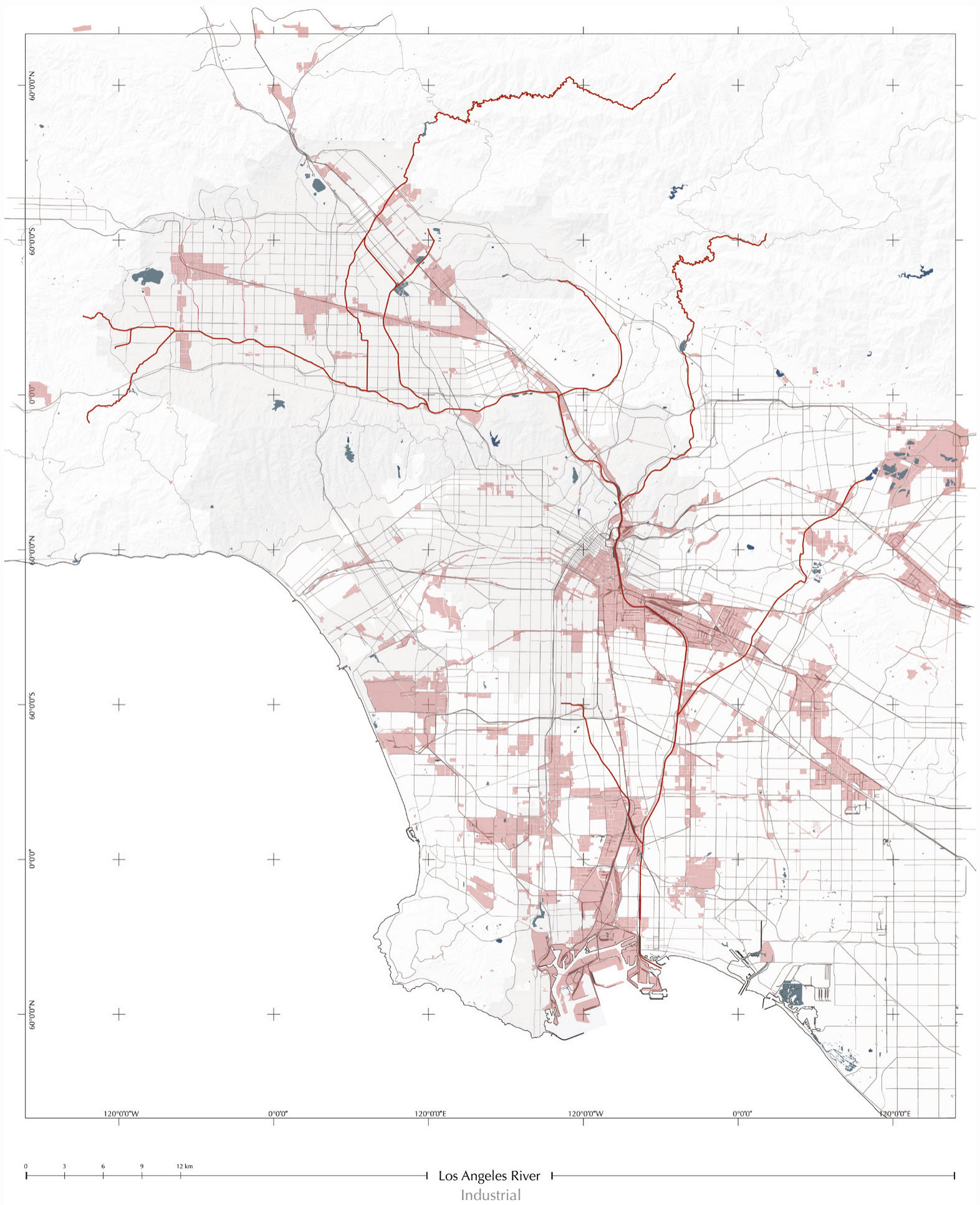

Figure 33: Map illustrates the industrial land uses in Los Angeles County. 


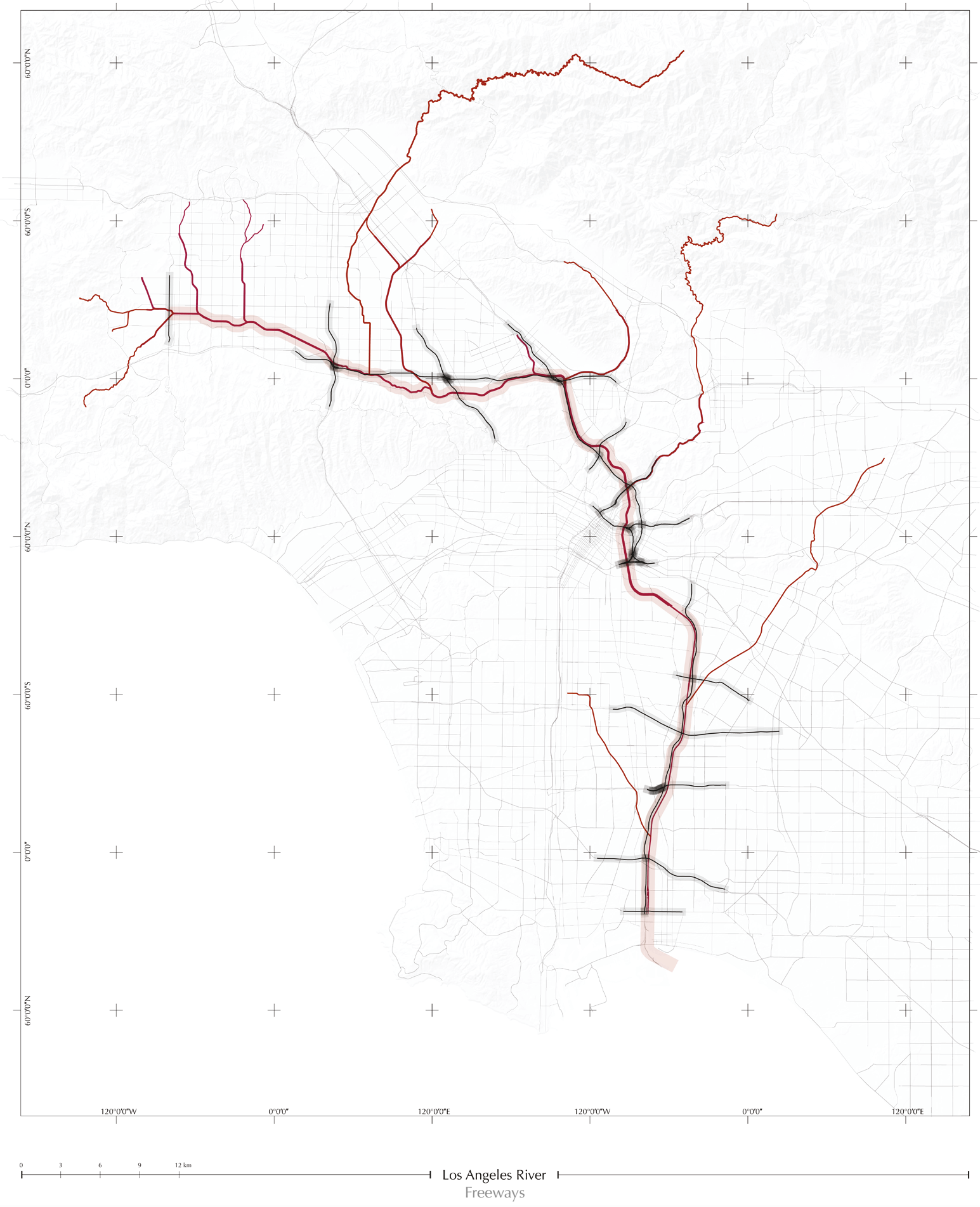

Figure 34: Map illustrates the freeways in Los Angeles County. 


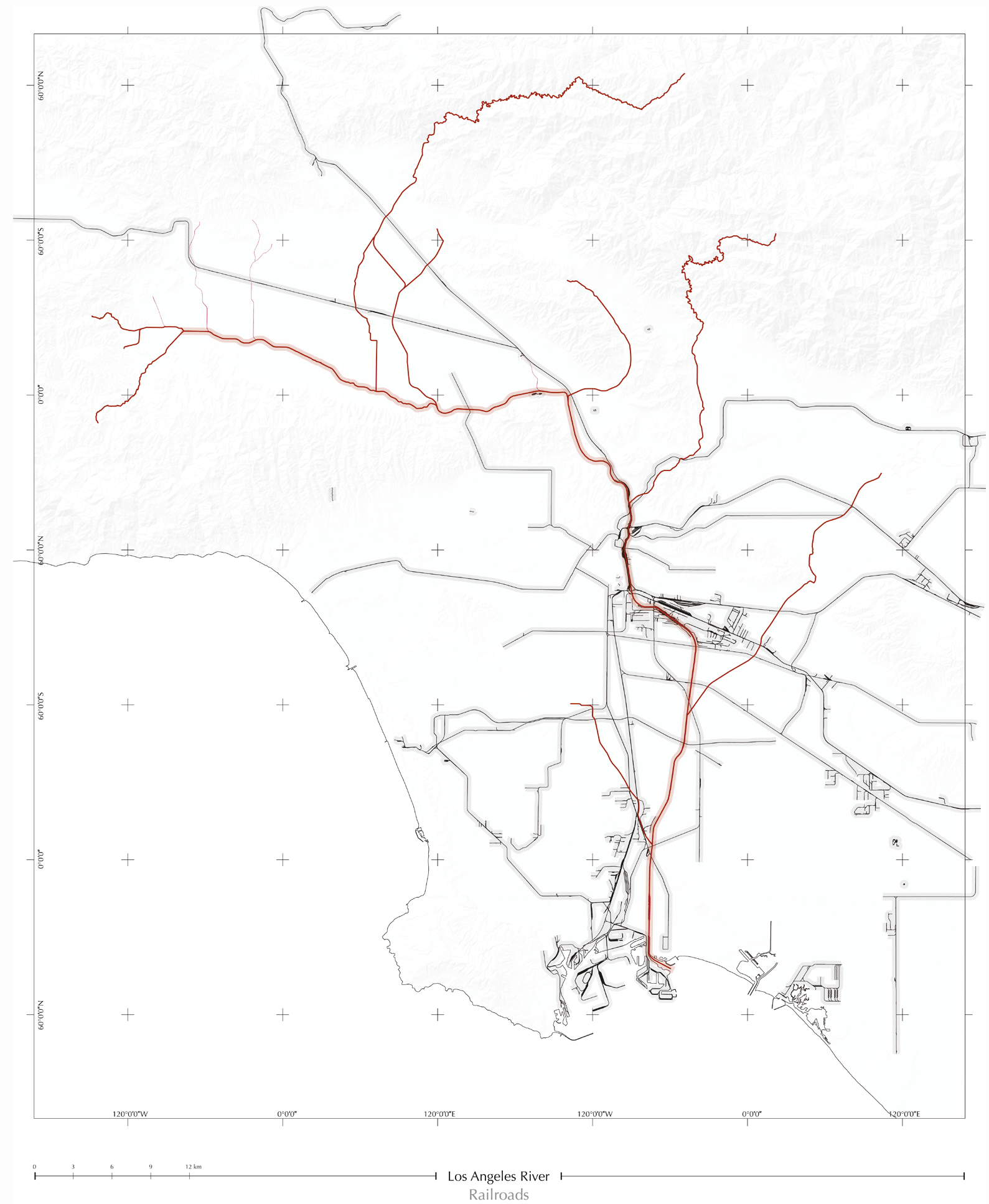

Figure 35: Map illustrates the railroads in Los Angeles County. 


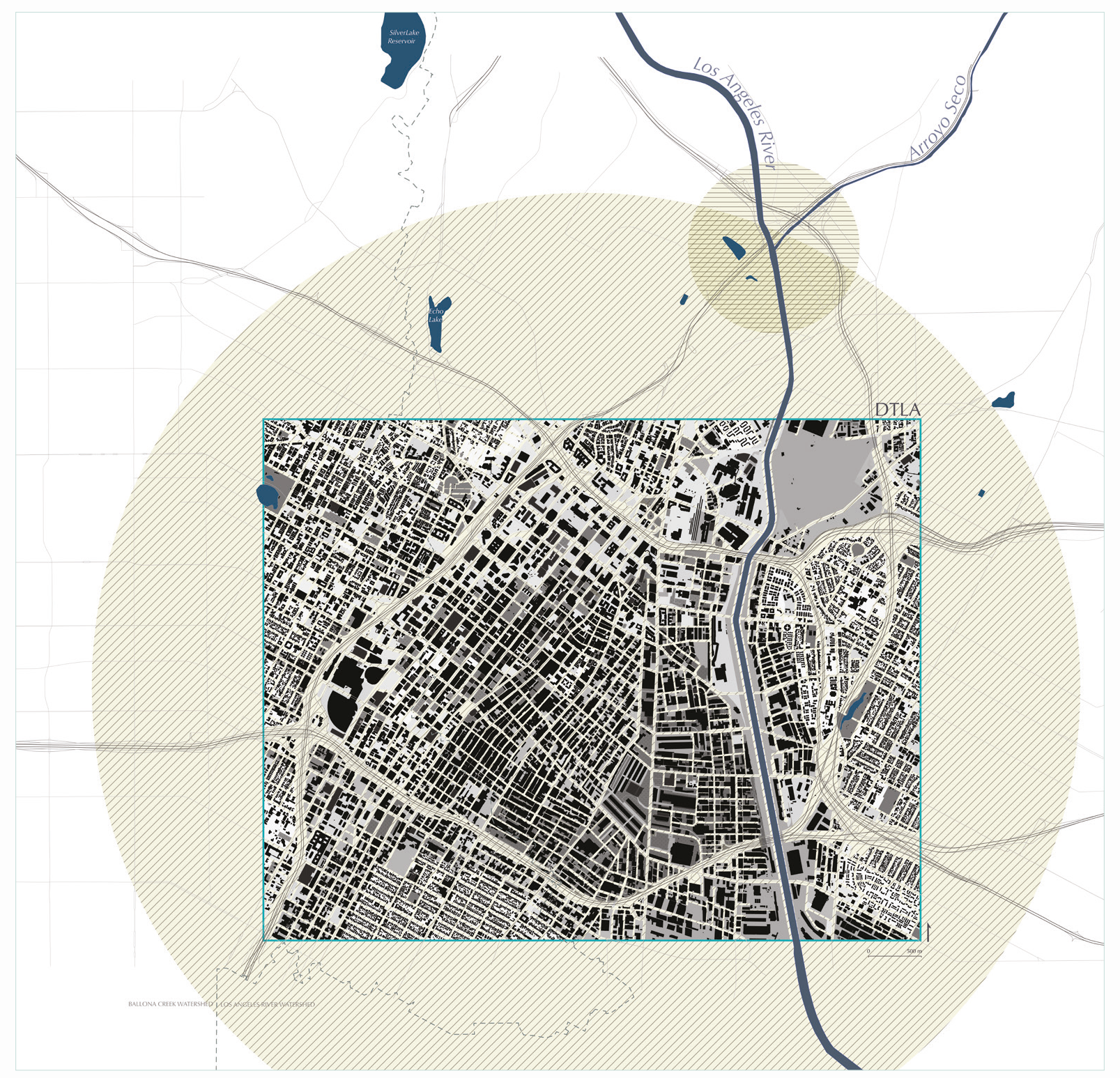


the concrete river as resembling a freeway far more than a waterway. In fact, in 1989, Richard Katz, a State Assemblyman, suggested to use the river during the summer months as a truck route and automobile expressway to alleviate traffic on the freeways. ${ }^{3}$ Although, this proposal was not realized as it would undermine flood protection, the following collage (Figure 37 on page 55) was inspired by this idea. It highlights freeways over the river to also draw a comparison between the two and to emphasize their importance as a defining feature and spatial identity in LA - a land that is in perpetual, linear motion. The river reflects the mentality of automobiles on the freeway, in both movement and interaction. The collage challenges the idea of the river two ways. First, it suggests that its water moves in the same way vehicles do: from point A to point B or source to outlet. Secondly, it suggests that its single purpose design does not allow for public engagement, just like vehicles act as capsules to one's destination and interfere with your experience of the surrounding environment.

Although multiple perspective views of freeways are collaged, the most prominent view is what constitutes the horizon as Los Angeles is most notably imaged through the camera lens and through the wind shield. In "Color= Place+ Time," Mark Eischeid states that "color has a strong geographical and cultural relationship to place." ${ }^{\text {Th }}$ This cannot be more true for Southern California, a romanticized landscape of sunshine and blue skies. The use of yellow and blue, sun and sky, symbolize the California dream. The circle suggests rotation, exchanging the yellow horizon for a skyline of freeway interchanges. All we see in the horizon is the road ahead. From infrastructure, we see infrastructure.

3 Gumprecht, 273

4 Mark R. Eischeid, "Color = Place + Time", in LA+, vol. 8 ("Time"). Philadelphia: University of Pennsylvania Press, 2018. 


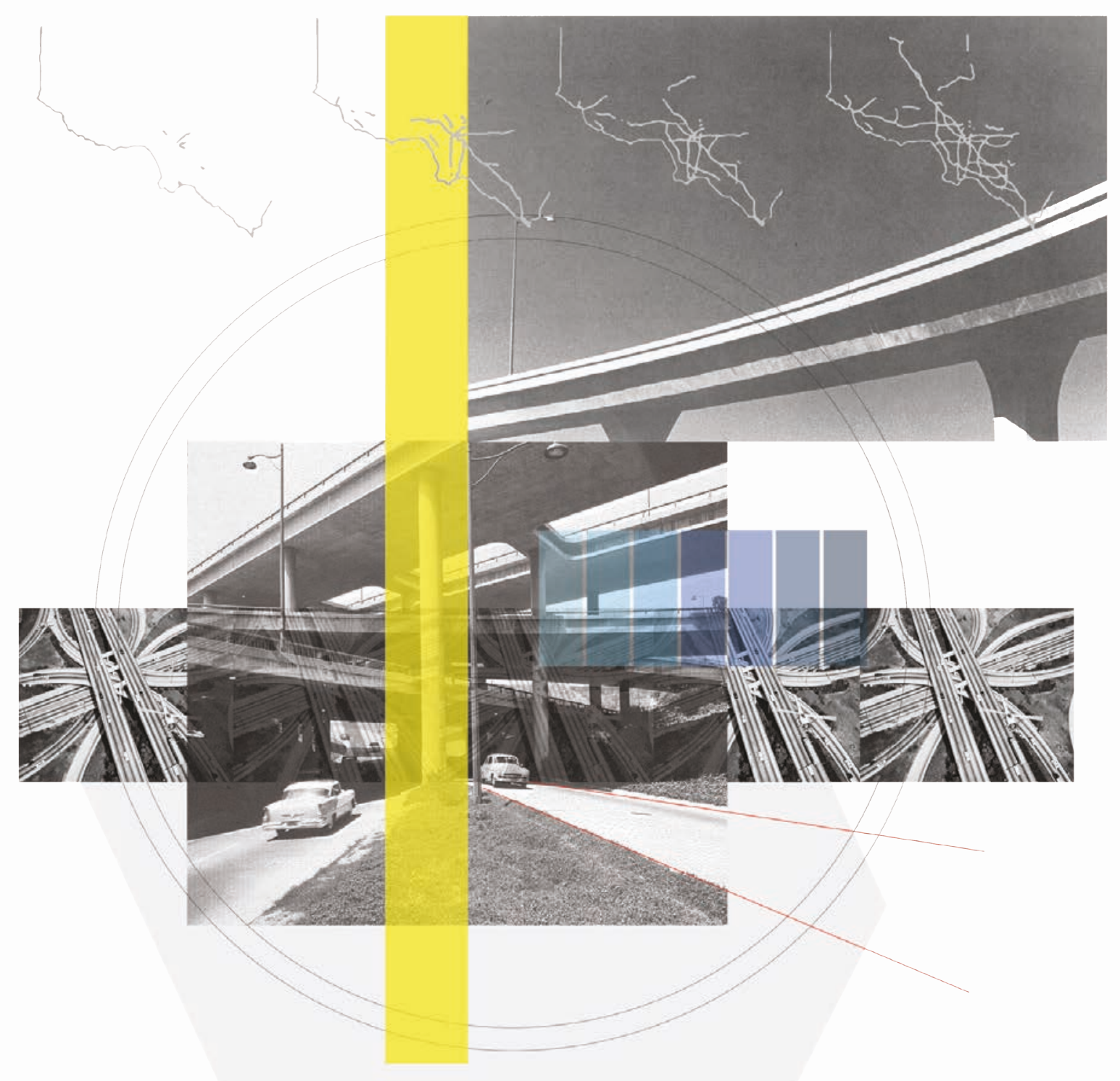

Figure 37: The Freeway River collage. 
The river in Los Angeles is invisible. It is a ghost or mirage, at once seen and unseen; we know it is there yet its presence is peripheral and ephemeral. Although the river is found throughout the city, it seems there is a collective blindness as the river most often goes unnoticed. It is only experienced in crossing at speed. The river lacks a sense of place, lost through channelization and now exists in an ambiguous state. The river, as a physical entity, is infrequently visible and is mostly expressed through its infrastructural edges. It is a river in time and in our collective imagination.

The river is unintentionally invisible, but it is functionally concealed. We can understand this narrative of loss through its historical context: from history to hardscape. The slowly diminishing water supply of the river initiated its decay as it could no longer be a source of life or life giving. With the construction of the Los Angeles Aqueduct, the Los Angeles River lost its identity as a resource, a superfluous space that solely appears in rain events. Only through channelization was there an abrupt and significant spatial alteration of the river that engendered its invisibility within the built environment. As the city densified and lapped up to the edge, the river developed into a formal void, with the river acting as a limit. Channelization created an interstitial spatial condition and a place of liminality. From this perception, the LA River "[became] a river in name only," experiencing a loss of place because its meaning has shifted. ${ }^{1}$

1 Blake Gumprecht, "Who Killed the Los Angeles River?" Land of Sunshine:AnEnvironmental History ofMetropolitan Los Angeles, by William Deverell and Greg Hise, University of Pittsburgh Press, 2005, pp. 115-134. 
From the same perspective, we can question what type of river exists today. The simple answer is that it is really not a river, since effluent is the only thing that fills the channel gully. The full breadth and depth of the river channel is full less than 36 days a year. ${ }^{2}$ By this measure it cannot be seen as a river.

The other, more specific option is that it is an effluent river. Lane Barden would liken this to a tertiary river because treated wastewater is what is keeping the river alive. Without this tertiary water, - flowing from tap, to sewer, to treatment plant - and then fed into the river, it would lead to a nearly dry river for much of the year. ${ }^{3}$ Tertiary water is the most consistent type of water found in the channel and it maintains a steady, but low baseflow. ${ }^{4}$

If we see the river as an infrastructural river, then to suggest its invisibility is to comment on its shift from a natural system to a concretized channel: a concrete channel that everyone wants to call a river. Though millions cross over the bridges or pass alongside while on the freeway everyday, few realize that the concrete channel that lies underneath is in fact the bed of a river. Perhaps this is because it is mostly inaccessible and is sunken beneath the ground plane, eight metres at its greatest. ${ }^{5}$ As a way to outline this kind of invisibility, we can continue this dialogue of flows as noted in the previous section. The image of Elysian Valley (Figure 38 on page 58) has been manipulated in order to draw a comparison between Los Angeles freeways and its river. Constantly in flux, they both facilitate movement and act as intermediary spaces. Despite having similar structural continuity from an aerial perspective,

2 John Erdman, "8 Reasons Why Rain Is a Big Deal in Southern California." The Weather Channel, 21 Mar. 2018, weather.com/science/weather-explainers/news/ los-angeles-rain-why-its-a-big-deal.

3 Lane Barden, "The Los Angeles River Picturing Los Angeles: Conduits, Corridors, and the Linear City." The Infrastructural City: Networked Ecologies in Los Angeles. Ed. Kazys Varnelis. Actar: New York, 2009, pp. 78-88.

4 David Fletcher, "Flood Control Freakology." The Infrastructural City: Networked Ecologies in Los Angeles. Ed. Kazys Varnelis. Actar: New York, 2009, pp. 258-274.

5 "Modeling Analysis for the Development of TMDLs for Metals in the Los Angeles River and Tributaries: Appendix A Details of Channel Geometry." California Waterboards - Los Angeles R4, 2004. 


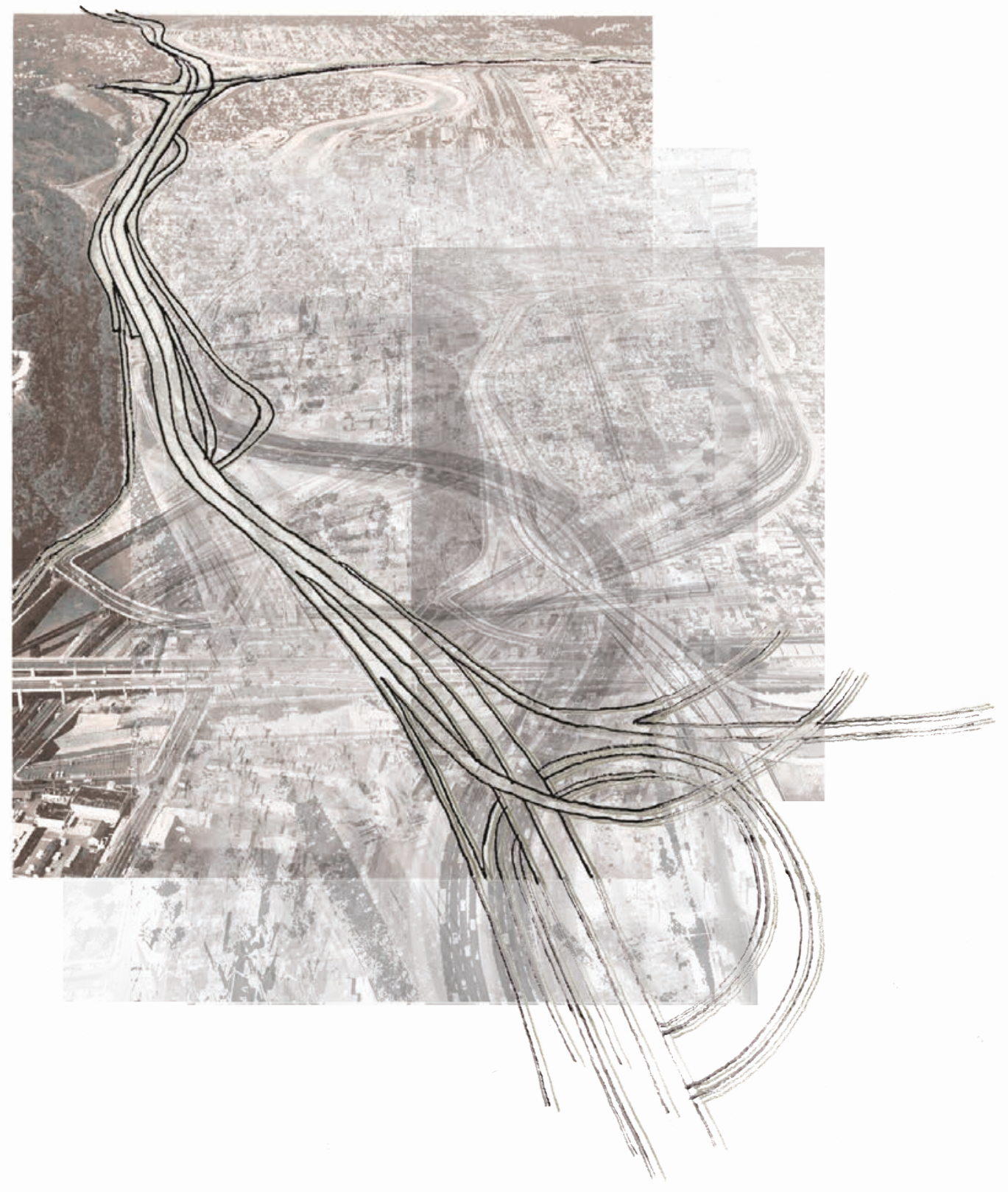

Figure 38: The Invisible River collage. 
the most prominent sinuous vectors on a map of Los Angeles are its freeways. As seen from this perspective, as in this image, the river is hardly noticeable. What is seen and reinforced through manually tracing the lines of movement is the presence of the freeway which structures and cuts across the urban landscape. The technique of duplicating, shifting, and layering the image highlights the river as a formal void where the freeway masks out the river. In this way, we understand that freeways are valued over the river and that despite the river being public land, the river is not a daily destination for the average Angeleno. The collage ultimately speaks to the condition of the river because Los Angeles is about the car. The river is out of the way, in isolation, yet totally integrated - it is one and the other at the same time.

This concept of the river as a transitory and ambiguous space can be linked to the urban theories of non-place and terrain vague. Marc Augé, a French anthropologist, defines a non-place as "a space which cannot be defined as relational, or historical, or concerned with identity." 6 Examples of places of transit or transient spaces are airports and motorways. Like a motorway, the river is designed as a space for movement, not a public space, and is experienced in the same manner. Bridges are the primary way of crossing the river and have become apart of the river's spatial identity. Because the river exists below the mobile urban fabric, it primarily functions as a space to move through. As an in-between space, bridges connect the urban fabric together facilitating a natural flow to other side. However, the pervasiveness of this architectural feature comes to overshadow its purpose as a connector. Because the act of driving across a bridge appears no different than driving on the street, the river is often overlooked; it is

6 Augé, Marc. Non-places: Introduction to an Anthropology of Supermodernity. Translated by John Howe. London and New York: Verso, 2008. 


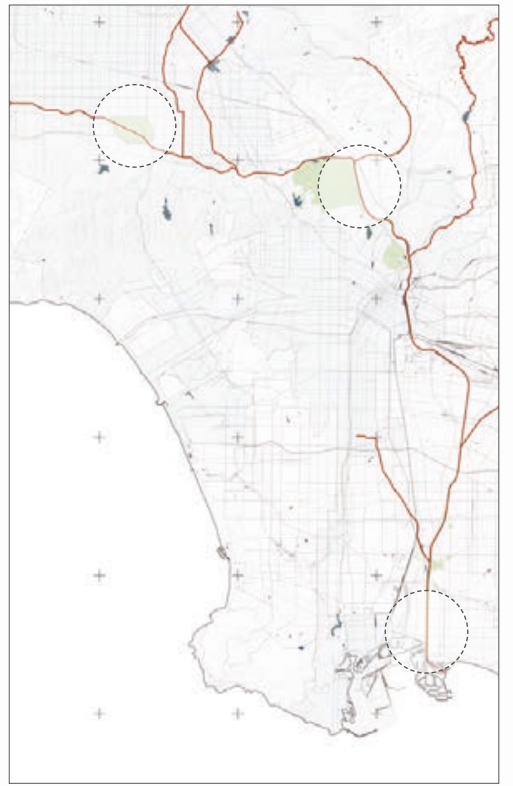

Figure 39: Map highlighting the three greenestareas near Los Angeles River. not in the driver's horizon nor the passenger's immediate perception. The river, experienced through crossing via this transitory space, exists in a state of placelessness, a formal and visible void.

Spanish Architect Ignasi de Sola-Morales, in the essay Terrain Vague discusses these voids as indeterminate spaces. ${ }^{7}$ The term terrain vague is usually associated with empty and abandoned spaces located within the urban fabric. It is a dual concept about land and its cultural connection and defines what the space is and how it is used. However, because the term 'vague' is a part of this condition, the meaning of place gives "the sense of 'indeterminate, imprecise, blurred, and uncertain."'8 These spaces according to de Sola Morales have become "spaces as internal to the city yet external to its everyday use." It is in these inherent dualities of being integrated and isolated at the same time that relates to the condition of the river. It exists in ambiguity: sometimes visible and invisible.

Together both theories begin to address the profound presence of the river as an urban phenomena. But it is also important to address the other condition of the river - when it is visible. It is at times visible from a bridge, walking along the riverwalk, seeing it from above at Elysian or Griffith Park. There are three points where the channel approaches a natural river (Figure 39 on page 60). Though they are not readily accessible, one can glimpse the flow of water at Balboa Park, Glendale Narrows, and the tidal estuary at its outlet. However, its presence is most obvious when it rains. Because rain and water is so rare a sighting, the channel at full capacity is often regarded as a spectacle. The phantom river becomes present as mother nature, but this fleeting moment retreats the following day after a storm. It is an ephemeral representation of nature at work in a completely unnatural setting.

7 IgnasideSola-Morales, "Terrain Vague". Terrain Vague: Interstices At The Edge OfThe Pale, Manuela Mariani and Patrick Barron, 1st ed., Routledge, New York, 2014, pp. 24-30.

8 de Sola-Morales, 26.

9 de Sola-Morales, 26 


\section{The Cinematic River}

The Los Angeles River is a cinematic landscape. Cinema is explored as a medium of representation and a medium of projection, in order to understand its form and place within the city and to see how the river is imaged or imagined.

Why is the Los Angeles River a cinematic river? Because it used for anything but a river. It is a channel that has been engineered for speed and volume (of stormwater), and is also well suited as a stage for car chases in Hollywood motion pictures. While, the river is a spectacle of engineering, power, and mother nature, it is most vivid as a cinematic spectacle. This unexpected spectacle became a second narrative shortly after the 1930's control of nature. In this way, the river, as a location, has been appropriated through film; it is a reading of something from which the intent was never there to begin with as films

portray a narrative unlike its original intent. Essential to this reading of the river as a cinematic construct, is the role the infrastructural and invisible rivers play in the creation of its cinematic atmosphere. Its infrastructural aesthetic and isolation create a certain ambiance that lends itself well to captivating movie scenes. It is a graphic space that attracts because of its stillness, emptiness, and hostile material qualities. It is one of the least picturesque rivers, but there is something so eerie and sublime about it.

The Los Angeles River has a global identity that is best recognized in film. Although the river is detached from the urban fabric, millions are witness to its portrayal as a backdrop for fast-paced, tough, and tense movie scenes. The role the river plays is central to a wide variety of films which fall within the genres of drama, crime, thriller, fantasy, and sci-fi. Portrayal of the LA River in film began with the release of Road Block in 1951. Since Road Block, there have been numerous films that have used the channel bed for film shoots: Point Blank (1967), 


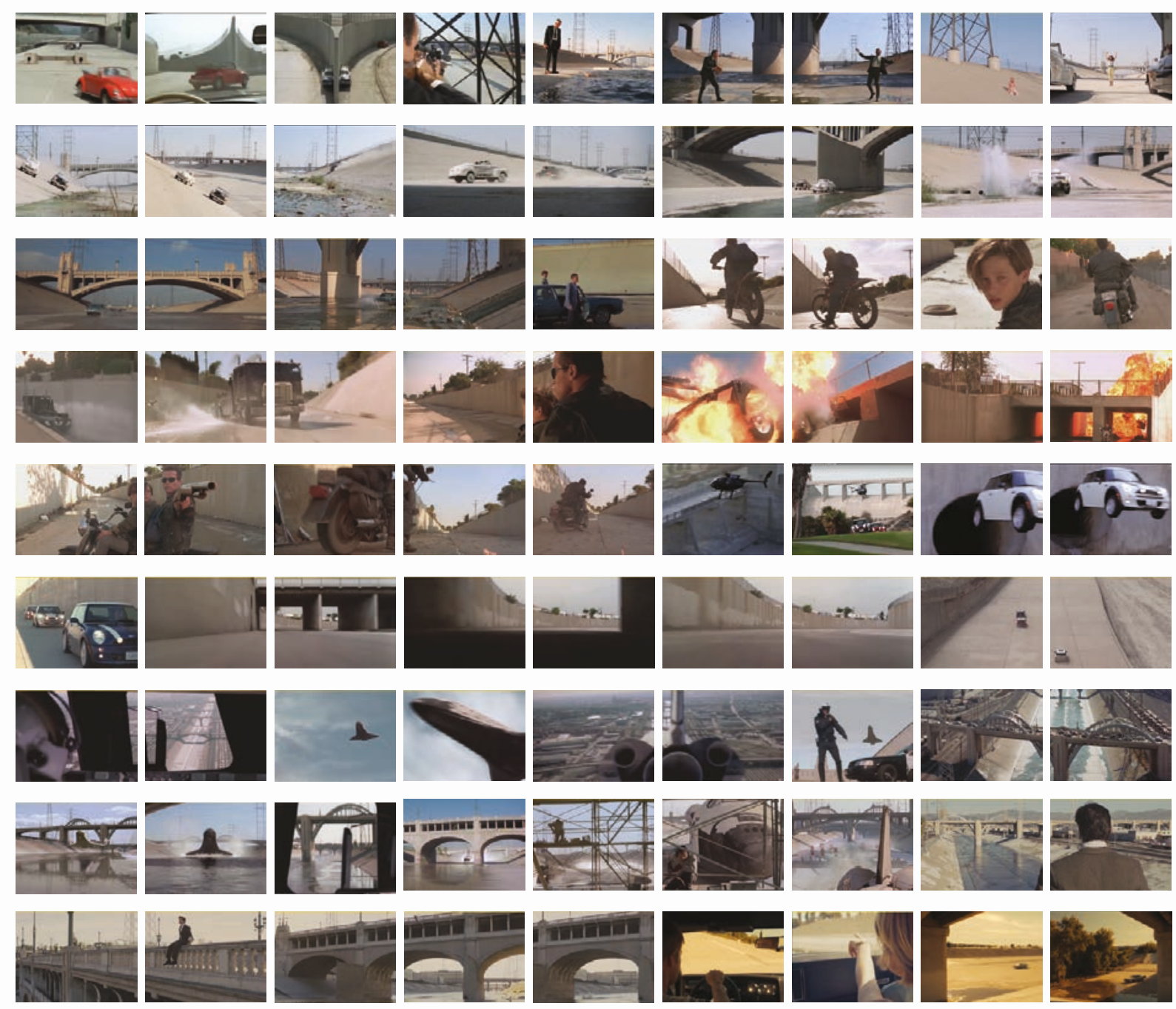


Grease (1978), Repo Man (1984), Terminator (1991), Italian Job (2003), The Core (2003), In Time (2011), and Drive (2011). Along with Hollywood blockbusters, music videos and independent films have also shot here. The scenes are mostly written as chase scenes: In Grease (1978), John Travolta participates in a drag race in the channel. In Italian Job (2003), a police helicopter flies over Sepulveda Dam following three mini coopers which shoot out of the storm drain and race down the channel in a getaway. In The Core (2003), they use the channel to land a space shuttle. It also a crime scene, where in Point Blank (1967), Lee Marvin is involved in a killing below the 4th Street Bridge.

Cinepedia (Figure 40 on page 62) is a collection of stills from the aforementioned films, acting as a deconstructed atlas of the mythologized river. Documenting the most well-known films that feature the river, the Cinepedia seeks to anthologize over sixty-five years of filmmaking and typologize the cinematic spatial experience of the river. As seen in the atlas, cinematic representations challenge the naturalized imagery one would traditionally associate with a river and affirm its identity as an invisible and infrastructural river.

This is because the river represented in movies reflects its action and inaction within the city. The cinematic spatial experience relies upon the architectural and spatial qualities of the river and is in part due to the river's isolation from the city. With a clear edge condition, the line that divides the built environment and the riverscape acts as a threshold between two worlds - the real and imaginary, and thereby casts this space as unguarded and unruly territory. It is an unwelcoming space, not designed for humans; it is appropriate to its depiction in sci-fi and crime genres. This place of otherness therefore contributes to its perception as a undesirable landscape, a site of alienation within a dystopian cityscape. 


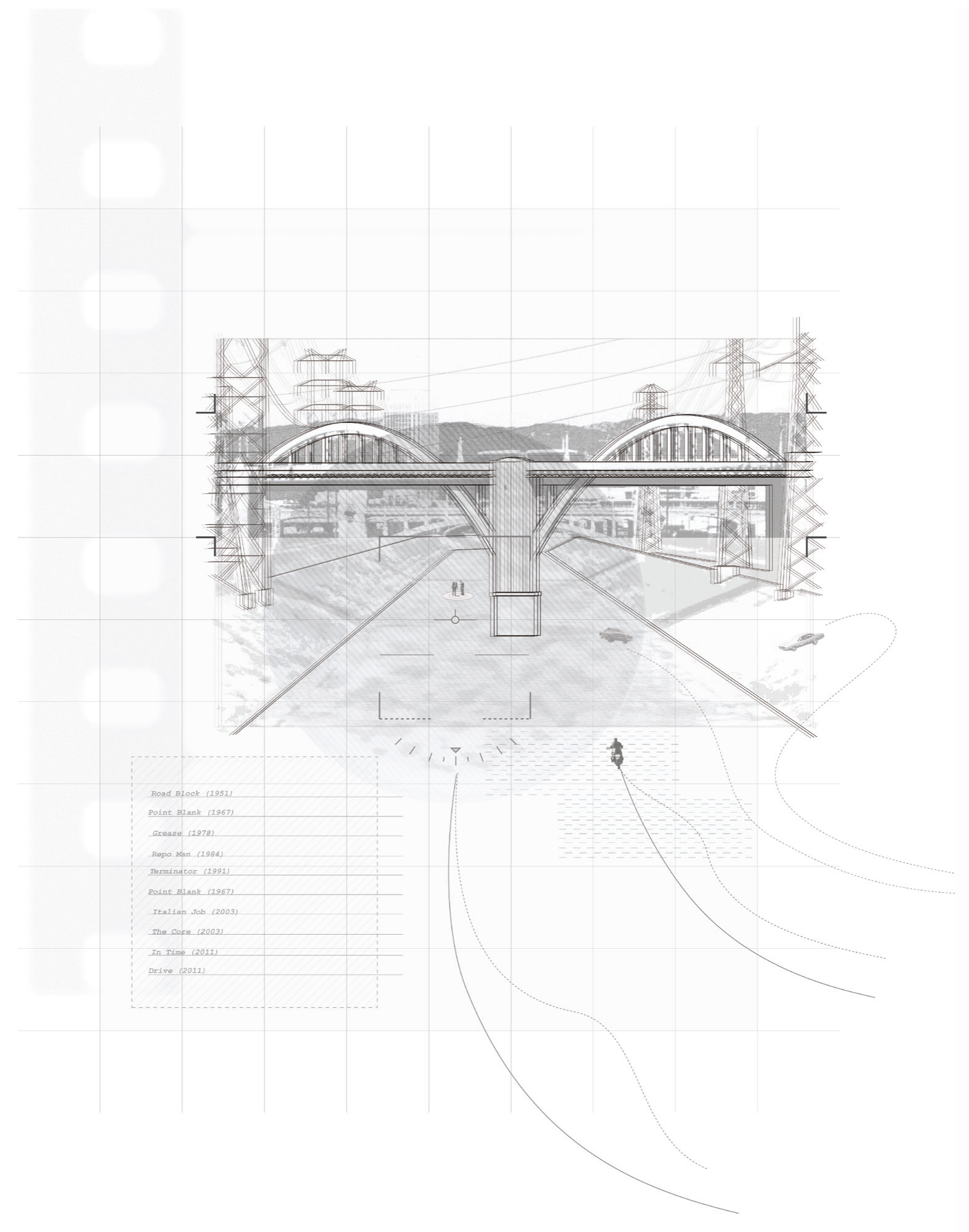


The portion of the river that is most often depicted in these films is the concrete channelized river found just south of Downtown. This reach is characterized by grand Art Deco bridges with industrial edges and has a sublime and monumental nature: its scale, color, and relation to the horizon, with unending views straight down the channel. The enormous width and depth of the channel which sits hidden below the ground plane along with the monotone grey channel create a graphic space that is stark and cold. An exposed concrete bed is so uncharacteristic of a river - its emptiness, void of people and nature alike also perpetuates this narrative.

Cinema as a medium represents otherness; it offers a great escape and displaces you to other times, other worlds, and other realities. It uses a given setting as a blank canvas on which to project a narrative. The only difference between the real and the fictive lies not in the spatial qualities presented before your eyes, but in the meaning ascribed to place according to the storyline. Films may represent the space as a wasteland, an escape, or a river. They can amplify or downplay, embellish or simplify, inform or misinform, beautify or disfigure.

The image (Figure 42 on page 66) simulates these cinematic techniques through layering three photographs from the scouting trip. It provides a new context and a new river that amplifies the cinematic and infrastructural nature of the river. The image collapses the trespassing biker, the still pond, the weird freakecologies, and the strange embankment conditions onto each other to create another kind of river. The illusion of a new landscape and narrative is created through this layering technique that exposes, masks, and condenses the essential cinematic river. 


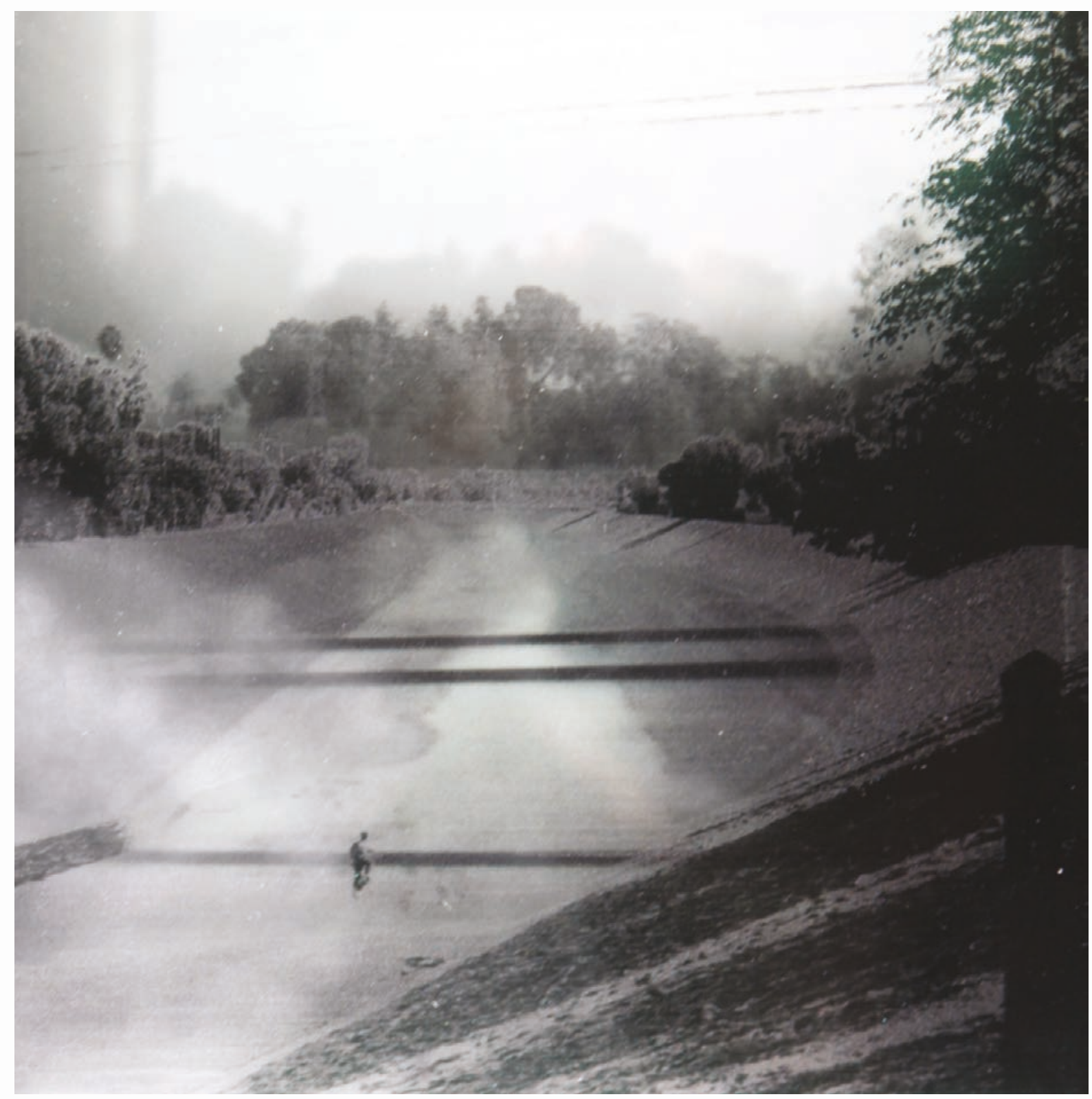

Figure 42: Three photographs taken during the

scouting trip layered on top of each other. 
While this is an example of manipulating a still image, a moving image provides additional grounds and methods for manipulation. This is because film is the most telling of all media because it captures the city in image and in sound, as immediate sensory content perceived right before our eyes. In this way, "cinema is at once a form of perception and a material perceived, a new way of encountering reality and a part of reality thereby perceived for the first time."' It can be argued that film is able to "cement a certain imaginary of place in the consciousness of the viewer." ${ }^{2}$ The river is detached from the city, but through film viewers are attached to the constructed imaginary of the river and water in Los Angeles. The reputation of the river in film is ingrained in our collective consciousness, influencing our understandings of place and space whether it is real or fiction.

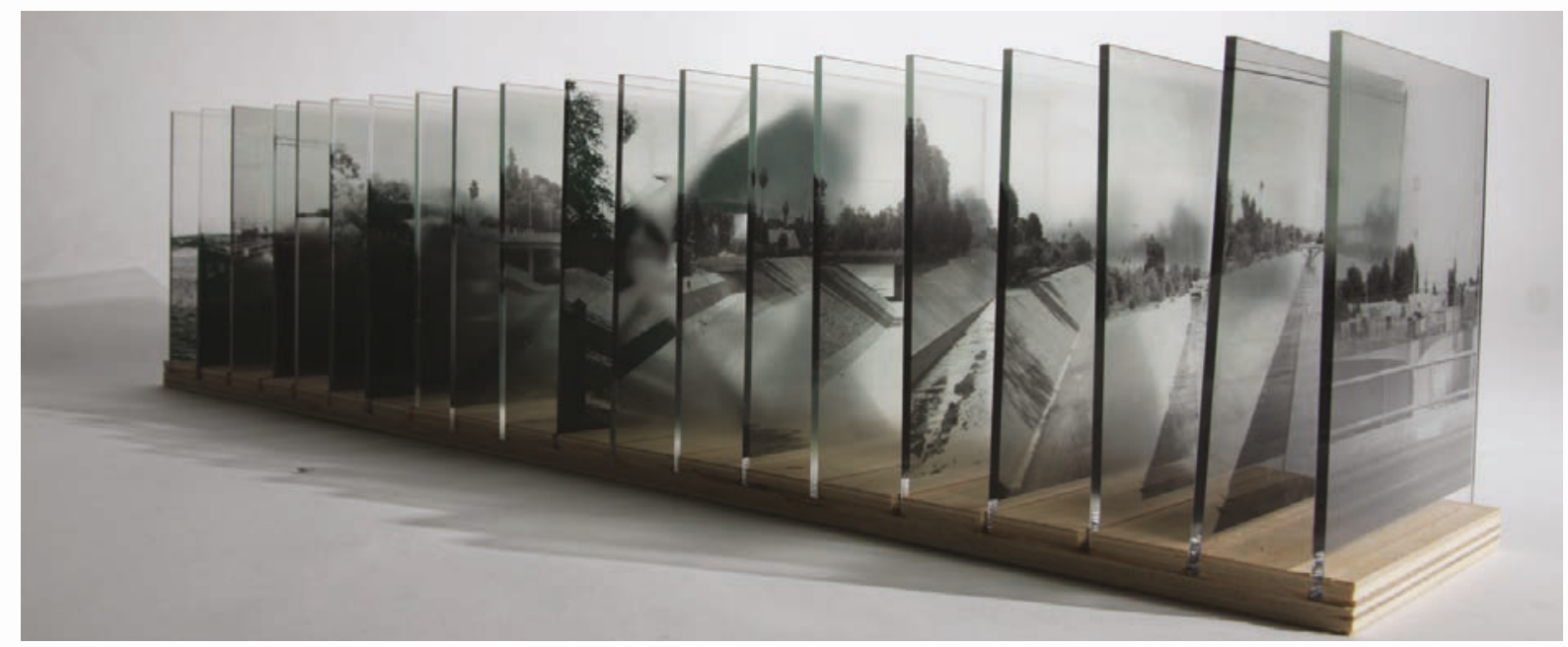

Figure 43: Serial slide model

1 David Clarke, The Cinematic City. Routledge, 1997, 2.

2 Les Roberts, Cinematic Cartography: Projecting Place Through Film, 2012, 77. 

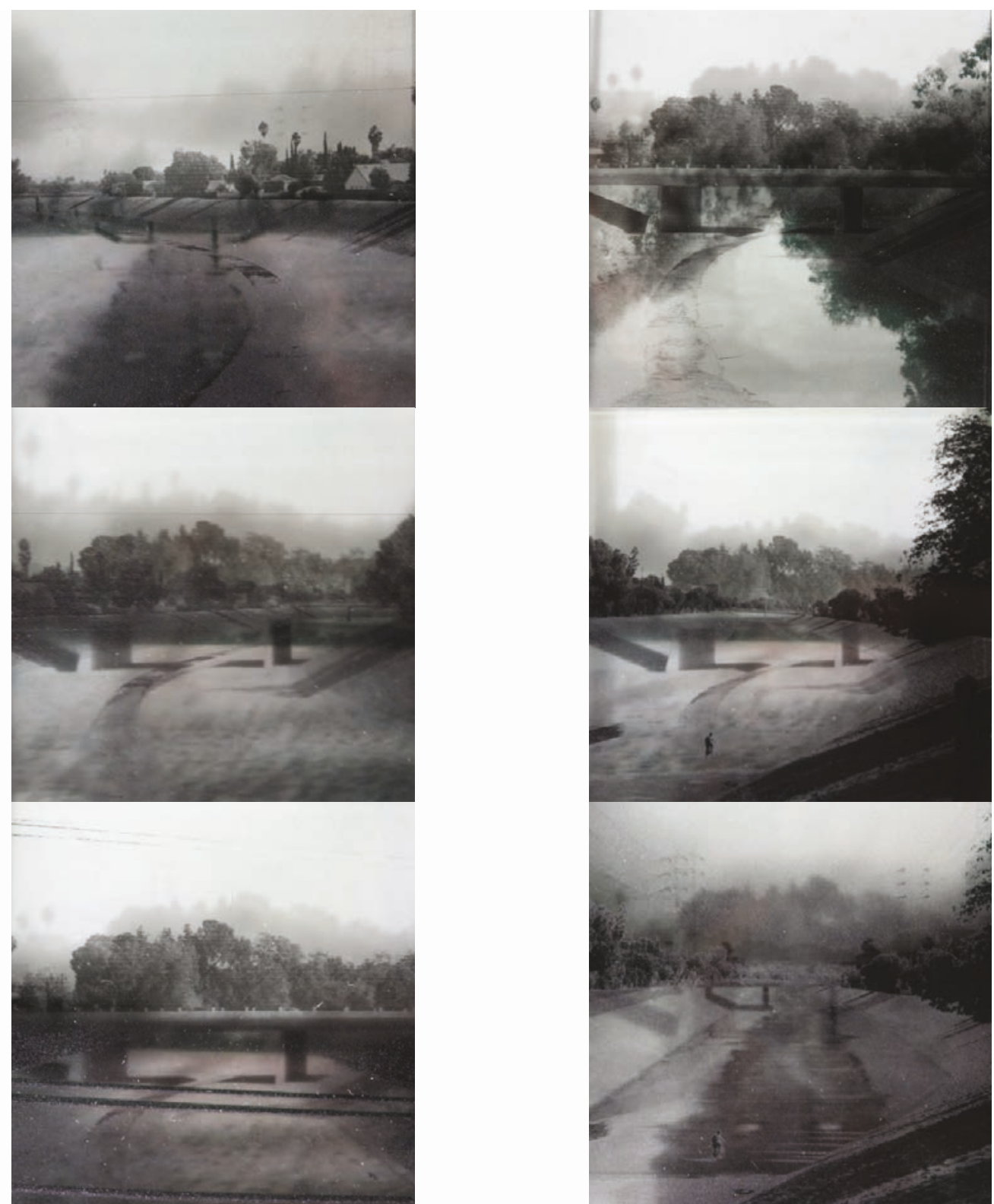

Figure 44: Layered slides
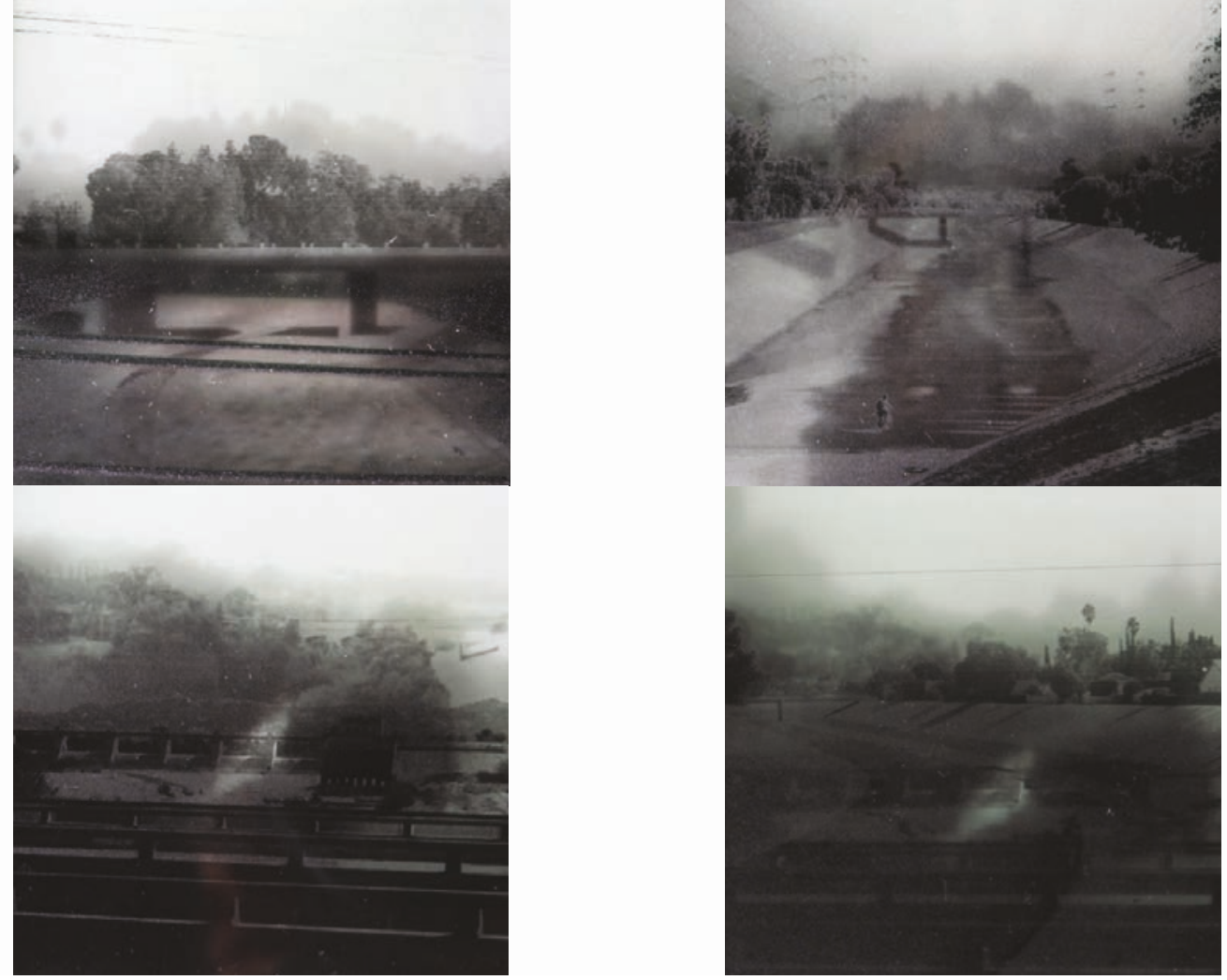
$\forall+y^{y}=$ 


\section{STAGING THE RIVER}

In order to further understand and engage with this landscape, we submerge into it through narrative. Bernard Tschumi inspired this foray into storytelling. In Manhattan Transcripts, he argues that "architecture is not simply about space and form, but also about event, action, and what happens in space." The Transcripts tell a story of a murder through photographs, plans, sections, and diagrams to represent various events, uses, and meanings of space. They "explore unlikely confrontations" and offer an alternative reading of architecture where the body and actions act as tools to interpret space. ${ }^{2}$

This chapter explores the potential of storytelling as a way to interpret the river from an outsider's perspective, to question existing perspectives, and to suggest alternate realities to engage the reader in a dialogue about the current state of the river before its potential renovation. To communicate the plurality of the river, stories are told in photographs, maps, collages, text and film screenplays. While the process of composing stories is similar to the architectural design process, the medium of storytelling was chosen for its ability to reach a diverse audience.

The river is a character within the city; it is an entity that is often overlooked and has a life of its own - its own history, set of interactions, and split personalities. The river becomes both the site and the stage, acting as more than a backdrop - as a protagonsist. In the Flux Atlas, the Los Angeles River is re-constructed and re-imagined using the invisible, the infrastructural, and the cinematic lenses as the framework and theme for the following fifteen stories and visualizations.

\footnotetext{
1 Tschumi, Bernard. The Manhattan Transcripts, 1976-1981, http://www.tschumi.com/ projects/18/\#.

2 Ibid.
} 
Whether present or absent, the role of water is the driving force behind the site selection and storyline. The narratives emphasize our relationship with this substance and make the river and its water or lack of water legible through these 'stagings'.

The sites are located along the length of the river and are chosen for their existing structure or program, surrounding context, or geological condition. The following narratives are three different interpretations of the river at five different sites. They include a dam, a sewer, a fissure, a reservoir, and a water wheel. Each site is represented as an invisible, infrastructural, and cinematic moment in time. The narratives and mode of representation change as the lenses we look through to the river change. They playfully engage above and below the ground plane and connect the activity that occurs along the river's edge. The invisible is inquisitive, the infrastructural is reality, and the cinematic is otherworldly. The invisible and the infrastructural perspectives set up the cinematic moment allowing the viewer a more visceral connection to the site. The cinematic representations are expressions of what the river can be - a place for engagement. 


\section{Invisible}

The invisible river is a reflection on my interactions with the river. The river is most commonly experienced while driving and perceived as a series of snapshots or glimpses. The blurry, black and white photographs taken from the car while driving highlight the rivers distance, isolation, edge conditions, and hydrology.

\section{Infrastructural}

The infrastructural river outlines the spatial conditions of the site. The maps illustrate the site in relation to its surroundings, showing both the possibilities and limitations: how the river negotiates its boundaries, its scales and its (in)accessibilities. It is a process drawing that expands on the invisible lens and foreshadows the cinematic nature of the site.

\section{Cinematic}

The cinematic river extends ideas explored in the invisible and infrastructural rivers and engages with imaginative projection. Formatted as a collection of eco-fiction screenplays, the scenes feature new interventions that are rooted in reality, but are amplified to create a fantasy water-world. Each scene suggests new interactions and relationships with the land, water, and the atmosphere. They reference the hydrological cycle, depicting water in different states, conditions, and containment and are fabricated using water infrastructure. These speculative collages invite the viewer to animate the image and take the story forward. 

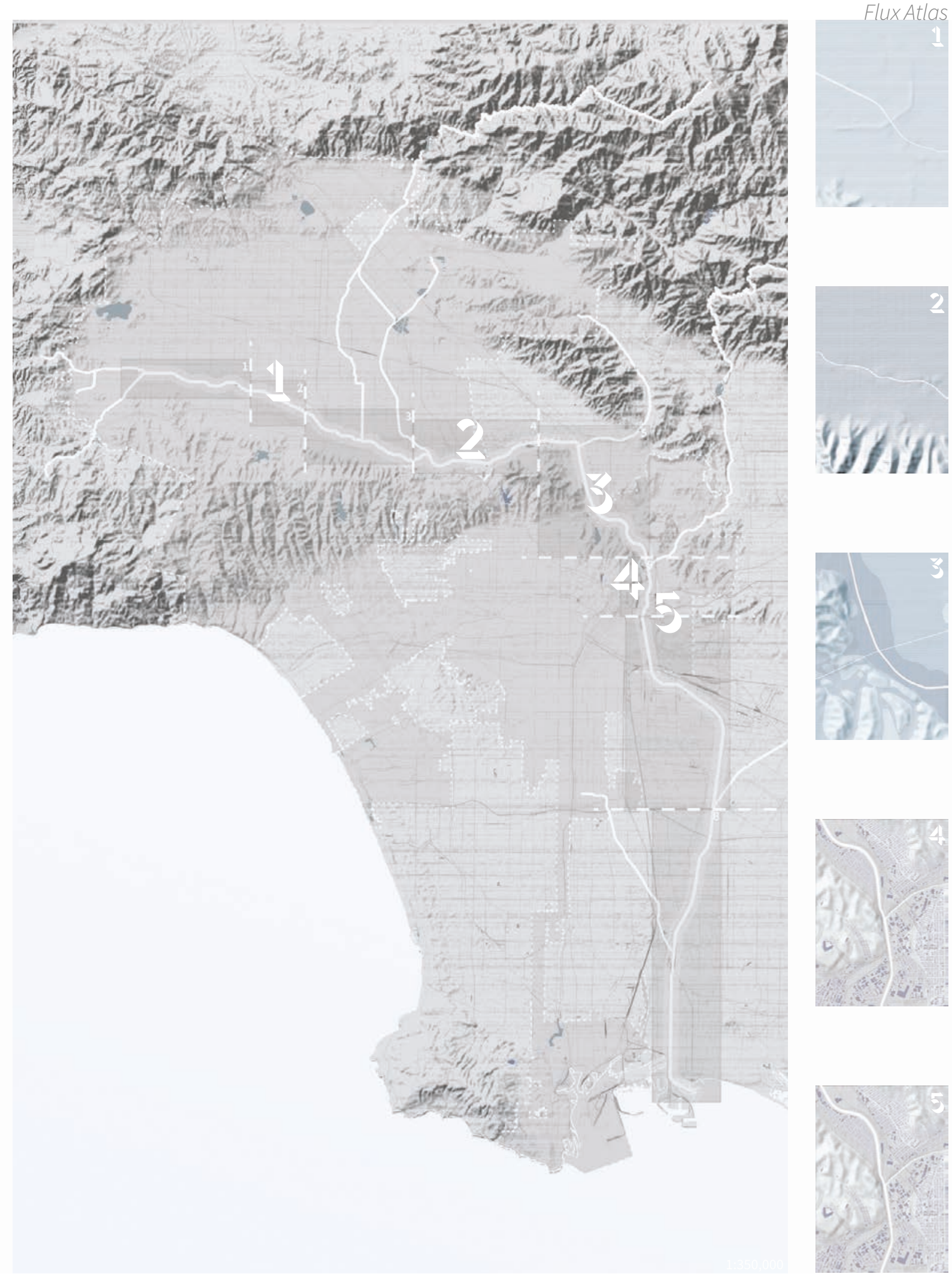
The Los Angeles River has a dam? It's not surprising that someone would ask this question: I did.

Heading north, I pass by the river on Burbank Blvd. Caught a glimpse of it and the dam on my right - only lasted two seconds. No longer concrete, but a sandy river bed - muddy beiges, stale greens, and dull grey hues - shallow ponds and a riverwash. Beyond, I see concrete feet and a big mouth.

It's far from the road - how do I get to it? Two pillars and a suspended chain block off a path. There are no signs. 


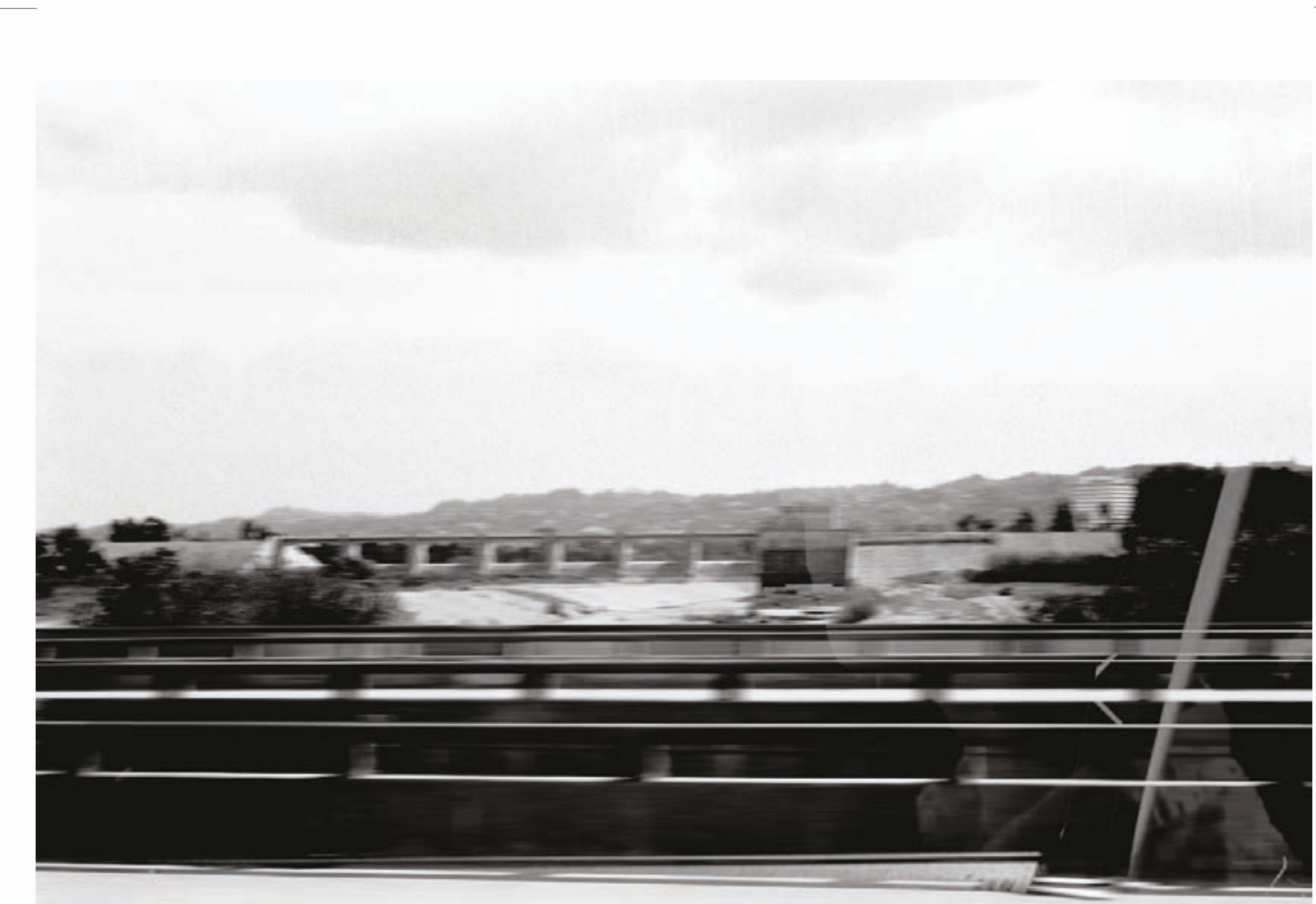


Freeways surround the Sepulveda basin on three sides - a bubble of green space that curbs the relentless suburban grid. Wider than it is tall, the basin blends into the surrounding landscape even though it has been in place since the 1938 flood.

The embankment walls are most prominent where they meet the dam and the spillway, though the dam's lookout tower can be seen from afar - the tallest building in the valley sticks up high above the landscape it supposedly protects. It graphically has no relation to its surroundings. It is a small brutalist dam, fortress-like. Its flood gate has menacing serrated teeth and the spillway has six towering freeboards. The raw concrete shows signs of water damage and decay. In drought conditions, the river is like a fossil of the surrounding area - evidence of the previous storm. Remnants and relics are scattered along its edges and cast into dirt mounds: a child's sandals, a toy truck, a comb, a can of spray paint, an empty mentos jar. Bulldozer tracks pressed into the mud show signs of maintenance, partitioned into piles. In the winter, the dam holds river water back, protecting the valley floor from flooding. When the floodplain is full, the basin roads disappear. 
1

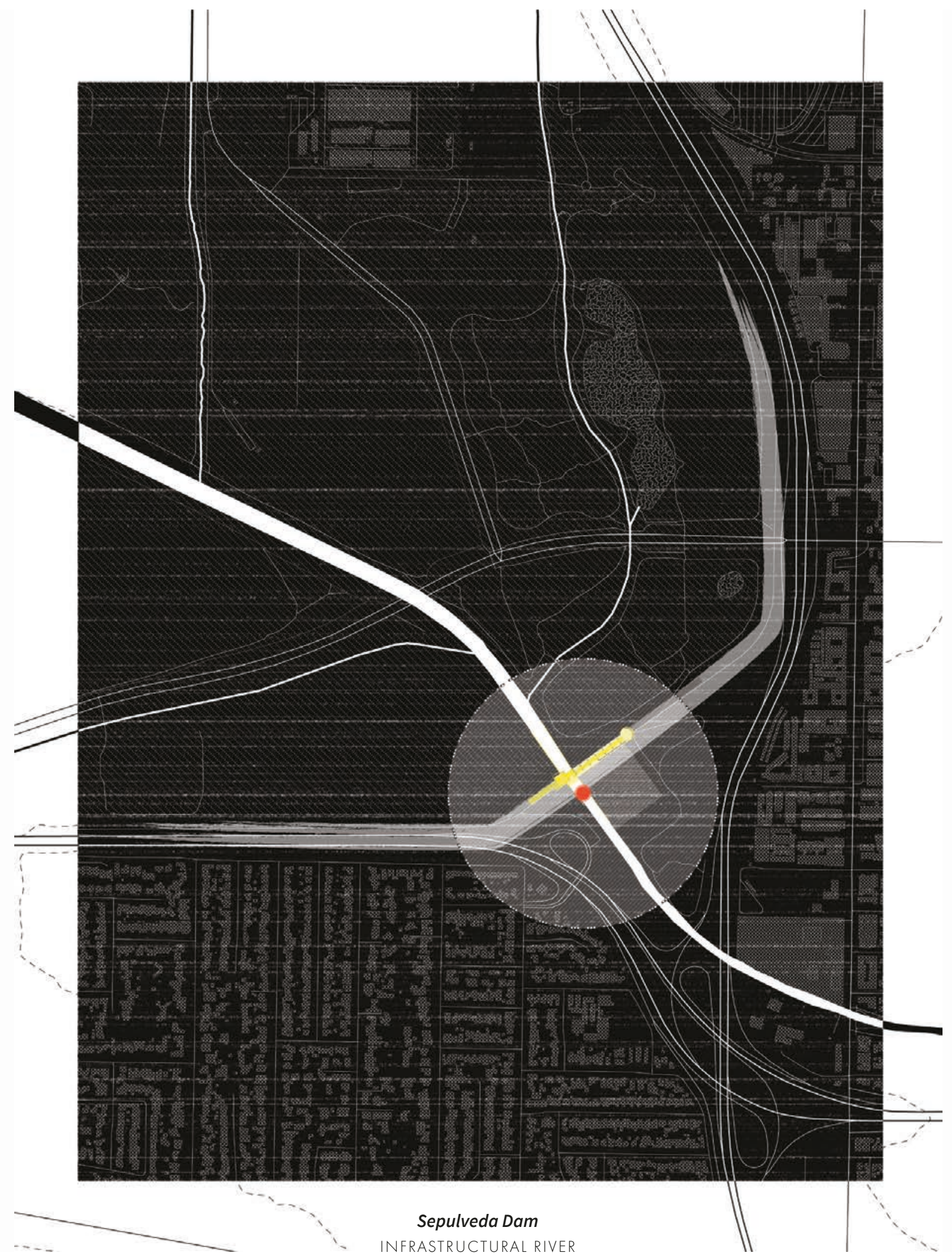

Where the bridge, the floodplain, and the dam intersect. 
FADE IN:

EXT. SEPULVEDA BASIN - EVENING

Night falls on the Sepulveda Dam. Day temperatures in the San Fernando Valley reached triple digits - rare for February. Night time provides relief. Like the rest of the valley the dam appears to fall asleep, hiding in the darkness of the floodplain and behind the smog. Pollutants hang thick in the air, coating the building roofs and surfaces. It is quiet - only the persistent noise of the freeway that runs perpendicular to the dam can be heard in between the breaks of wind. A cool gust slices between the sixty-two foot tall tower and the adjacent exterior stairwell. The structures vibrate in the wind and the wind drags clouds of dust across the valley floor. The air is charged with the possibility of a storm.

The only visible trace of the dam's presence lies at the top of the tower. We see a light and its faint reflection flickering on the water held behind the dam. The water level is high, not far from breaking this year's record. On the other side of the dam, the river is as dry as a bone.

A shadow appears in the tower. We zoom in to the to see a man peering out, overlooking the dam. He picks up his radio with conviction.

WILLIAM

Open the gates, a storm is approaching.

CUT TO

Three men in the control room located directly above the floods gates. They look at each other, hesitating.

CUT TO

The gates swing open, releasing water at a rate enough to fill an average swimming pool every ten seconds. An immediate roar and billowing mists of water consumes the air. 


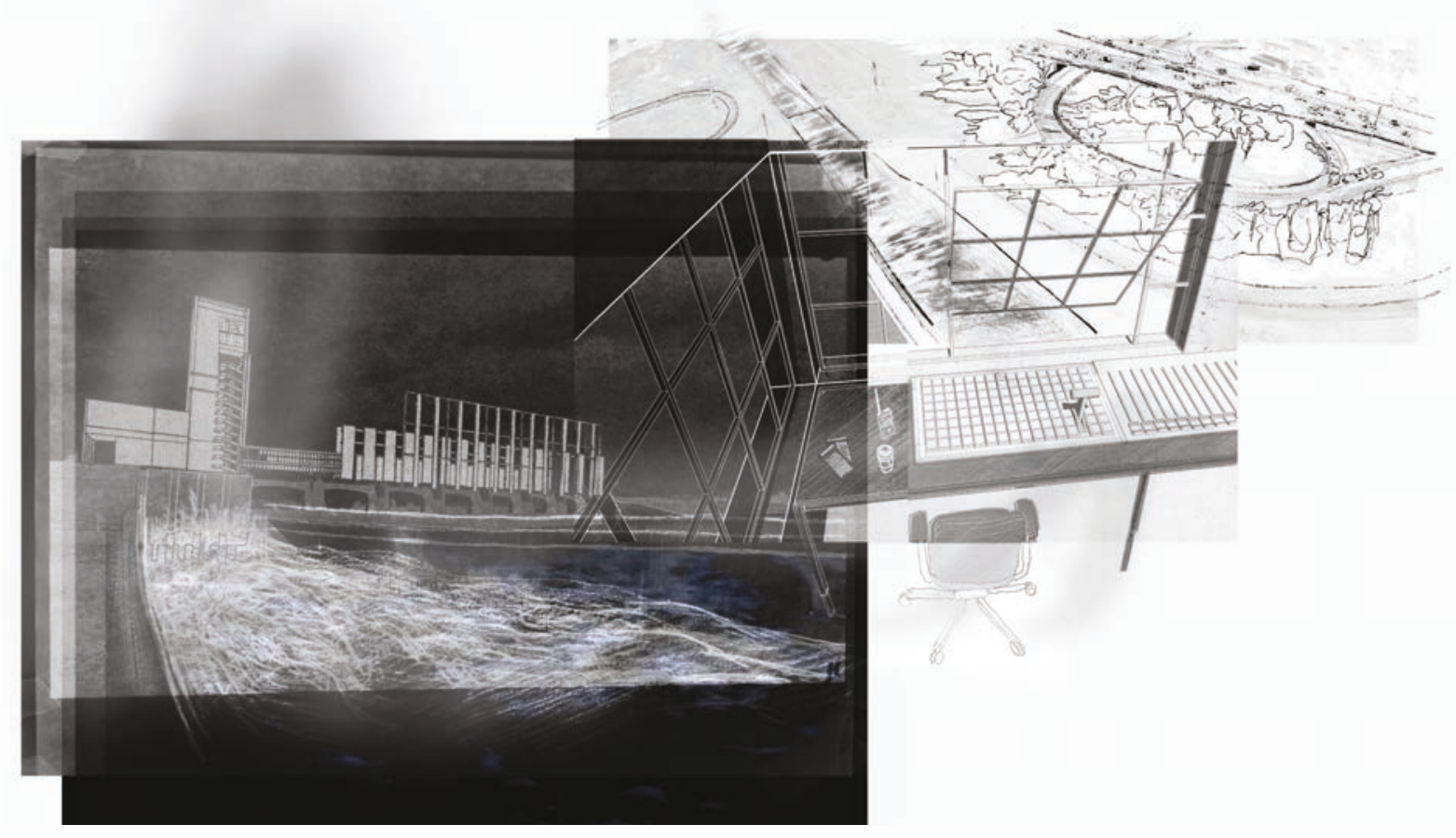


I crossed the river on Hazeltine Avenue at 11:22am. A small flash of darkness breaks the monotony of the concrete between the bridge slats. No water reflects behind the thick railing - it wasn't the channel gully.

I get out to investigate.

Graffiti found along the river is mostly illegible, but here I can make out a tag that asks: How are there fish here? Maybe goldfish flushed down the toilet, I think. They would shoot out here, right out of this storm drain. Bulbs of moss hang and weeds sprout up between the cracks in the concrete. The concrete embankment is no longer grey, but blackened with grime. Here, the infamous toppled-over-shopping cart is partially buried in mud.

Things aren't always swept away. There is time for things to grow, to bloom, to decay, for vegetation to take over. It is a different kind of wilderness, where weird natures can assert themselves. 


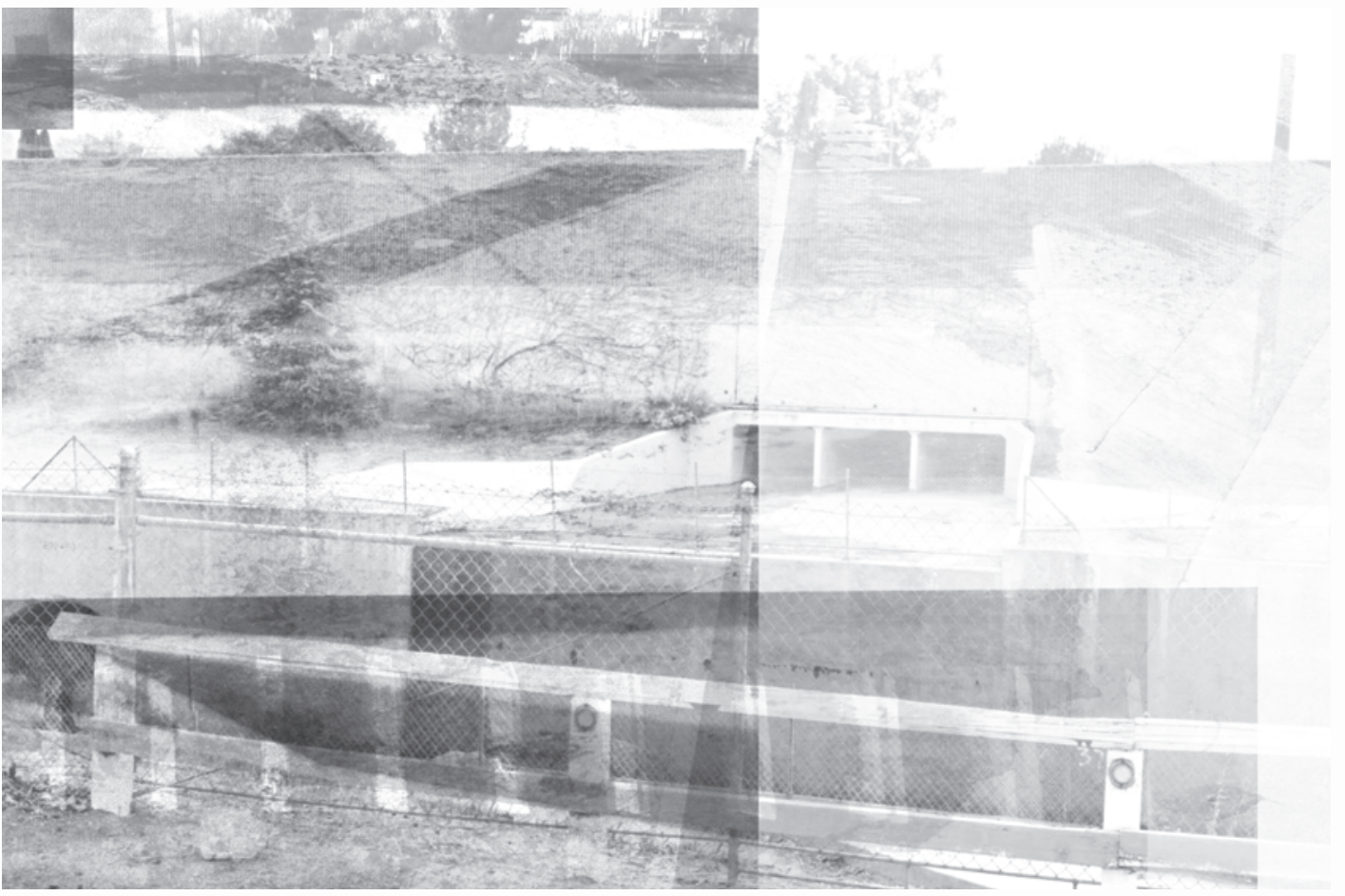

Valley Storm Drain

INVISIBLE RIVER

Where moss and weeds grow, a new wetlands. 
Storm drains are connected to the river along its entire length. Their invisibility is based on concealed infrastructure that exists below grade - an infinite city of pipes. This is a network of calculation: the speed of flow, the volume, the diameter of pipes, the slopes, the intersections, and the outlets.

Storm drains are a new kind of mother ditch, a Zanja which flows into the river, disposing water as opposed to delivering water. The utility of the city's storm drains are most visible during a rainstorm. Where they join the river, they are confluences of urban flows. Funnels.

Water rushes along the sides of the roads, flowing into the nearest drain, down into a larger drain, and emptying into the Pacific Ocean. 29 million gallons a minute. Not everything makes it out there. Some garbage survives along with a sludge mat. 


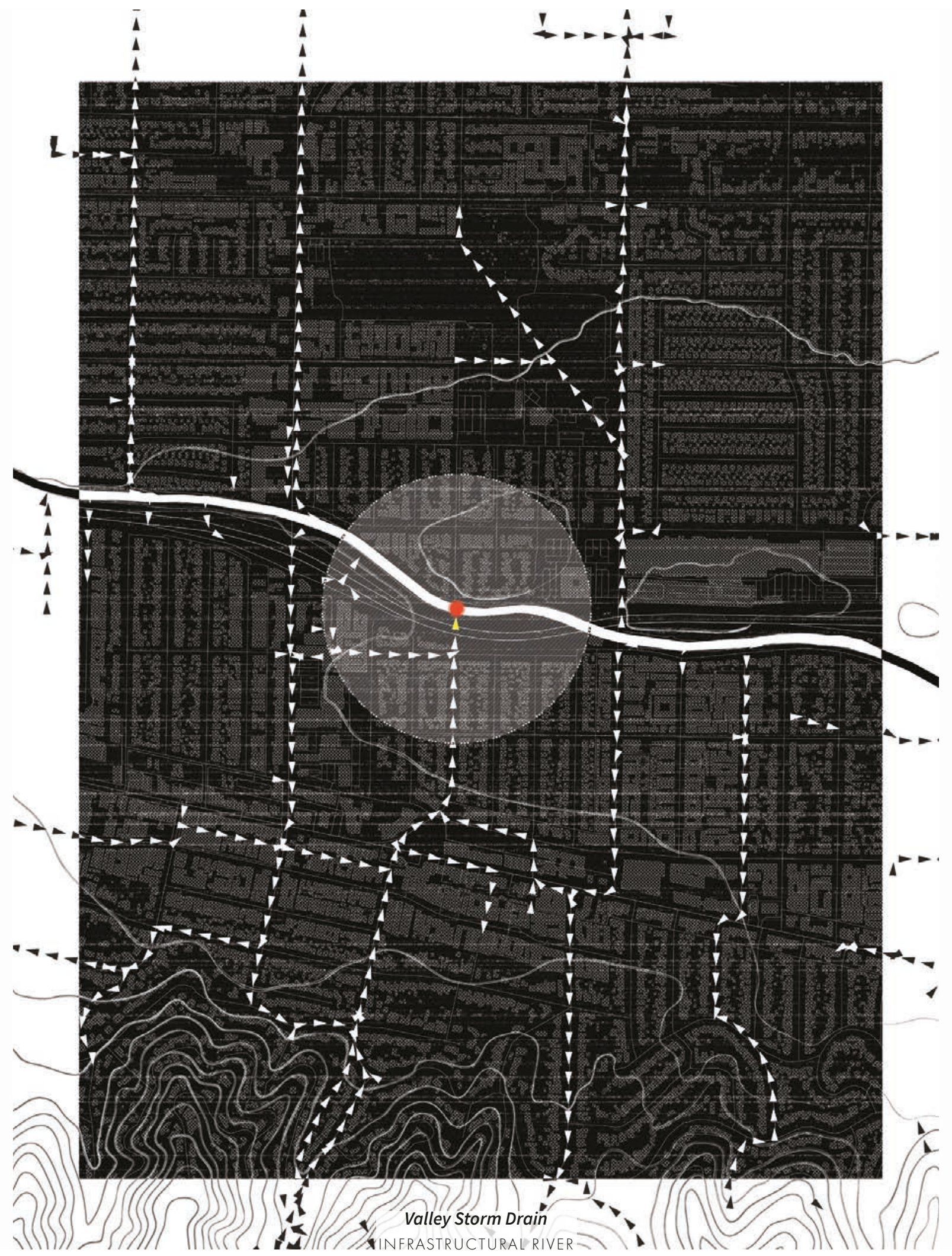

Where the new Zanja meets the river. 
FADE IN :

EXT. GEYSER AVE. - LATE AFTERNOON

Open on a small residential street in Van Nuys with single family 1940s bungalows. It is a beautiful winter day, the valley sun shining as always. Cars are parked in the driveways. Kids are home from school and parents are home from work.

The sky is now gradually darkening as the sun begins its descent. There is no lucky red sunset tonight just a brisk air moving in. The trees that line the street move in the wind.

Matthew races over to Otto's house on his bike and runs up to his front door. He is always ready for an adventure. He shows up unexpectedly and knocks on Otto's door. Otto opens it in surprise.

OTTO

Yo! What's up Matt?

MATTHEW

Sam told me today at school about the creature that lives in the big sewer. The entire Valley knows it only comes out to play in the winter when the rain comes. C'mon let's go!

Otto laughs and then hesitates.

OTTO

Ha. Don't believe him. But I'm down for a ride.

They grab their bikes and set out to find him. The sky is now a darker shade of blue.

EXTERIOR - LOS ANGELES RIVER - EARLY EVENING

Otto and Matt are popping wheelies and ramping up the embankment wall, cruising down the riverbed. As they ride they eye every sewer along its length. The sewers sit halfway up the embankment like windows on a facade, the sills dripping murky water.

PAN from just before the 101 swoops over the river, where the channel narrows from 200 feet to 50 feet. The embankments turn vertical and blocks any light left in the fading day. It looks like a tunnel.

Otto stops ahead of Matthew and hops off his bike. Matts stops too.

OTTO

I don't like this one. 
Pfttt.

Matt and Otto stand in front of a sewer that sits lower than all the others. The round, corrugated storm drain is rusted and bars block the entrance. Water is dripping down from over the channel wall. They can't make out what is up there. There is a sound of gushing water in the distance.

OTTO

Fine, I dare you to go in.

MATTHEW

No way, you crazy!

The water released from the dam rushes downstream and starts filling up the channel soaking the boys shoes and jeans. The boys look at each other and start panicking. The walls are too high to climb out.

отто

Where is this water coming from? How the hell

are we going to get out of here?!

Matthew takes the lead, searching for a way out. He looks into the sewer and sees a ladder with the top three steps lit - a manhole.

MATTHEW

This is our only way out.

The water level is rising towards their waists and they are struggling to fight the current that just swept their bikes away.

Matthew swallows his fear and slips through the grate. The dank smell immediately hits him. He grimaces, taking a step back reaching for the wall, too slimy to keep his balance. It reminds him of the porta-potties at baseball tournaments.

The sewer seems endless in the darkness. There is an eerie silence - the kind where you can tell you are being watched. The circular walls and ceiling are coated in a dark green scum and cobwebs. Old pipes drape from the ceiling, dripping water on his head. He flinches and nervously glances back at otto. He turns back and sees a shadow stir beyond. A sloshing sound echoes against the walls.

MATTHEW

Get over here, quick!

Otto rushes in through the grates and stands behind Matthew.

They catch a glimpse of a pair of glowing eyes wading just below the surface of the water. They look at each other in disbelief. SPLASH! 


\section{2}

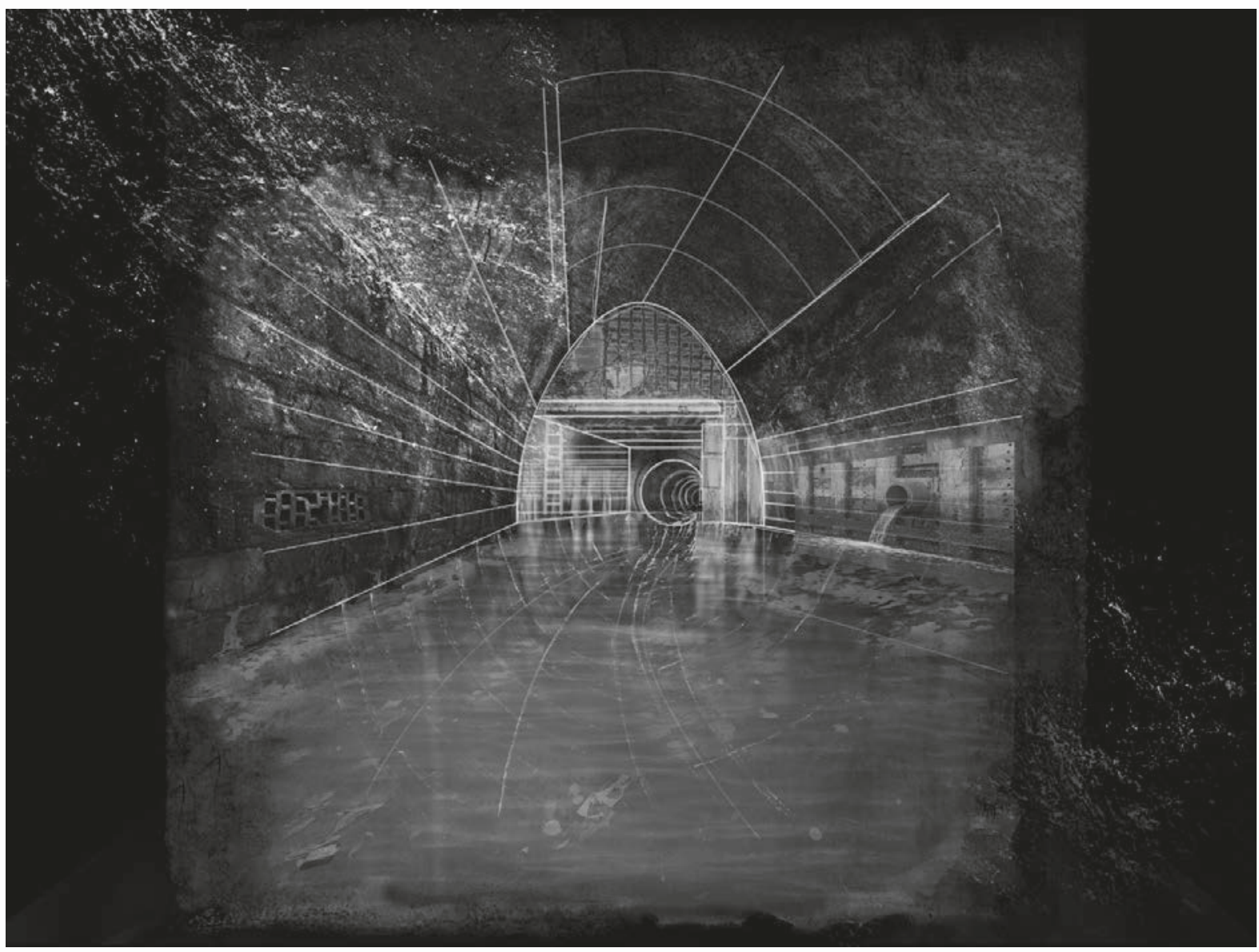

Valley Storm Drain

CINEMATIC RIVER

"They look at each other in disbelief - a pair of glowing eyes wades just

above the water's surface. SPLASH!" 
How do I get to the green section of the river? There are no major roads that parallel the river near Atwater Village. I take Sunnynook Drive which dead ends at a 12 foot rubble wall. A break in the wall reveals a rugged dirt path leading up to an elevated platform. I know the river is on the other side of the wall, but I cannot see it from here. I climb up to the riverwalk which opens up to an almost panoramic view of the river, Los Feliz hills, and Griffith Park mountain. A pathway with transmission towers lines the channel on both sides connected by a pedestrian bridge wide enough for two people to shimmy passed each other. I hesitate crossing. This bridge has seen better days. Halfway along I can hear the slight trickling of the water amidst the incessant howl of traffic.

Willow groves, cattails, sycamores, and oaks sprout out of this soft bottomed riverbed. Vegetation and water hug the center. The channel bed is too wide to brush its edges. Water ripples and burbles over twigs, cobbles, and small rocks. White foam hovers on the surface where the current slows. An egret wades in the shallow blanket of water that cannot hide the mossy green bed beneath.

I wrestle over the sandbag dike wall and climb down the steep and rough concrete embankment wall to take a water sample. Close up I can see trash caught in the bent grasses and bowed over brambles, now the smell of the pungent, algae-scented water kicks in. 


\section{3}

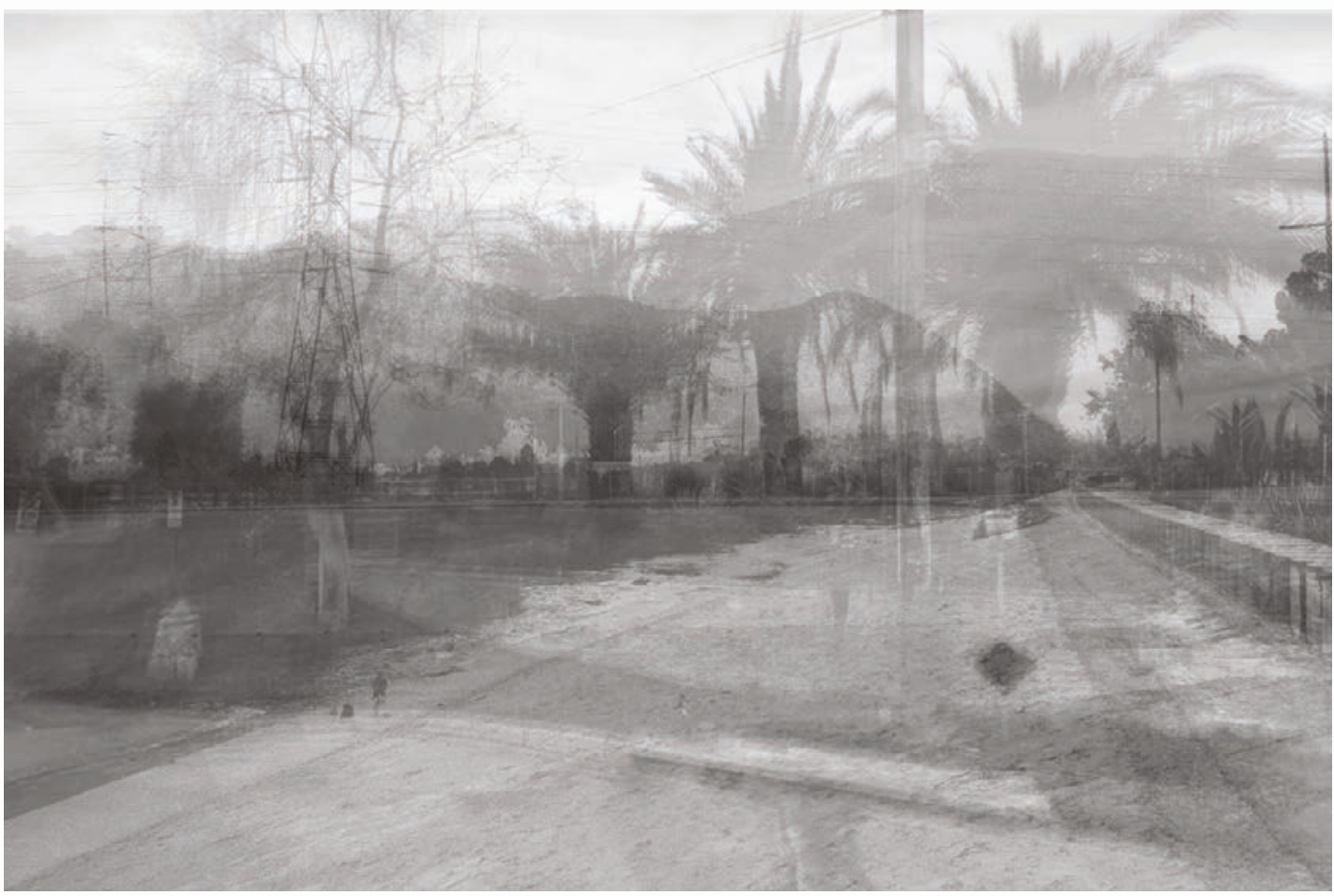

Glendale Narrows

INVISIBLE RIVER

Where groundwater re-emerges at the oasis. 
The river and the I-5 interstate freeway parallel each other in this reach - two lines of flux fixed in course and flow that connect and divide.

The river of cars is just on the other side of the fence with the tops of the 18-wheeler trucks rush past. Sunnynook bridge passes over the 12 lane interstate freeway connecting communities on either side of the freeway and river.

Curving around the base of Griffith Park on course towards Downtown, for three miles, the river approximates its former riparian personality with vegetation and wildlife in the channel bed. Concrete walls are built to contain its lateral flow as this section repeatedly meandered. The vegetation is not dense enough to drown out the noise of the interstate.

Glendale Narrows is where the river insists on emerging: groundwater pushes up through the bedrock, only forty feet below through the sand, silt, gravel, and cobble. Evidence that much of the land underneath the channelized river has a vast, natural infrastructure beneath. It is one of the few spots in LA where nature is irrepressible. 


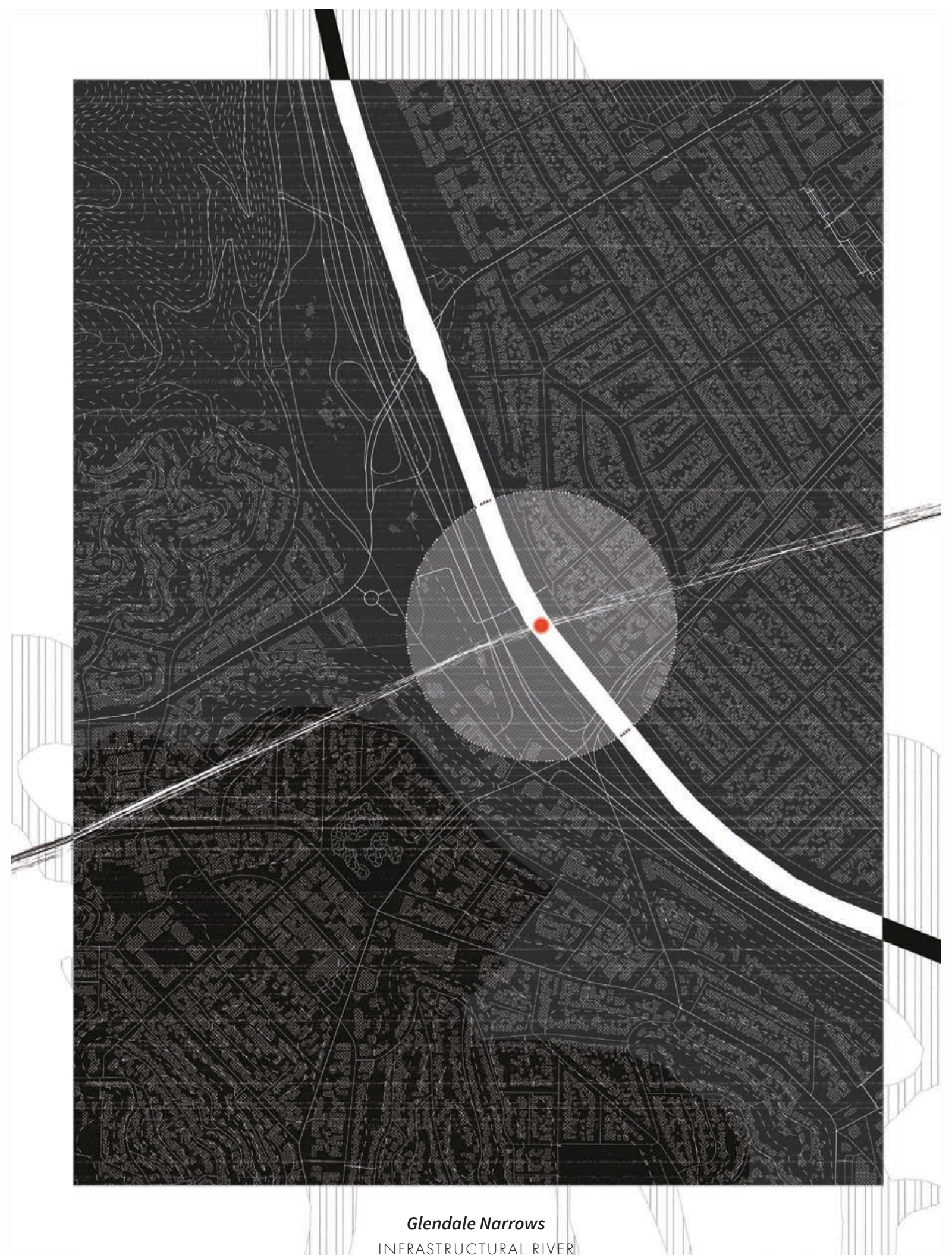

Where Raymond fault crosses and groundwater emerges into the concrete river. 
TITLE CARD:

2021

Open on a television set, tuned to channel 5 breaking news.

REPORTER

A magnitude 8.7 Earthquake shakes Los Angeles near Griffith Park. USGS states the earthquake happened at 3:55 a.m., 15 miles southwest of Griffith Observatory, at a depth of 8 miles. The earth split open along Raymond fault. Asphalt and concrete crumbled and collapsed into the fissure.

EXT. ATWATER VILLAGE - AERIAL - EARLY MORNING

From a helicopter we see the mile long fissure cut across the landscape, severing the freeway, the river, and the residential neighborhoods on either side, stopping traffic and disrupting the flow of water. A dark and bottomless hole lies between.

zOOM into the eastern edge of the river.

The layers of the concrete embankment exposes the alluvial soil - the soil that liquified and subsided earlier this morning. The channel gully leaks water down the face of the newly formed cliff. It percolates into a soil desperately thirsty for water.

At the eastern edge of the river on SUNNYNOOK AVE.

Houses, cars, utility poles, and trees are collapsed over the edge, some barely holding on.

A family whose home just missed the mark, saved by 10 feet of space, walk out of their home in shock.

POV Family: Just opposite to them, they see a house that oscillates between land and abyss. They creep towards the edge, curious.

An uncharted underworld is revealed below the house: a subterranean mining village. Tunnels emerge, like anthills with doors leading to who knows where. The circular drill, blades still wet with dirt, is set inside a large vertical hole. At the bottom lies an empty well, where groundwater pooled just yesterday. 


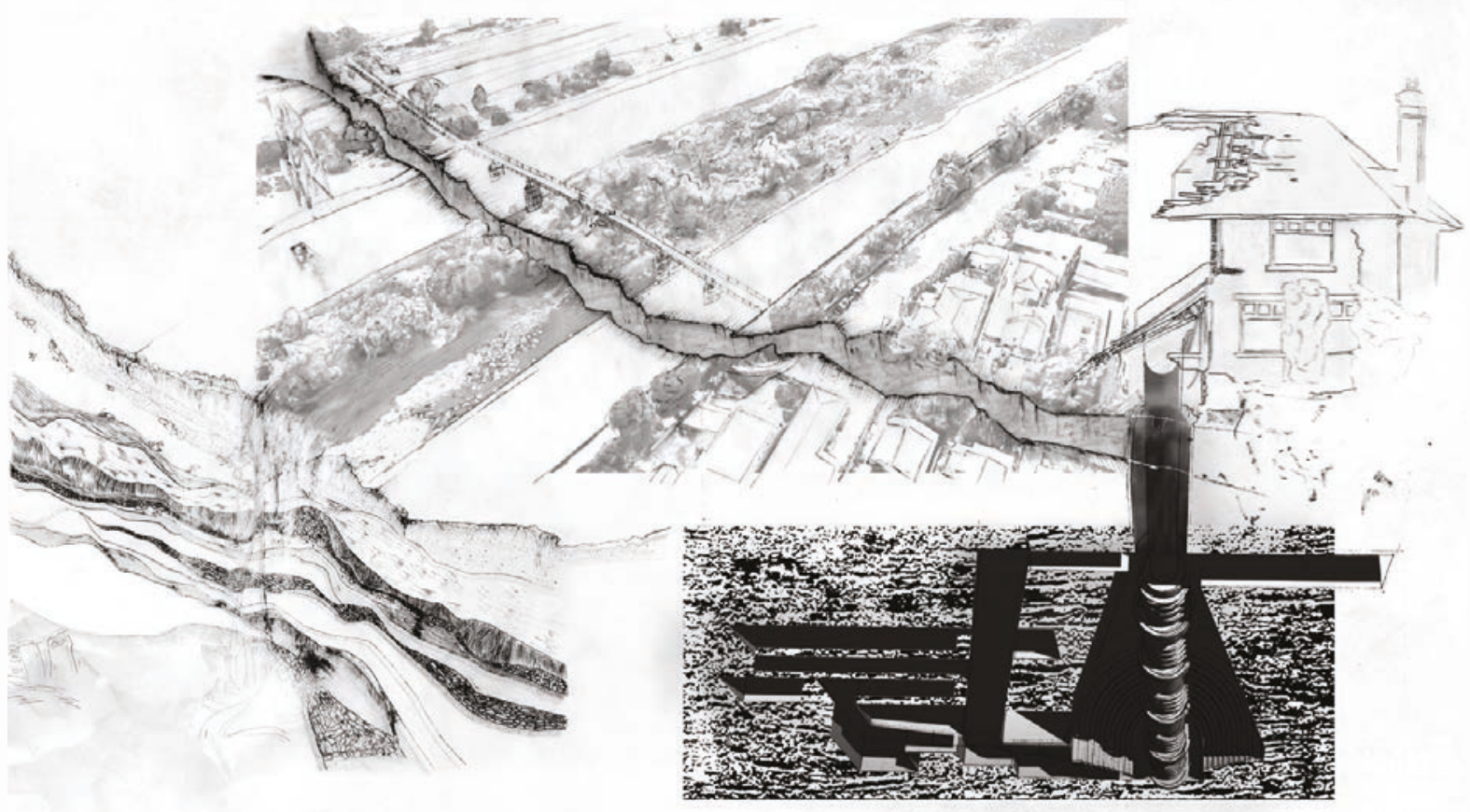

CINEMATIC RIVER 
On the way to the Point Grandview Park lookout, I cross over the bridge that extends high above the 101 freeway. There are about four different groups on this bridge, one includes a professional photographer. I slow down to let a couple cross to take a photograph with the silhouette of downtown Los Angeles and the amber sky.

I see no one after I pass. I wrap around the eastern side of the hill that blocks the setting sun. The color of the vegetation changes from green to grey in the shade. Vegetation frames my ascent: collapsed weeds, sad branches, and unpruned trees. The road continues to circle around the reservoir. Behind the fence and a layer of overgrown vegetation lives the reservoir sitting alone in a nook, tucked away from every facade and protected by hills on three sides. All I can see through the layers of vegetation is a black hole in the ground. Why is the reservoir empty?

Palm trees perch atop the hill sticking out amongst chaparral, oak, cedar, and eucalyptus trees. I reach the peak and pull over. It is peaceful to watch from above: I can see the river 270 feet below and its floodplain - the overwhelming expanse. My gaze shifts back to the river, headlights of two tailgating cars emerge in the channel bed. I can make out a small film crew - a car commercial? 

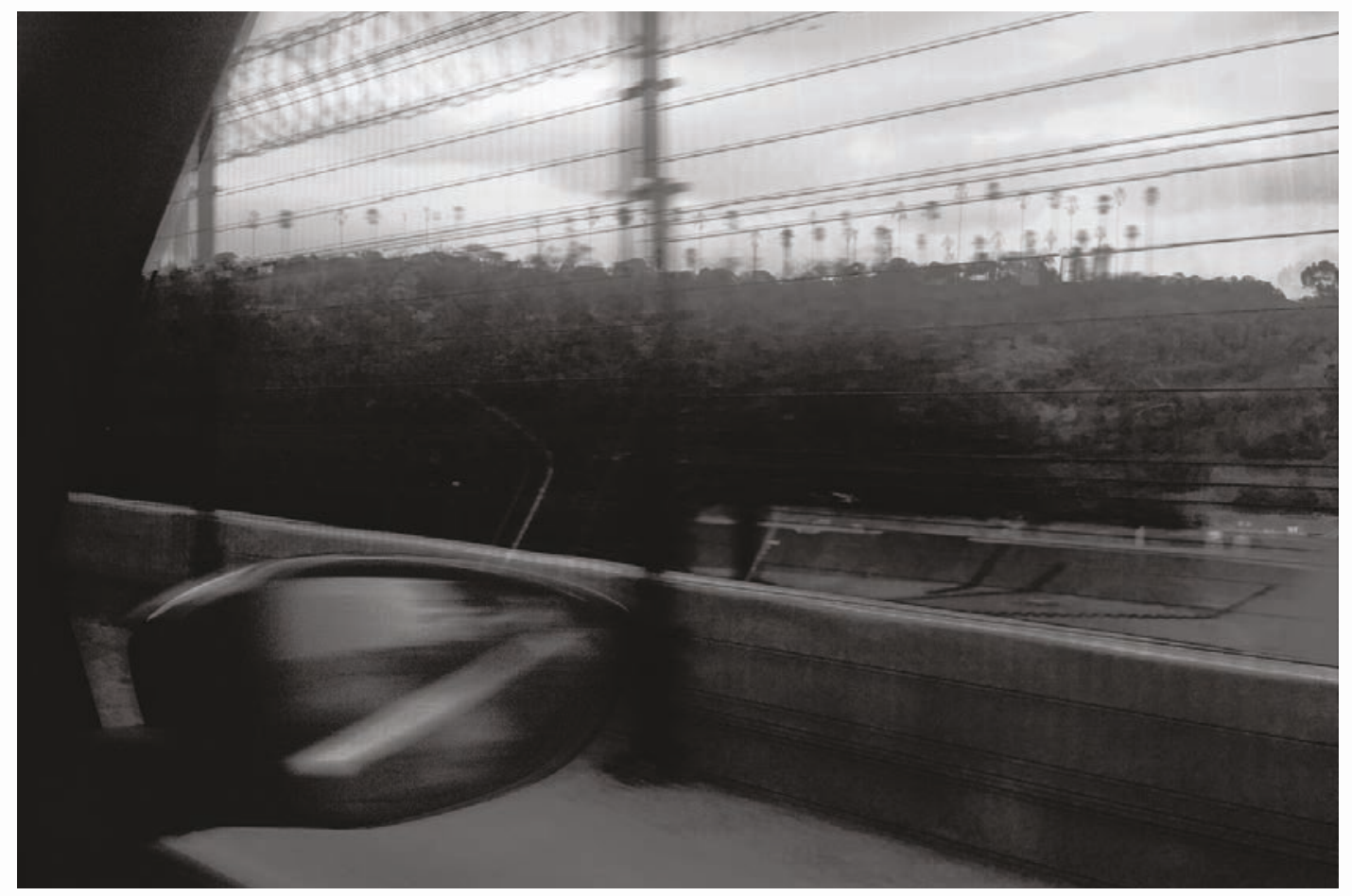
Located three and a half miles from downtown, a little over half a mile east of Dodgers Stadium, and a quarter mile west of the Los Angeles River, the seven-acre reservoir, originally called the Buena Vista Reservoir, rests in a canyon adjacent to the 101 freeway. It has been here since Elysian Park was founded in 1888 and is the last remaining large piece of the original Pueblo of Los Angeles public land grant. ${ }^{1}$ It once stored and supplied water to surrounding neighborhoods 285,000 people living in downtown Los Angeles, Chinatown, Echo Park, Boyle Heights, Lincoln Heights, and Mount Washington. Today, it remains an obsolete infrastructural object removed from the city's water network in 2007, due to bromate contamination - caused by exposure to the persistent California sun.

There is no place to get out and walk around the fenced-off reservoir. A road takes you around it and up to Point Grand View Park.

A collection of black tarps line the bottom of the shell, masking the concrete. There is no indication of water in the reservoir - a fossil reminding us of a time of plenty, where the reservoir was never empty and the river never failed to flow.

1 "Elysian Park." Echo Park Historical Society, http://historicechopark.org/history-landmarks/ places-landmarks/elysian-park/. 


\section{4}



Where the reservoir awakens. 
EXT. ELYSIAN PARK RESERVOIR - DAY - FLASHBACK

The midday sun streams down into the canyon where the reservoir water shines. Families and friends are out on the water in multi-colored paddle boats.

$$
\text { ( V.०.) }
$$

Hurry up, I hear as one paddle boat chases the other.

The sound of giggling sweeps through the air.

$$
\text { ( V.०.) }
$$

I know I'm not Hockney's Bigger Splash light blue or Diebenkorn's Ocean Park marine blue, even in the day, but that doesn't mean I am less enjoyable. I can splash and ripple, crash and tumble too. People seem to like me.

Not all paddle boarders are racing each other. Some hang close to the edge, relaxing and soaking in the sun. Just behind the sunbathers, a man is snoozing on his boat. A family appears on the side of the reservoir, the father showing his two kids how to fly a kite that billows and flaps in the wind.

$$
\text { ( V.०.) }
$$

I was in the river and arrived only yesterday. I came through a ditch and shot out here through a pipe. I take over every corner of this vessel. I'm not running anymore, but waiting. I feel safe here, there's always a Zanjero watching over me. He paces along my edge, tests my temperature and checks my level every morning and night. 


\section{4}

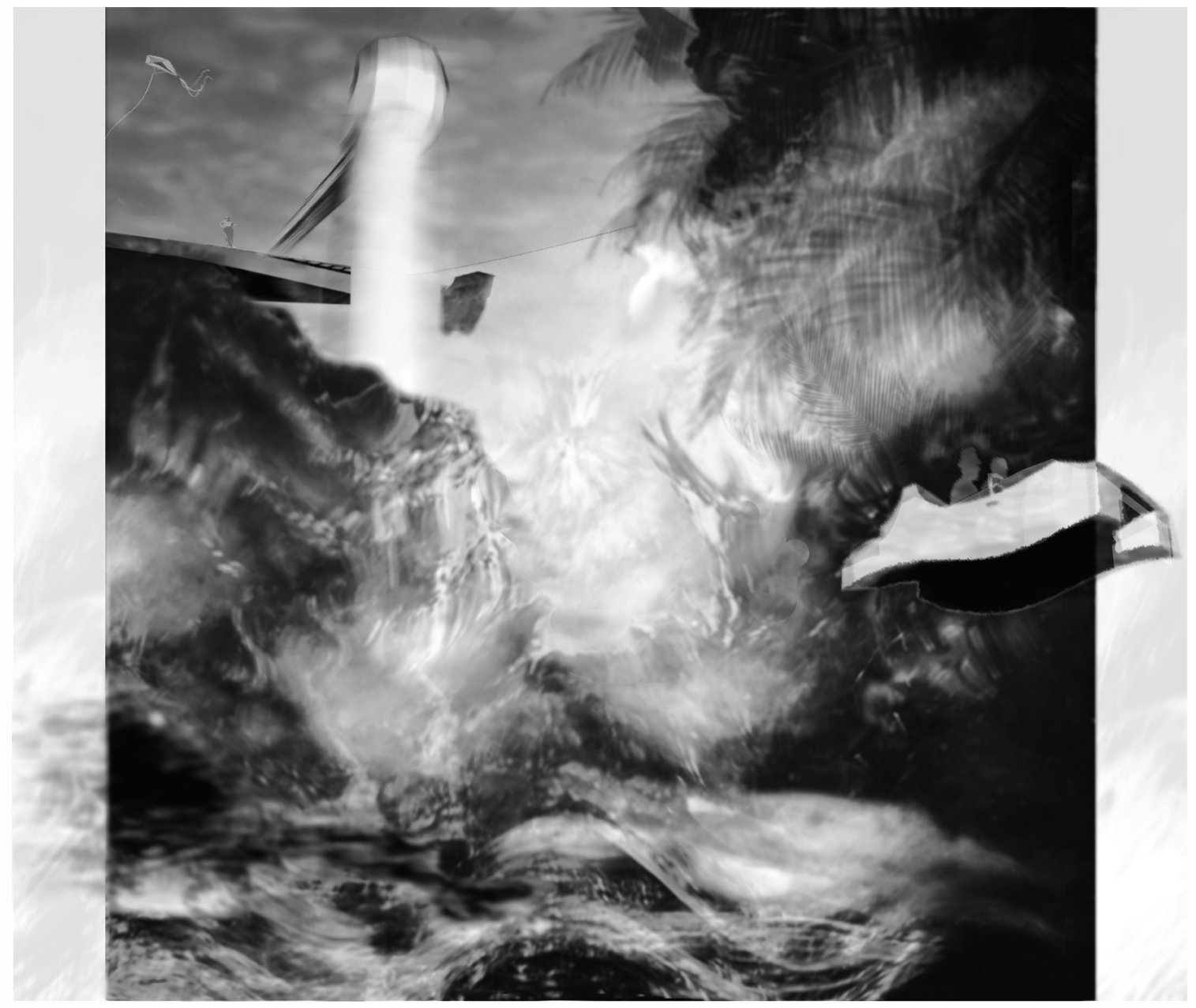

Elysian Reservoir

CINEMATIC RIVER

"I was in the river and arrived only yesterday. I came through a ditch and

shot out here through a pipe." 
How do I get to the site? There are no public paths that line the freeway in this location.

About eight minutes away from Los Angeles City Hall, North 19 Avenue bends left, steering everyone away from the bougainvillea covered fencing. A break in pink reveals over eight railway tracks behind. A railway graveyard?

The road leads underneath four bridges. The rhythmic pounding of traffic above penetrates through the car windows. These must be underpasses. The road straightens to parallel the river. Still only syncopated snapshots of the river are seen, the green steel fence partitioning my view at $35 \mathrm{mph}$.

I turn around and drive by again. I couldn't see the river. Coming out from the last underpass, a little more slowly, I notice the difference in fencing. I look to the opposite side and see the water-filled gully of the channelized Arroyo Seco. The fancy, palm tree stenciled fence and old fashioned lamp posts ornament the right side of the road and mark the confluence. Through the fence, I see the railway floating above it. Behind, I can only distinguish the river's edge by the railroad tracks carving into the hill face of Elysian Park on the opposite side. As soon as the railway bridge touches the ground, the fence turns to wire mesh, then to solid concrete. Out of sight. 


\section{5}

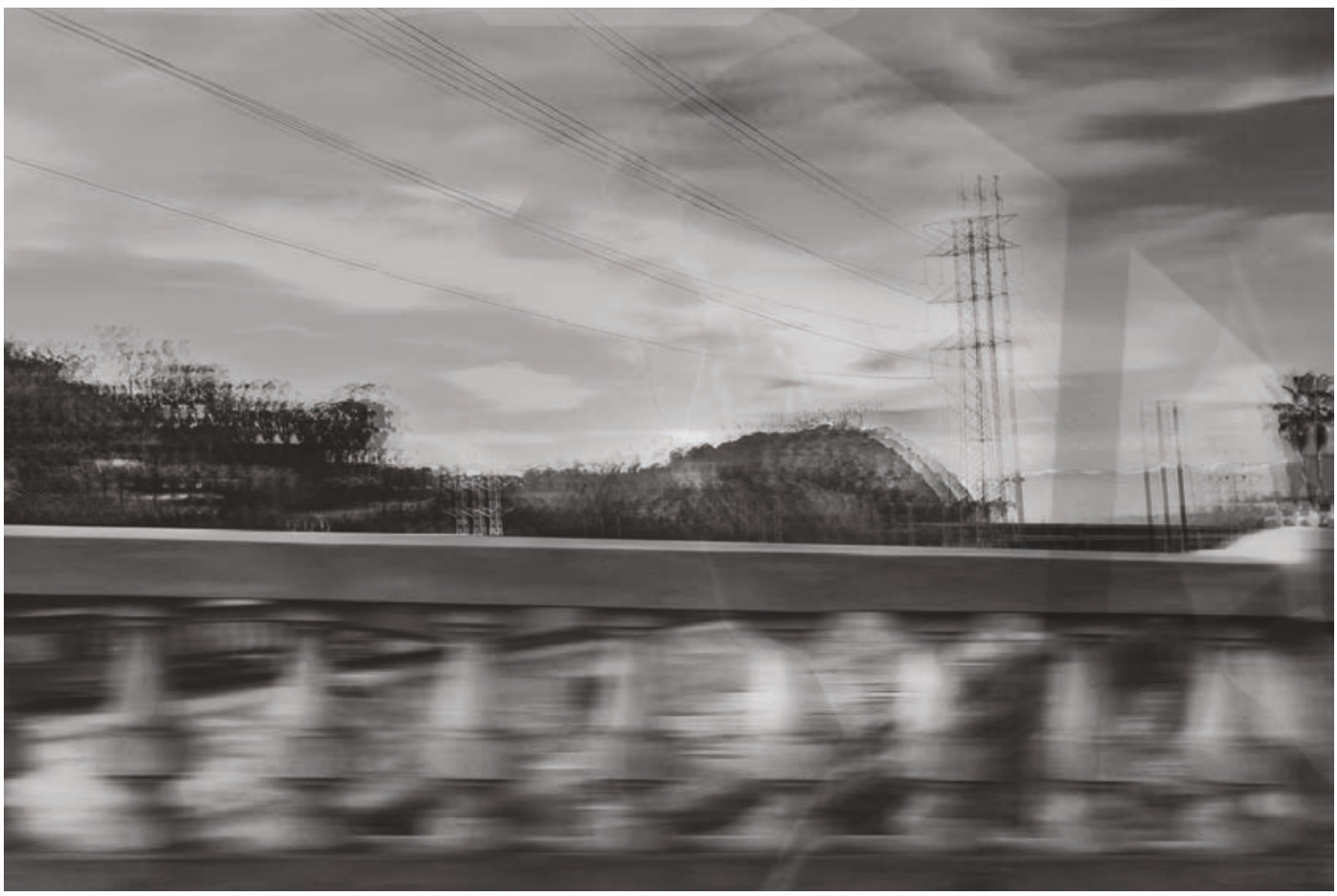

Arroyo Seco Confluence

INVISIBLE RIVER

Where three freeways, two railways, and a pedestrian bridge overlie the river. 
Graffiti colors the sidewalks, the concrete footings, and the bridge underpasses. Layer after layer of infrastructure defines this reach: telephone poles, transmission towers, railroad tracks, and bridges. It is a fast paced and calibrated zone located just below the reservoir.

The stream shot water wheel animates the edge of the river, sunken halfway into the channel, but visible from the adjacent bridge. It is a more robust version of the wooden water wheel that once lifted water up to the pueblo. On a good day, the vertical wheel with a horizontal axis lifts the liquid gold that would have been lost to the Pacific Ocean up to the reservoir - a holding pool prior to treatment. Along the entire length of the river water is harvested. However, the greatest infrastructural spectacle is where the original water source of the pueblo, the Arroyo Seco folds into the river. 
5

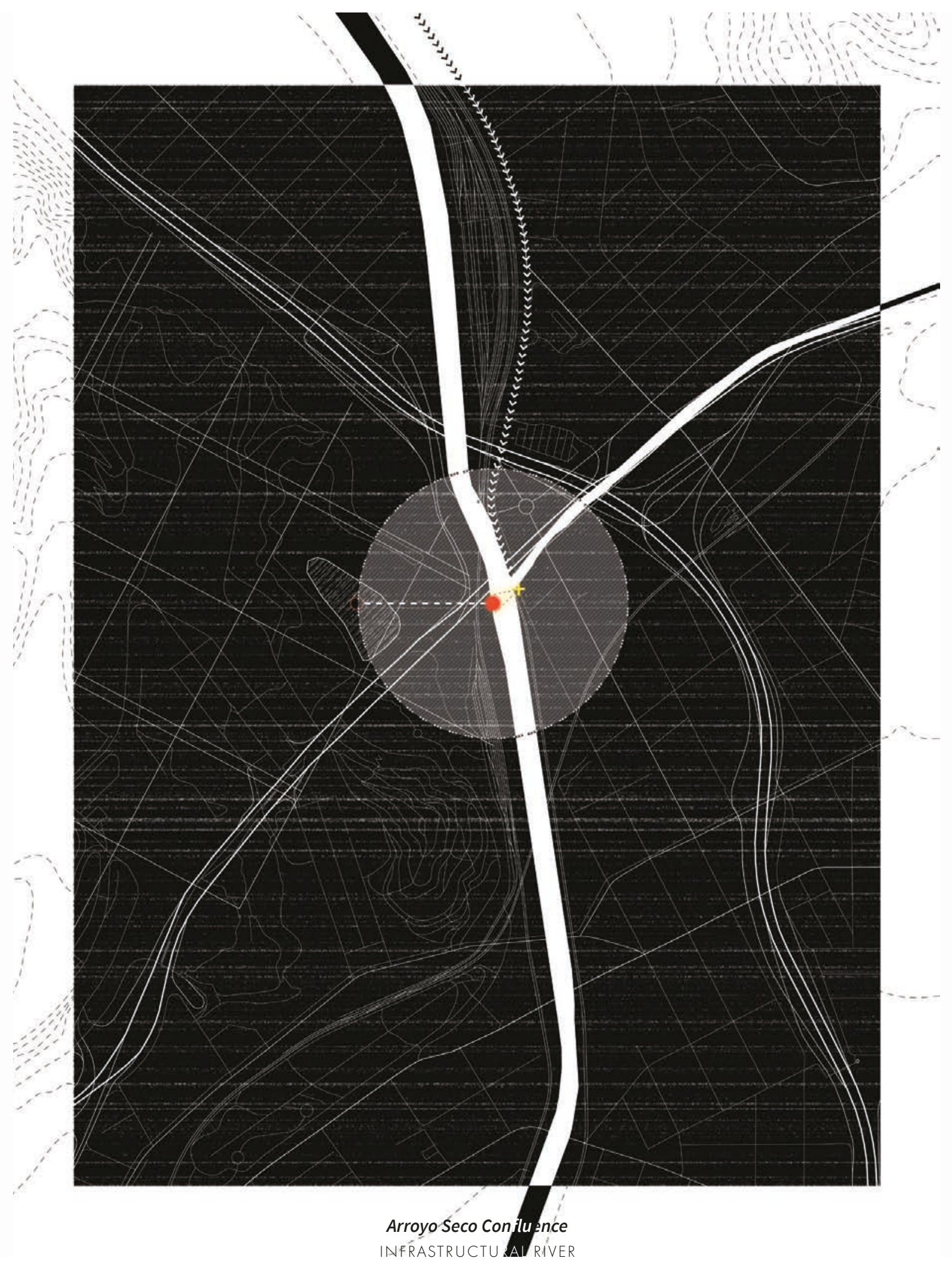

Where multiple water infrastructures merge and energize. 
EXT. LOS ANGELES - AERIAL - DAY

Los Angeles has been in a drought. Today may offer some relief.

SOARING OVER

We pan quickly through Los Angeles during a torrential rain, tracking the river. The dark grey clouds charged with energy, desperately release rain that lashes onto the streets, roofs, cars, and the faces of the people who celebrate it. Through the merciless grid of right angles, the concrete river appears and disappears between the clouds and fog, below roads, behind buildings and cell towers. An infinite landscape.

Nothing catches our eye until...

A waterwheel exposes itself. FREEZE ON.

CUT TO

THE CHANNEL at Hyperion Bridge. The river awakens from its ethereal state into a resonant and powerful force. It is swollen with turbulent waters. Water surges and flows at great volume and intensity creating waves that rival Venice Beach.

A group of onlookers gather on the opposite side of the river. Nate, Harvey, and Sandy join the group and are elated to see the river full. They walk right up to the front. Ben raises his arms above his head and hangs onto the chain link fence, peering through.

NATE:

Yesterday, the river was as dry as a bone. Ain't

this crazy?

Max nods his head while Alice lets out a sigh of relief.

SANDY:

We've all been waiting for a rain like this.

HARVEY:

How much do you think we'll get?

NATE:

It could last a few weeks. It's a big one, but we've been empty a while. 
zOOM to the water wheel in front of Hyperion bridge. It is turning quickly, gears screeching from infrequent use, battling the tide. Buckets lift water up and onto the launder. Water sprays off each bucket as it rips out of the river, creating an additional layer of mist in its wake.

POV SANDY: Her view of the waterwheel is blurred by the diagonal sheets of rain and the humidity that hangs thick in the air. She strains to make out what is happening beyond, but sees two men climb down from a stairwell and rush toward the wheel. Rain rolls off their jackets as they attempt to fix the pit wheel that connects to the main shaft.

Everyone around Sandy starts to nervously whisper. And the waterwheel comes to a SCREECHING halt. 


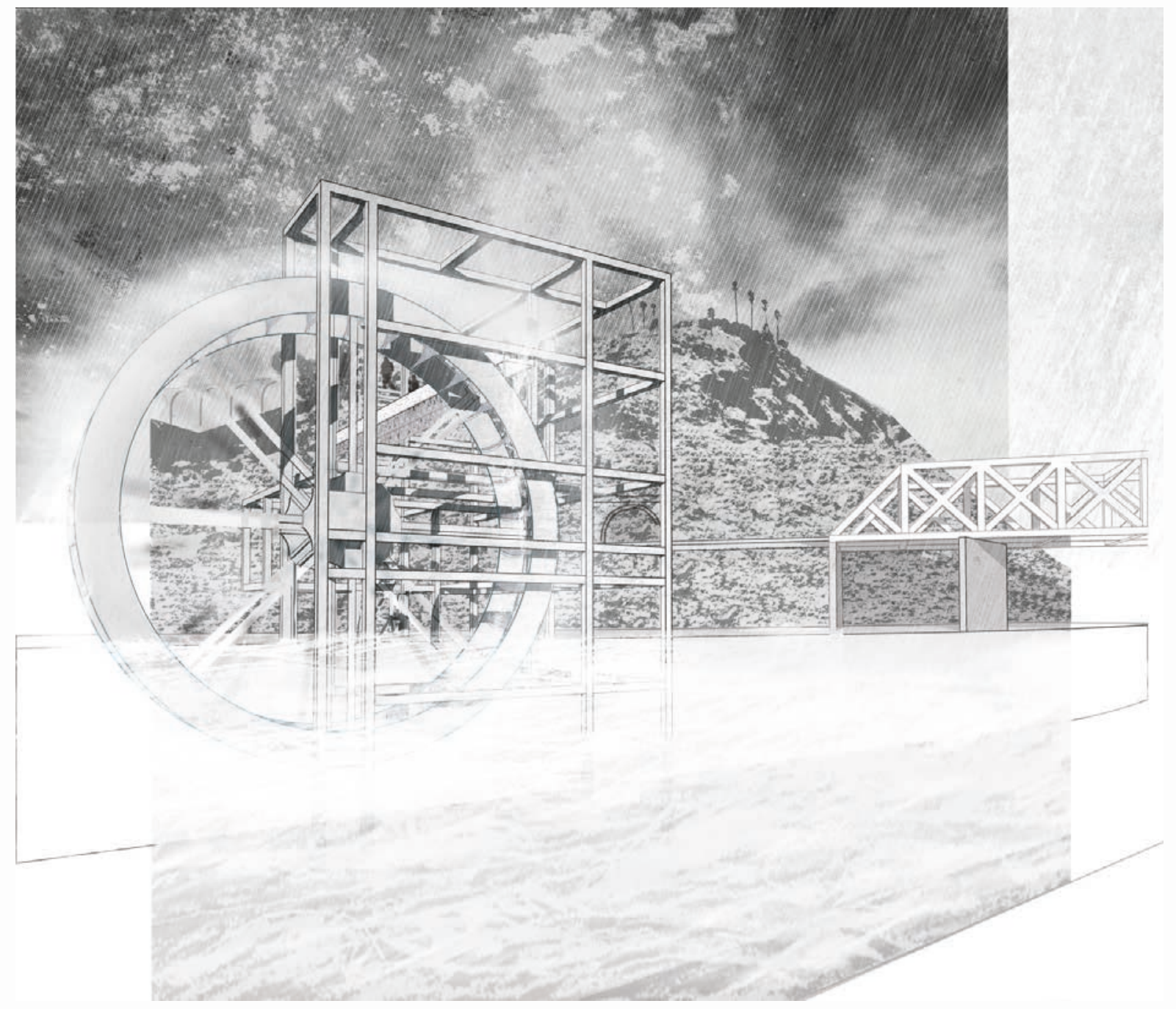

CINEMATIC RIVER

"Two men rush to service the wheel that comes to a screeching halt." 


\section{S CONGLUSION}

This thesis began as an inquiry into the particular condition of the Los Angeles River as a place of otherness. Research revealed that water and river shaped the founding and future of Los Angeles and altered ecologies impacted Angeleno's relationship to this landscape.

Driven by field work, LA RIVER(S) de-constructs, re-constructs, and conceptualizes the river. From an outsider's perspective the river was scouted, documented, and analyzed as a spatial condition realized through infrastructural, invisible, and cinematic lenses. Photographs, mappings, sections, and diagrams reflect on its presence and absence in the city. Atlases were created to gather and visually communicate these critical observations and interpretations of the river.

Using storytelling as a tool to re-imagine, re-activate, and re-think the meaning of river, LA RIVER(S) re-constructs alternative views of the infrastructural, invisible, and cinematic rivers. Narratives composed of layered visions in image, text and film screenplay allow for multiple interpretations of river. The stories highlight multiple relationships with water and discuss water as a resource, commodity, and necessity through suspense, caution, and truth. The fabricated worlds are unsettling reflections meant to call attention to the uncertain future of not only the river, but water in Southern California, and to contribute to the discourse of the future of the river. 


\section{REFIECTION}

This chapter serves as a reflection on the role of agency and the use of narratives, particularly screenplays in this thesis as discussed during the defense.

The Los Angeles River is an extraordinarily complex hydrological, ecological, technological, and experiential landscape. This thesis sought to bring an architectural and spatial understanding to these challenges. In this spatial investigation, focus was placed on the potentiality of the space as opposed to intervention. The narratives and their visualizations are not idealized visions or design solutions for the Los Angeles River - they are speculative design situations that challenge current notions of what this river might be and respond to the opportunities and challenges of the river and its revitalization.

Over time the channelized river gained a life of its own, with few, but multiple users and diverse, emphatic ecologies. While there was a discussion about the current users of the space during the defense, the intention was to engage people who are unfamiliar with the river, like I was eight months ago and ultimately provoke and encourage a discussion.

The narratives act as architectures of initiation, provocation, and spatial agents. The narratives are useful in their ability to re-engage a river that lost its primary role within the city through making it its own character. They serve as a device to rethink our relationship with the landscapes around us and the infrastructures that are implicated by it through a visceral rather than empirical understanding. As architects we are taught to have a critical eye and to understand relationships to see things and to see things differently. Stories create relationalities 
between things real and things possible and allow us to generate ways to think about people, space, or events and critically reflect on their multiplicity.

Screenplays were chosen as the climactic narrative medium as they respond to one of the characteristics of the river and one of the defining characteristics of Los Angeles. They are the architecture of a story made for film. Through action, commands, and shifting points of view, screenplays set the tone, indicate various atmospheric conditions, communicate events, and evoke an emotional response. In this way, the process and techniques used to bring a screenplay to life relate to an architectural understanding of space. They are both about framing, composition, and sequence of bodies in space and the architectures of the space itself.

The discussion that arose at the end of this thesis was about how the river will never be an idyllic river. The re-greening of the river that is prevalent in the current thinking is hard to imagine given the current ecological and climatological conditions. This is in part due to the lack of availability of water in the channel - water that is primarily treated wastewater. Thus, the narratives sought to address a different discourse of the river. They are ways in which to reflect on the river as an important cultural artefact in our consciousness that isn't something that needs to be returned to pre-settlement conditions. LA RIVER(S) looks forward, in order to advocate for alternative approaches to re-engagement. 


\section{EIBLIOGRAPHY}

\section{Books and Articles}

Augé, Marc. Non-places: Introduction to an Anthropology of Supermodernity. Translated by John Howe. London and New York: Verso, 2008.

Banham, Reyner. Reyner Banham Loves Los Angeles, BBC, 1972.

Banham, Reyner. Los Angeles: The Architecture of Four Ecologies. University of California Press, 2009.

Barden, Lane. "The Los Angeles River Picturing Los Angeles: Conduits, Corridors, and the Linear City." The Infrastructural City: Networked Ecologies in Los Angeles. Ed.Kazys Varnelis. Actar: New York, 2009, pp. 78-88.

Bolton, Herbert Eugene, 1870-1953. "Fray Juan Crespi : Missionary Explorer on the Pacific Coast. 1769-1774." B. Berkeley: University of California Press, 1927. Original Format: University of British Columbia. Library. Rare Books and Special Collections. F5813.1.C92 B7. Web. 24 Jan. 2019. <https://open.library.ubc.ca/ collections/bcbooks/items/1.0363412>. BC Historical Books.

Clarke, David. The Cinematic City. Routledge, 1997.

de Sola-Morales, Ignasi. "Terrain Vague". Terrain Vague: Interstices At The Edge Of The Pale, Manuela Mariani and Patrick Barron, 1st ed., Routledge, New York, 2014, pp. 24-30.

Deverell, William, and Tom Sitton. Water and Los Angeles: A Tale of Three Rivers, 1900-1941. University of California Press, 2017.

Eischeid, Mark R. "Color = Place + Time", in LA+, vol. 8 (“Time"). Philadelphia: University of Pennsylvania Press, 2018.

Erdman, John. "8 Reasons Why Rain Is a Big Deal in Southern California." The Weather Channel, 21 Mar. 2018, weather.com/science/ weather-explainers/news/los-angeles-rain-why-its-a-big-deal.

Fletcher, David. "Flood Control Freakology." The Infrastructural City: Networked Ecologies in Los Angeles. Ed. Kazys Varnelis. Actar: New York, 2009, pp. 258-274.

Fogelson, Robert M. The Fragmented Metropolis: Los Angeles, 1850-1930. University of California Press, 1993.

Gumprecht, Blake. "Who Killed the Los Angeles River?" Land of Sunshine: An Environmental History of Metropolitan Los Angeles, by William Deverell and Greg Hise, University of Pittsburgh Press, 2005, pp. 115-134.

Gumprecht, Blake. The Los Angeles River: Its Life, Death, and Possible Rebirth. The John Hopkins University Press, 2001. 
Gumprecht, Blake. "51 Miles of Concrete: The Exploitation and Transformation of the Los Angeles River." Southern California Quarterly, vol. 79, no. 4, 1997, pp. 431-486. JSTOR, www.jstor. org/stable/41171869.

Hoffman, Abraham, and Teena Stern. "The Zanjas and the Pioneer Water Systems for Los Angeles." Southern California Quarterly, vol. 89, no. 1, 2007, pp. 1-22. JSTOR, www.jstor.org/stable/41172351.

Kahrl, William L. "The Politics of California Water: Owens Valley and the Los Angeles Aqueduct, 1900-1927." California Historical Quarterly, vol. 55, no. 1, University of California Press, California Historical Society, 1976, pp. 2-25.

Klaver, Irene J. and J. Aaron Frith. "A History of Los Angeles's Water Supply: Towards Reimagining the Los Angeles River," in: A History of Water, Series 3, Vol. 1. From Jericho to Cities in the Seas: A History of Urbanization and Water Systems. Editors Terje Tvedt and Terje Oestigaard. I.B. Tauris. London, New York, New York, 2014, pp. 520-549.

Lutsky, Karen, and Sean Burkholder. "Curious Methods." Places Journal, no. 2017, May 2017, doi:10.22269/170523.

Lassche, T. Modelling the LA River: Threats and opportunities for the Los Angeles River, USA. 2016. University of Twente.

Mathur, Anuradha. "Neither Wilderness Nor Home: The Indian Maidan." Recovering Landscape: Essays in Contemporary Landscape Architecture, edited by James Corner, Princeton Architectural Press, 1999

Roberts, Les. "Cinematic Cartography: Projecting Place Through Film." Mapping Cultures, 2012, pp. 77.

Reisner, Marc. Cadillac Desert: The American Westand Its Disappearing Water, Revised Edition. Penguin, 1993.

Singley, Paulette. "Los Angeles - Between Cognitive Mapping and Dirty Realism." Shaping the City: Studies in History, Theory and Urban Design, edited by Rodolphe El-Khoury and Edward Robbins, Taylor \& Francis, 2004, pp. 132-60.

Tobar, Hector. "Finding the Real L.A." Los Angeles Times, 14 May 2010, articles. latimes.com/2010/may/14/local/la-me-tobar-20100514.

Tschumi, Bernard. The Manhattan Transcripts. 1976-1981, http://www.tschumi. com/projects/18/\#.

Varnelis, Kazys. Infrastructural City: Networked Ecologies in Los Angeles., Actor, New York.

Worster, Donald. Rivers of Empire: Water, Aridity, and the Growth of the American West. New York Pantheon Books, 1985. 


\section{Reports}

"Elysian Park." Echo Park Historical Society, http://historicechopark.org/ history-landmarks/places-landmarks/elysian-park/. Accessed 1 Mar. 2019.

"Flood Risk Management: Expand the LA River from a Single-Purpose Flood Channel to a Multi-Functional Waterway." LA River Index, Gehry Partners LLP, 2016, riverlareports.riverla.org/ flood-risk-management/.

"Functional Flow Rate (FFR)." LARiver Index, http://riverlareports.riverla.org/ tools-2/functional-flow-rate-ffr/. Accessed 26 Feb. 2019.

"Governance." Los Angeles River Revitalization, https://www.lariver.org/ governance. Accessed 15 Jan. 2019.

Hydrologic Report 2016-2017, County of Los Angeles Department of Public Works. Water Resources Division available at http://ladpw.org/ wrd/report/. Accessed on 15/5/2018.

LA River Modeling Analysis for the Development of TMDLs for Metals in the Los Angeles River and Tributaries - Appendix A. www.waterboards. ca.gov/losangeles/board_decisions/basin_plan_amendments/ technical_wdocuments/2005-006/04_0712/Dry\%20Weather/ LA\%20River\%20Metals-Appendix\%20A.pdf.

LACDPW: Los Angeles River Watershed. https://dpw.lacounty.gov/wmd/ watershed/la/.

Los Angeles River Revitalization Master Plan. City of Los Angeles, 2007.

Los Angeles Regional Water Quality Control Board. Recreational Use Reassessment Of The Engineered Channels Of The Los Angeles River Watershed. 2013, https://www.waterboards.ca.gov/losangeles/ water_issues/programs/basin_plan/RECUR/RECUR\%20Draft\%20 Report_std.pdf.

"Los Angeles River Watershed." City of Los Angeles Stormwater Program, https://www.lastormwater.org/about-us/about-watersheds/ los-angeles-river/. Accessed 5 Jan. 2019.

"Modeling Analysis for the Development of TMDLs for Metals in the Los Angeles River and Tributaries: Appendix A Details of Channel Geometry." California Waterboards - Los Angeles R4, 2004.

US Army Corps of Engineers, Los Angeles District, Los Angeles River Ecosystem Restoration Integrated Feasibility Report (September 2015), 3:66.

"Water and Power Associates Informing the Public about Critical Water and Energy Issues Facing Los Angeles and California." Water and Power Associates: Water in Early Los Angeles, waterandpower.org/ museum/Water_in_Early_Los_Angeles.html.

"Water Sources." Department of Public Works, dpw.lacounty.gov/wwd/web/ YourWater/WaterSources.aspx. 


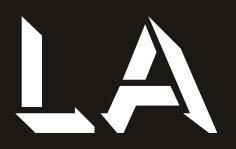

RIVER(S) 